\title{
FINITE ELEMENT ANALYSIS OF A REINFORCED EARTH WALL
}

by

Mosaid M. Al-Hussaini, Lawrence D. Johnson

Soils and Pavements Laboratory

U. S. Army Engineer Waterways Experiment Station

P. O. Box 631, Vicksburg, Miss. 39180

July 1977

Final Report

Approved For Public Release; Distribution Unlimited

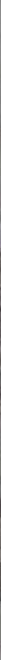

Prepared for Office, Chief of Engineers, U. S. Army

Washington, D. C. 20314

Under Project 4Al6I102AT22, Task A2

Work Unit 004 
READ INSTRUCTIONS

REPORT DOCUMENTATION PAGE

T. REPORT NUMBER

Technical Report S-77-6

4. TITLE (and Subtitlo)

FINITE ELEMENT ANALYSIS OF A REINFORCED

EARTH WALL

7. AUTHOR(0)

Mosaid M. Al-Hussaini

Lawrence D. Johnson

9. PERFORMING ORGANIZATION NAME AND ADDRESS

U. S. Army Engineer Waterways Experiment Station

Soils and Pavements Laboratory

P. 0. Box 631, Vicksburg, Miss. 39180

11. CONTROLLING OFFICE NAME AND ADDRESS

Office, Chief of Engineers, U. S. Army

Washington, D. C. 20314

T4. MONITORING AGENCY NAME ADDRESS(Il dillorent from Controlline Ollico)

10. PROGRAM ELEMENT. PROJECT, TASK

Project 4A161102AT22, Task A2, Work Unit 004

16. DISTRIBUTION STATEMENT (of thio Roport)

Approved for public release; distribution unlimited.

17. DISTRIBUTION STATEMENT (of the abotrect entored in Block 20, If dilforent from Roport)

10. SUPPLEMENTARY NOTES

19. KEY WORDS (Continue on severee elde If neceecery end Identlfy by block number)

Finite element method

Reinforced earth

Walls

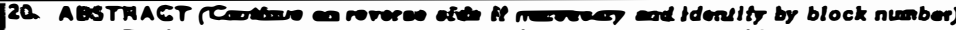

Reinforced earth consists of a soil mass whose engineering characteristics and performance have been improved by the introduction of small quantities of frictional material that possesses a relatively high tensile strength. The analysis of a reinforced earth system which incorporates metal strips placed at known intervals in the vertical and transverse directions within the soil mass is a complex problem. The complexity arises from the fact that reinforced earth is a three-dimensional problem and cannot be solved without imposing (Continued)

DD. FOAM 1783 EDTION OF I MOV GS IS OBSOLETE

U. S. ARMY ENGINEER OISTR:CT, LOUISVILLE

TECHN CAL LIBRAIYY

P. O. ROK 59
Unclassified

SECURITY CLASSIFICATION OF THIS PAGE (Wmon Date Entored) 


\section{ABSTRACT (Continued).}

simplification with regard to the mechanical behavior of the system as well as the constitutive relationship governing the interaction between various components of the reinforced earth mass.

The investigation reported herein describes a simplified approach for analyzing the instrumented reinforced earth wall which was previously constructed and loaded to failure at the U. S. Army Engineer Waterways Experiment Station. The three-dimensional problem was approximated by a structurally equivalent two-dimensional system and a two-dimensional finite element method was used in the analysis. The nonlinear behavior of the earth fill of the reinforced earth wall was simulated by hyperbolic formulation. The behavior of the metal skin element and reinforcing strips was assumed linear elastic until the yield stress was reached; thereafter, these metal components were assumed to fail plastically. Interface elements, to accommodate slippage between components of the reinforced earth wall, were also employed in the analysis.

Ochc 3217862 
THE CONTENTS OF THIS REPORT ARE NOT TO BE USED FOR ADVERTISING, PUBLICATION, OR PROMOTIONAL PURPOSES. CITATION OF TRADE NAMES DOES NOT CONSTITUTE AN OFFICIAL ENDORSEMENT OR APPROVAL OF THE USE OF SUCH COMMERCIAL PRODUCTS. 
The study reported herein was conducted at the U. S. Army Engineer Waterways Experiment Station (WES) under the sponsorship of the Office, Chief of Engineers, Project 4Al61102AT22, "Theory and Principles of Reinforced Earth," Task A2, Work Unit 004.

The finite element and parametric studies described were performed during the period July 1975 through February 1977 by Drs. M. M. Al-Hussaini and L. D. Johnson, assisted by Mr. Y. S. Jeng, all of the Soil Mechanics Division (SMD), Soils and Pavements Laboratory (S\&PL). This report was written by Dr. Al-Hussaini, assisted by Dr. Johnson, under the ieneral direction of Mr. C. L. McAnear, Chief, SMD, and Mr. J. P. Sale, Chief, S\&PL.

Directors of WES during the investigation and the preparation of this report were COL G. H. Hilt, CE, and COL J. L. Cannon, CE. Technical Director was Mr. F. R. Brown. 
PREFACE . . . . . . . . . . . . . . . . . . . . 2

CONVERSION FACTORS, U. S. CUSTOMARY TO METRIC (SI) UNITS OF

MEASUREMENT . . . . . . . . . . . . . . . . . . . 4

PART I: INTRODUCTION . . . . . . . . . . . . . . . . 5

Background ..................... . . . 5

Purpose and Scope . . . . . . . . . . . . . . 8

PART II: MODELING THE MATERIAL BEHAVIOR OF THE REINFORCED

EARTH WALL . . . . . . . . . . . . . . 10

Stress-Strain Behavior of Foundation Material . . . . . 10

Stress-Strain Behavior of Sand Fill . . . . . . . . . 15

Stress-Strain Behavior of Reinforcing Strips . . . . . . 16

Elastic Behavior of Skin Element . . . . . . . . . . 17

Behavior of Interface Elements . . . . . . . . . . 17

PART III: IDEALIZATION OF THE REINFORCED EARTH WALL • • • • • 30

Idealization as 2D Problem . . . . . . . . . . 30

FE Mesh Design . . . . . . . . . . . . . . 35

Examination of the FE Mesh . . . . . . . . . . 37

PART IV: FE ANALYSIS OF THE REINFORCED EARTH WALL . • • • . . 43

FE Analysis . . . . . . . . . . . . . . . 44

Concluding Remarks on the FE Analysis . . . . . . . . 53

PART V: PARAMETRIC STUDY . . . . . . . . . . . . . . . . 55

General Objectives . . . . . . . . . . . . 55

Concluding Remarks on the Parametric Study . . . . . . . 60

PART VI: CONCLUSIONS AND RECOMMENDATIONS . . . . . . . . . 63

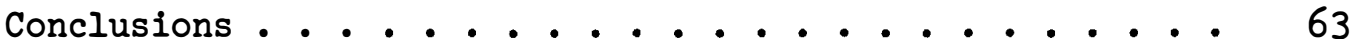

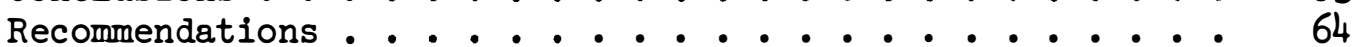

REFERENCES . . . . . . . . . . . . . . . . 65

APPENDIX A: COMPUTER CODE . . . . . . . . . . . . . . . . . Al

APPENDIX B: NONLINEAR STRESS-STRAIN BEHAVIOR FOR SOIL . • • • • BI

Homogeneous Soil Element . . . . . . . . . . . B2

Interface Soil Elements . . . . . . . . . . . . B4

APPENDIX C: NOTATION . . . . . . . . . . . . . . . . Cl 
U. S. customary units of measurement used in this report can be converted to metric (SI) units as follows:

\begin{tabular}{|c|c|c|}
\hline Multiply & By & To Obtain \\
\hline inches & 25.4 & millimetres \\
\hline feet & 0.3048 & metres \\
\hline square inches & 6.4516 & square centimetres \\
\hline square feet & 0.09290304 & square metres \\
\hline pounds (mass) & 0.4535924 & kilograms \\
\hline $\begin{array}{l}\text { pounds (force) per } \\
\text { square inch }\end{array}$ & 6894.757 & pascals \\
\hline $\begin{array}{l}\text { pounds (force) per } \\
\text { square foot }\end{array}$ & 47.88026 & pascals \\
\hline $\begin{array}{l}\text { kips (force) per } \\
\text { square inch }\end{array}$ & 6894.757 & kilopascals \\
\hline $\begin{array}{l}\text { pounds (mass) per } \\
\text { cubic foot }\end{array}$ & 16.01846 & kilograms per cubic metre \\
\hline inches per minute & 25.4 & millimetres per minute \\
\hline degrees (angle) & 0.01745329 & radians \\
\hline
\end{tabular}




\section{PART I: INTRODUCTION}

\section{Background}

1. Reinforced earth consists of a soil mass whose engineering characteristics and performance have been improved by the introduction of small quantities of frictional material that possess a relatively high tensile strength. Many reinforced earth walls are designed as gravity structures, the stability of which depends on the frictional stresses between the reinforcing elements and the surrounding soil and the strength and elastic properties of the reinforcing material. The basic design concept of a reinforced earth wall assumes that the soil mass is in active failure governed by Rankine earth pressure theory. The developed lateral pressure is assumed to be counterbalanced by the friction force that develops between the reinforcement and the surrounding soil.

2. An instrumented reinforced earth wall was constructed at the U. S. Army Engineer Waterways Experiment Station (WES) to determine the performance of such a wall during construction and surcharge loading. ${ }^{l}$ The wall, shown in Figure 1, was reinforced with galvanized steel strips, 4 in.* wide, 0.024 in. thick, and $10 \mathrm{ft}$ long, spaced at intervals of 2 and $2.5 \mathrm{ft}$ in the vertical and horizontal directions, respectively. Three galvanized strips along the center line of the wall, located at elevations 1, 5, and $9 \mathrm{ft}$ above the bottom of the wall (Figure 2), were instrumented with full SR-4 strain gage bridges-at points- 1, 2.5; 5; and $7.5 \mathrm{ft}$ from the face of the wall. At the elevation of each instrumented tie and $1 \mathrm{ft}$ away from the face of the wall (i.e., skin element), two pressure cells were placed to measure the induced vertical and horizontal pressures within the fill material.

A table of factors for converting U. S. customary units of measurement to metric (SI) units is shown on page 4. 


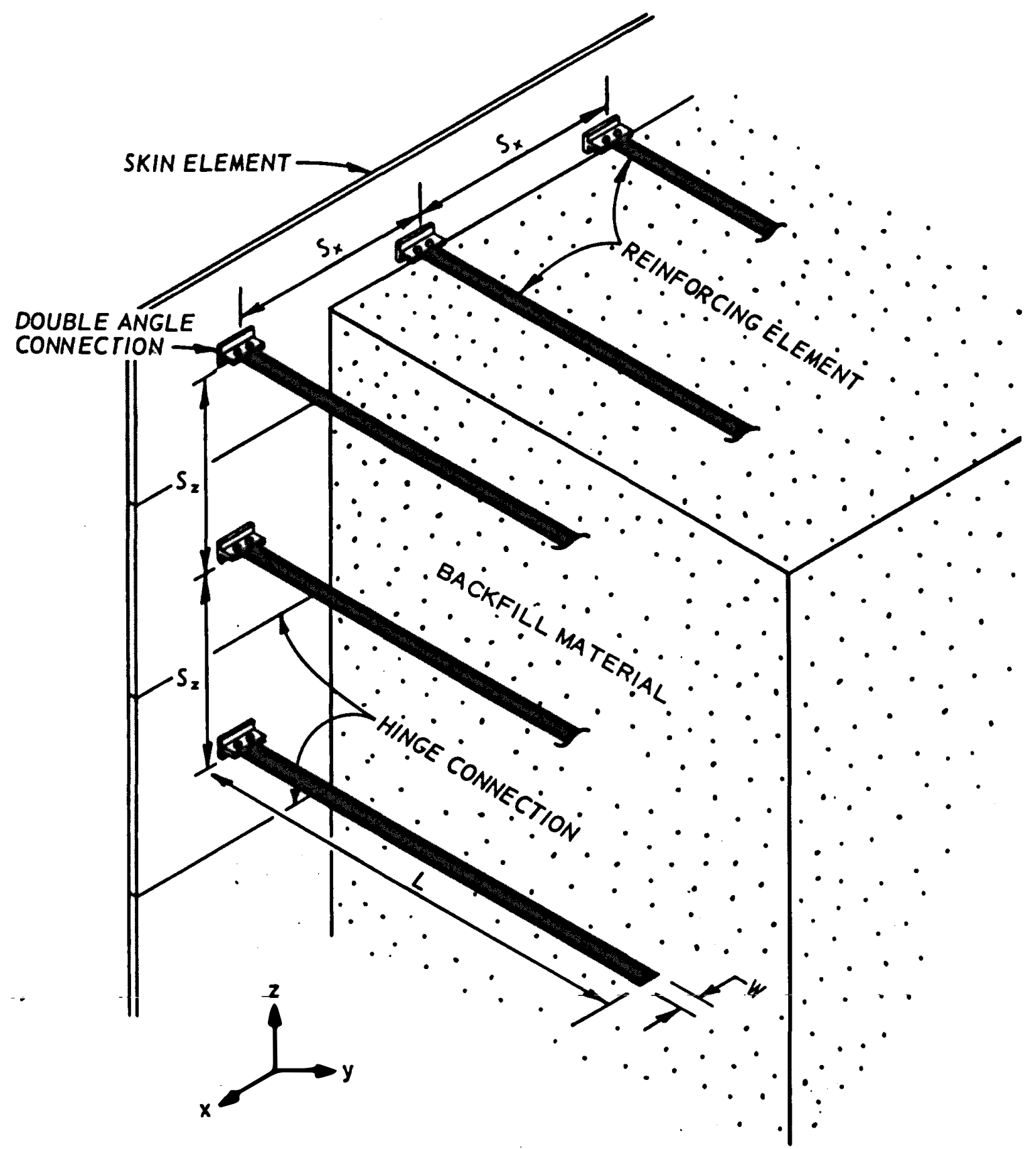

Figure 1. Schematic of major elements of reinforced earth wall 


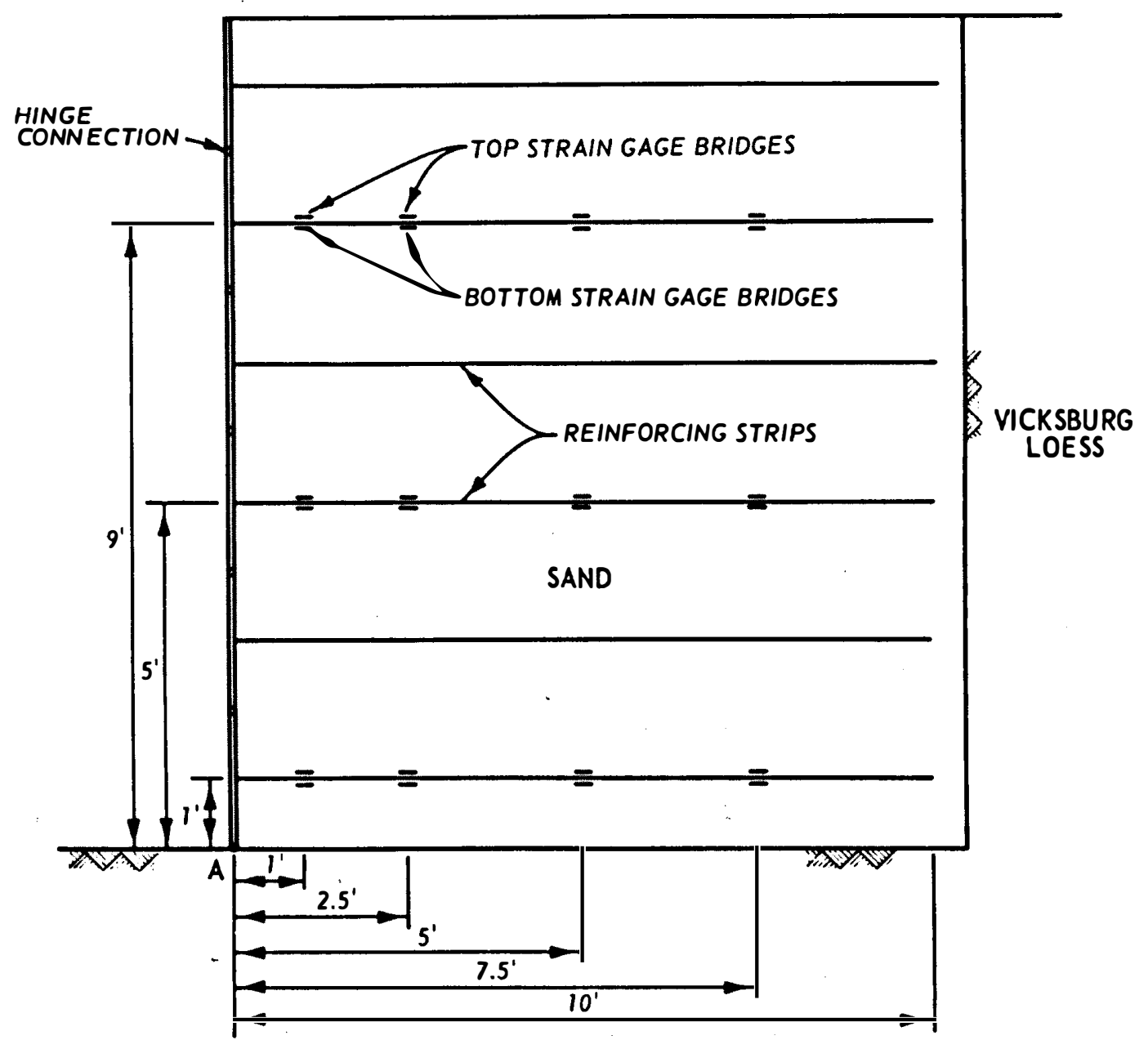

Figure 2. Schematic showing the location of the electric strain gage bridges along the center line of the retaining wall

3. The skin element, which comprised the exposed surface of the wall, was made of Alcoa Tll high-strength aluminum panels normally used in the expedient construction of airfields. Each panel was $2 \mathrm{ft}$ wide, $12 \mathrm{ft}$ long, and $1.6 \mathrm{in}$. thick and can be connected lengthwise to other panels by integral hinge-type connections, Figures 1 and 2. The reinforcing elements were fixed to the skin element by double angle connectors, Figure 1. Further details of these components are discussed later. A full description of the reinforced earth wall is presented by Al-Hussaini and Perry. ${ }^{l}$ 
4. The reinforced earth structure was constructed to a height of $12 \mathrm{ft}$ and loaded by a uniform surcharge pressure to failure. Instrumentation readings and analyses during construction and surcharge loading are given in Reference 1 . The exact cause and pattern of failure are not known since failure was catastrophic; however, it is probable that failure was initiated either by fracture of one of the connections which Joined the reinforcing strips to the skin element, by failure of the skin element due to buckling and shear, or by failure of the reinforcing strips.

\section{- Purpose and Scope}

5. Accurate analysis of a system incorporating reinforcing strips placed at known intervals in the vertical and transverse directions within the soil mass poses a three-dimensional (3D) problem. Proper modeling of a reinforced earth wall also involves reasonable simulation of (a) the mechanical behavior of the earth fill, skin element, and reinforcing strips, and (b) the interaction mechanisms between these components of the wall. Field observations during and subsequent to the construction of the reinforced earth wall at WES were not in complete agreement with the theoretical method proposed originally by Vidal $^{2}$ and later by Lee. 3

6. The finite element (FE) method was consequently proposed to simulate as closely as possible various sequences of construction of the reinforced earth wall constructed at WES and to predict the distribution of stresses and deformations within the reinforced earth mass. Although 3D formulations and codes based on the FE method are possible, their use for reinforced earth walls would involve great amounts of human and computer effort. The 3D problem is therefore approximated by a structurally equivalent two-dimensional (2D) system.

7. The soil-structure plane strain $2 \mathrm{D} \mathrm{FE}$ code originally developed by Clough and Duncan ${ }^{4}$ for analyses of Port Allen and Old River Locks and subsequently modified by Radhakrishnan and Jones ${ }^{5}$ was adopted for use in this study. This code (see Appendix A), which uses the 
5-node isoparametric quadrilateral element, is capable of simulation of the incremental buildup of the wall and the concentrated loading construction sequences needed for this study. The nonlinear behavior of the earth fill of the reinforced wall is simulated by a hyperbolic formulation developed by Duncan and Chang. ${ }^{6}$ The behavior of the metal skin element and reinforcing strips is assumed linear elastic until the yield stress is reached; thereafter, these metal components are assumed to fail plastically.

8. Interface elements available in the $F E$ code were also used to accommodate slippage between and separation of the components of the reinforced wall. The interface elements are especially important in separating the ends of the reinforcing strips from the original in situ earth face which supports the back of the reinforced earth mass, thereby permitting the stresses in the reinforcing strips to approach zero at the ends.

9. FE analyses of the reinforced wall were performed for the construction of the wall and surcharge loading to failure. The numerical predictions of the $\mathrm{FE}$ analyses are compared with field observations, and conclusions regarding design analyses are presented. 
10. Because of the composite nature of the reinforced earth wall, it is essential that the stress-strain relationships for the foundation soil, fill material, reinforcing strips, and skin element are accurately defined. It is also essential that the interaction between these composite materials within the reinforced mass be considered.

\section{Stress-Strain Behavior of Foundation Material}

11. The stress-strain relationship for the foundation material was approximated by the hyperbolic formulation, surmarized in Appendix B, and stated by the following expressions:*

$$
\begin{gathered}
E_{t}=\left(1-\lambda_{1}\right)^{2} E_{i} \\
E_{i}=K P_{a}\left(\frac{\sigma_{3}}{P_{a}}\right)^{n} \\
\lambda_{1}=\frac{R_{f}\left(\sigma_{1}-\sigma_{3}\right)(1-\sin \phi)}{2 c \cos \phi+2 \sigma_{3} \sin \phi}
\end{gathered}
$$

where

$$
\begin{aligned}
E_{t} & =\text { tangent modulus } \\
E_{i} & =\text { initial modulus } \\
-K & =\text { hyperbolic loading parameter } \\
P_{a} & =\text { atmospheric pressure } \\
\sigma_{3} & =\text { minor principal stress } \\
n & =\text { pure number } \\
R_{f} & =\text { failure ratio }
\end{aligned}
$$

* For convenience, symbols and abbreviations used herein are listed and defined in the Notation (Appendix $C$ ). 


$$
\begin{aligned}
\sigma_{1} & =\text { major principal stress } \\
\phi & =\text { angle of internal friction } \\
c & =\text { cohesion }
\end{aligned}
$$

12. Laboratory tests were not conducted on the foundation material because these tests were not required in the conventional design analysis of the wall. However, several triaxial $Q$ tests previously conducted on soil specimens with similar characteristics were used in the FE analysis. The stress-strain curves and Mohr-Coulomb criteria of the ML soil used in the FE analysis are presented in Figures 3 and 4, respectively. The stress-strain data were replotted in the linear form, Figure 5, which shows that most of the data points of each test fell on a straight line, indicating that the shape of the stress-strain curve of the ML material conforms with the hyperbolic representation. From Figure 5, the value of the initial modulus $E_{i}$, represented by the inverse of the intercept on the ordinate, and the value of $\left(\sigma_{1}-\sigma_{3}\right)_{u l t}$, represented by the inverse of the slope of the line, were obtained. The failure ratio $R_{f}$ is equal to $\left(\sigma_{1}-\sigma_{3}\right)_{f} \mid\left(\sigma_{1}-\sigma_{3}\right)_{u l t}$ where $\left(\sigma_{1}-\sigma_{3}\right)_{f}$ is the principal stress difference at failure, as illustrated in Figure 3. A summary of the MI soil-parameters needed for the hyperbolic stress-strain representation is tabulated below.

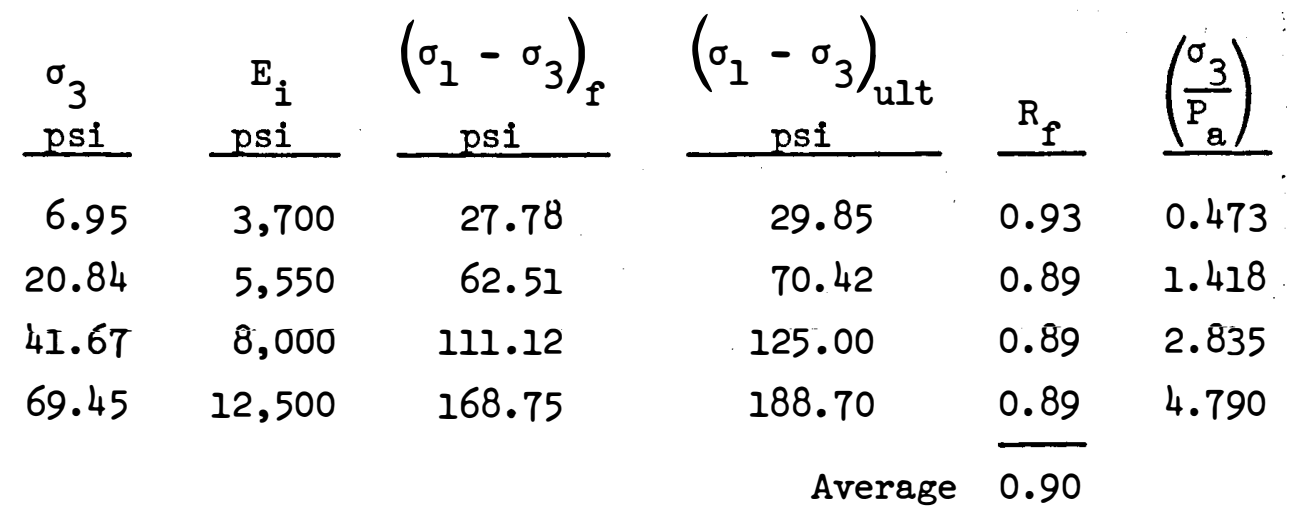

13. The values of the loading stiffness $K$ and the exponential constant $n$ needed to incorporate the effect of the confining pressure $\sigma_{3}$ in the hyperbolic constitutive model are obtained by plotting $E_{i}$ versus $\left(\sigma_{3} / P_{a}\right)$ as shown in Figure 6 . The best fit line was used for the 


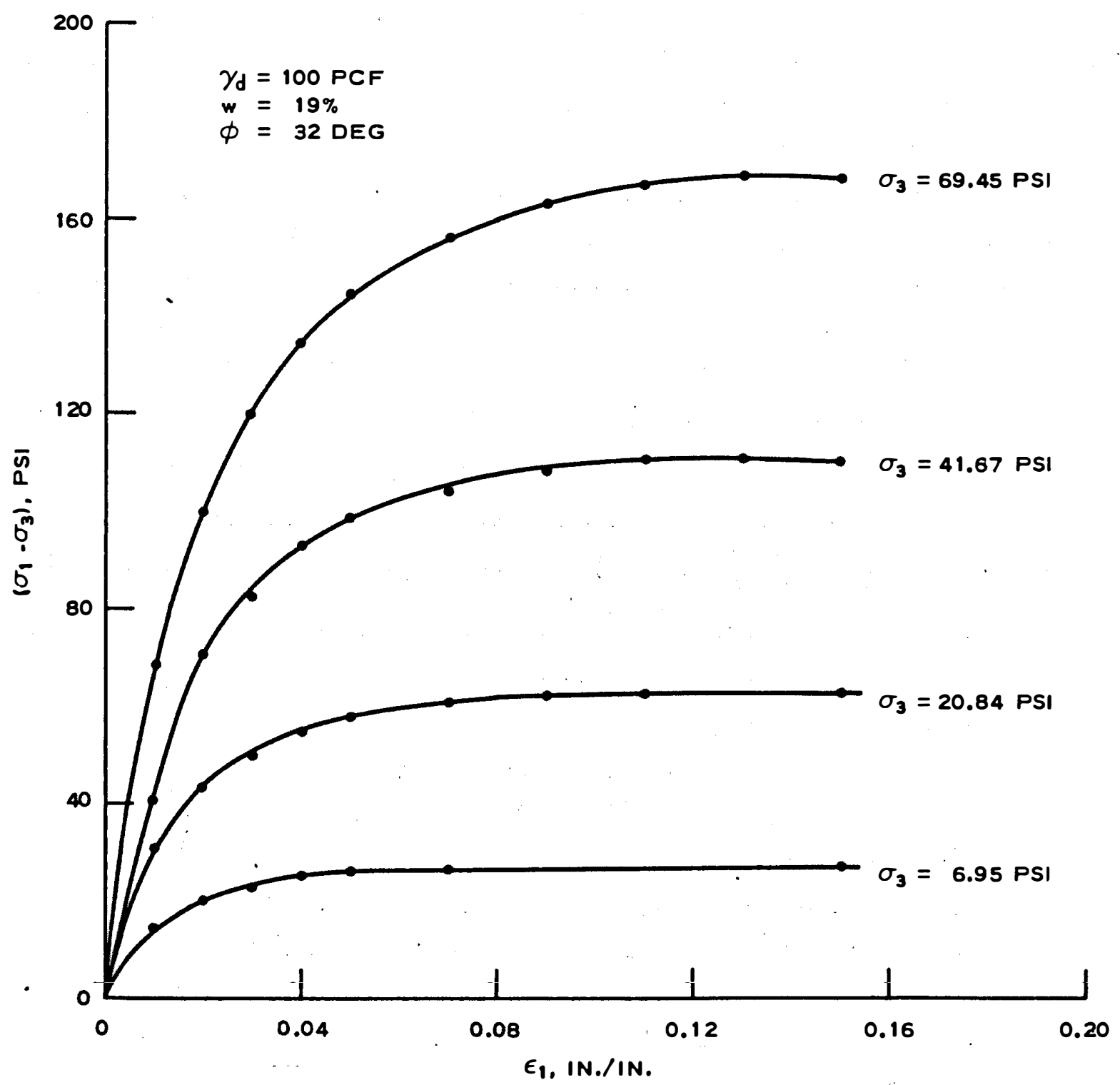

Figure 3. Stress-strain curves for the ML soil 


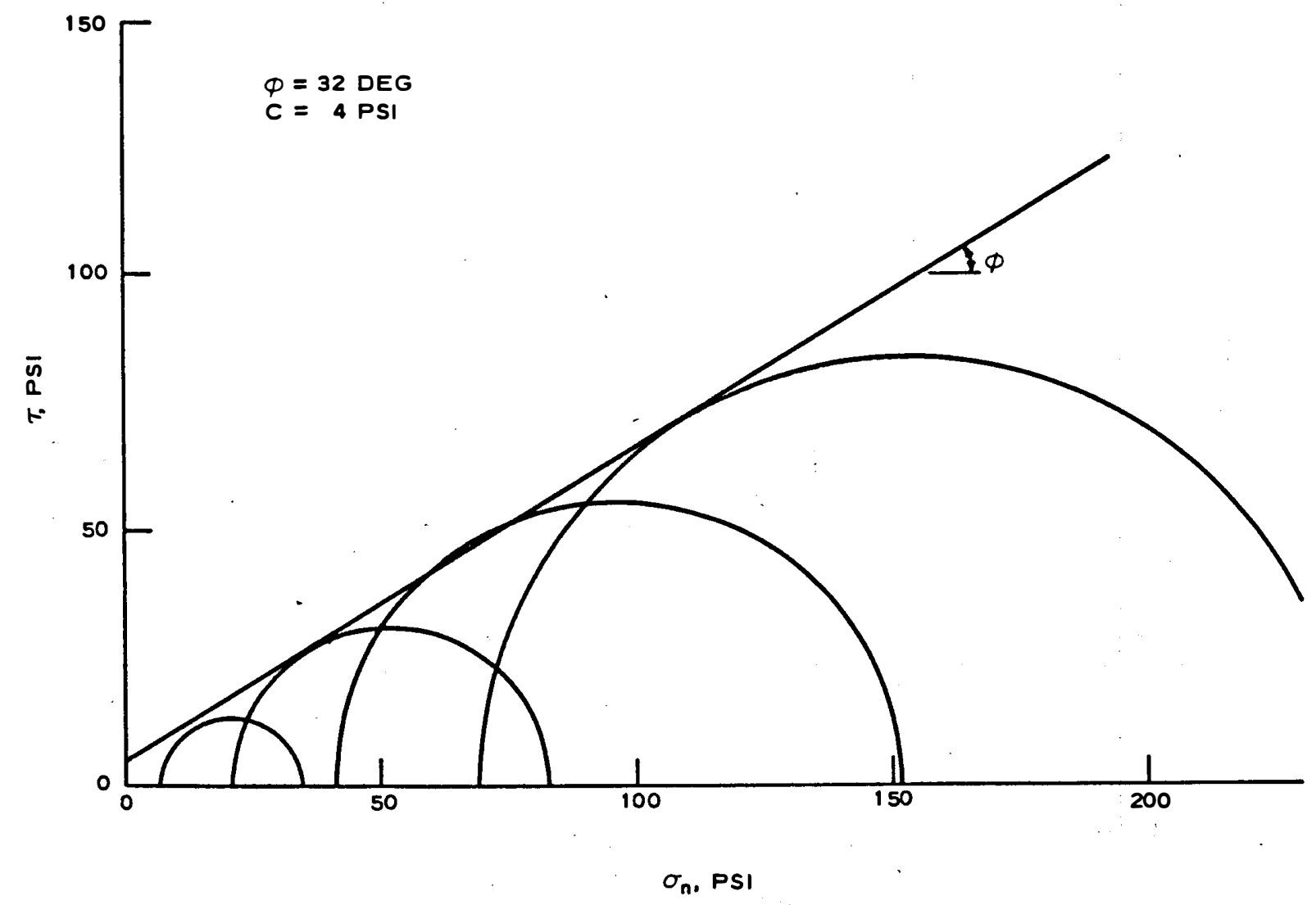

Figure 4. Mohr's failure envelope for the MI soil 


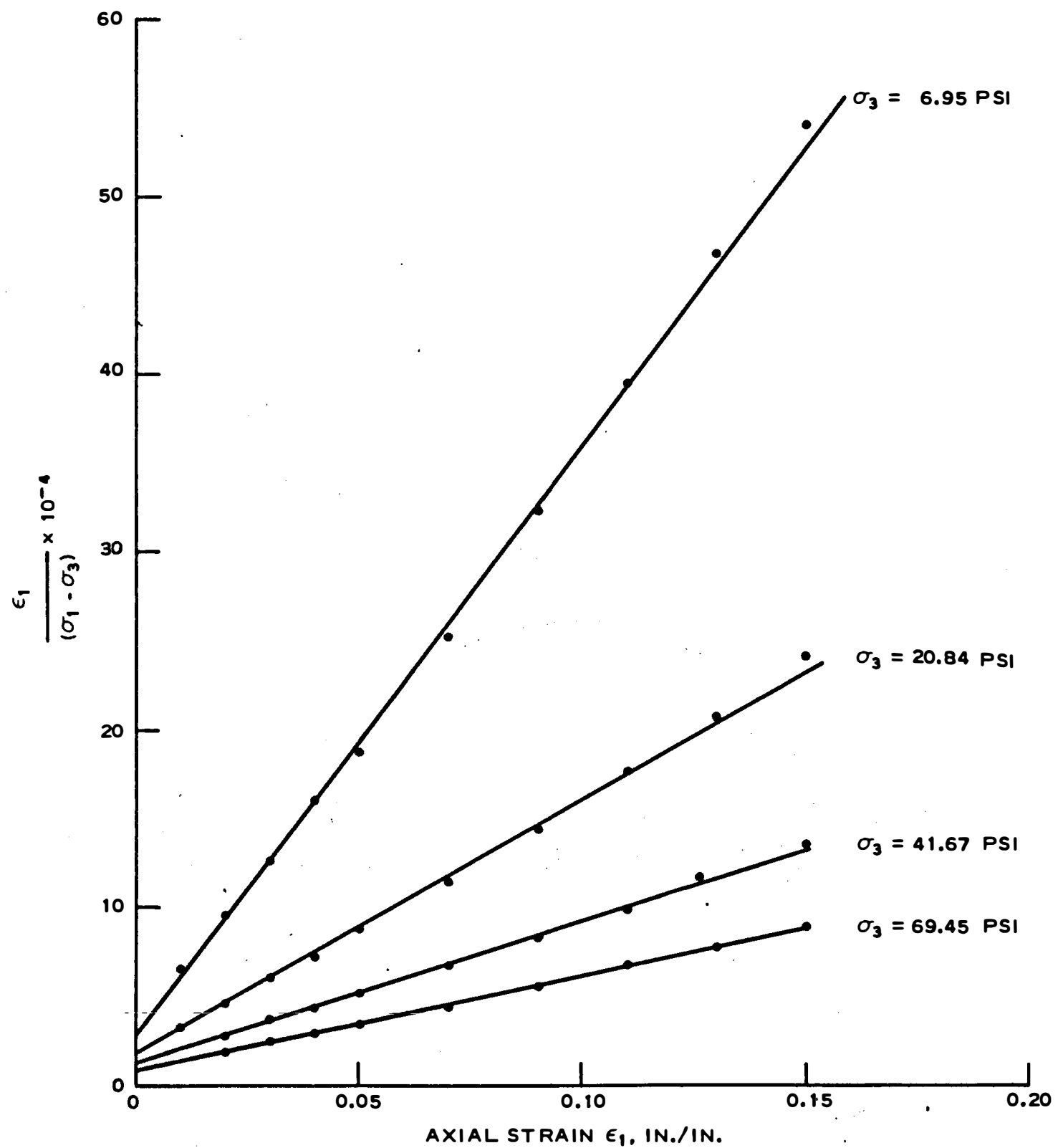

Figure 5. Linearized stress-strain curves for the ML soil 


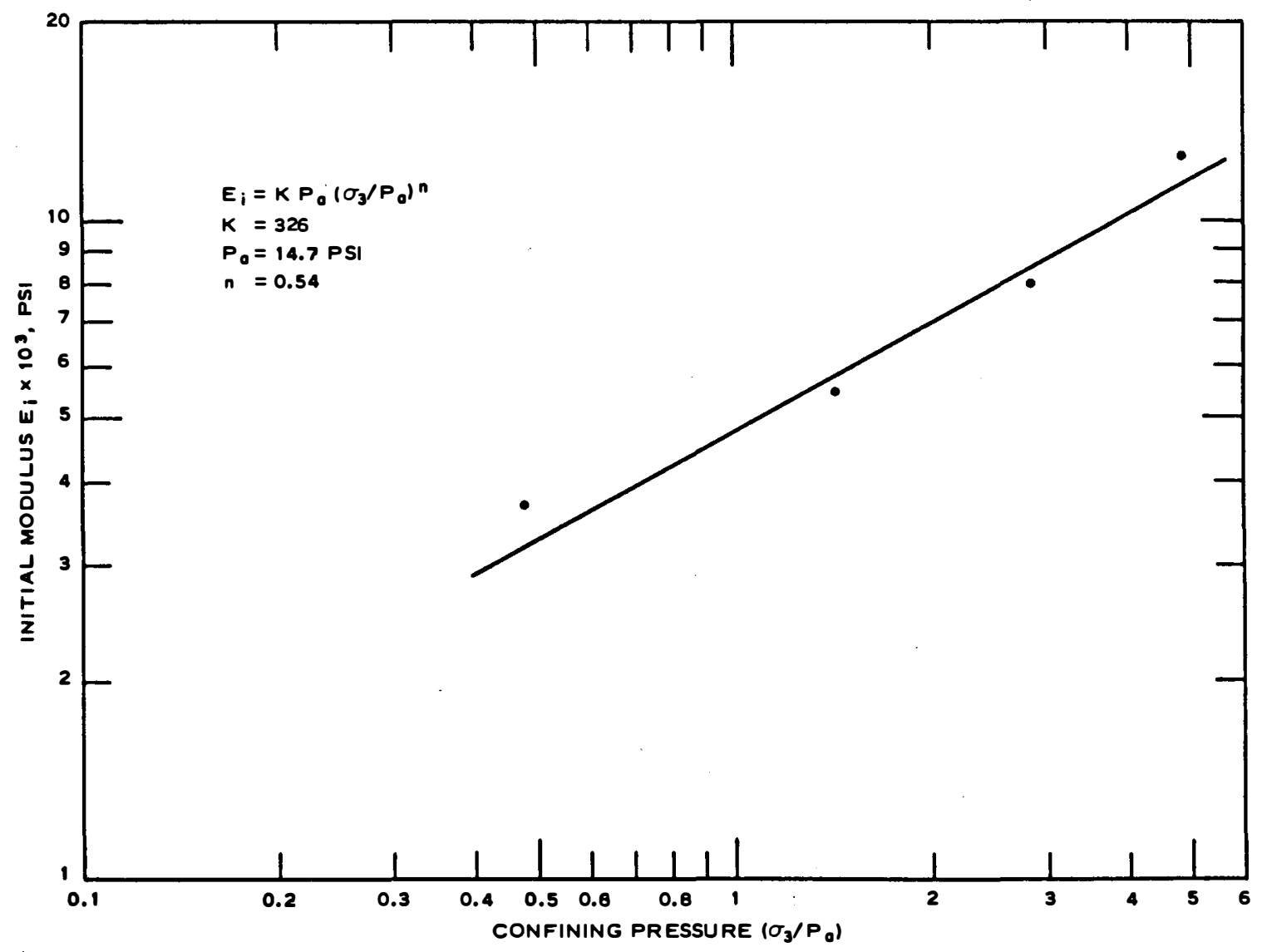

Figure 6. Variation of the initial modulus $E_{i}$ versus $\left(\sigma_{3} / P_{a}\right)$ for the ML soil

analysis. Since adequate information on the volumetric behavior of the $\mathrm{ML}$ soil was not available, Poisson's ratio $v$ was assumed constant at 0.33. Poisson's ratio at failure was assumed to be 0.48 .

\section{Stress-Strain Behavior of Sand Fill}

14. The fill material used in the construction of the reinforced earth wall was clean concrete sand with particles ranging from subangular to angular. More detailed physical properties of the sand fill used are presented in an earlier report. ${ }^{l}$ The same procedure of hyperbolic stress-strain analysis, presented previously in describing the behavior of the foundation soil, was used to obtain the constitutive equations for the sand fill. The hyperbolic parameters and other properties adopted for the FE analysis were as follows: 


\begin{tabular}{|c|c|c|c|c|c|c|}
\hline$R_{f}$ & K & $\mathrm{n}$ & $\begin{array}{r}\gamma_{\mathrm{d}} \\
\text { pcf } \\
\end{array}$ & $v$ & $\begin{array}{c}\phi \\
\text { degrees } \\
\end{array}$ & $\begin{array}{c}c \\
\text { psf } \\
\end{array}$ \\
\hline 0.85 & 580 & 0.5 & 97.2 & 0.30 & 36 & 0 \\
\hline
\end{tabular}

Poisson's ratio at failure was assumed to be 0.48 .

\section{Stress-Strain Behavior of Reinforcing Strips}

15. The steel reinforcing strips used in the earth wall were made from galvanized zinc-coated, 24-gage steel. Each strip was 0.025 in. thick, 4 in. wide, and $10 \mathrm{ft}$ long. The stress-strain curve for a 1/2-in.-wide strip is shown in Figure 7. This curve shows the classical

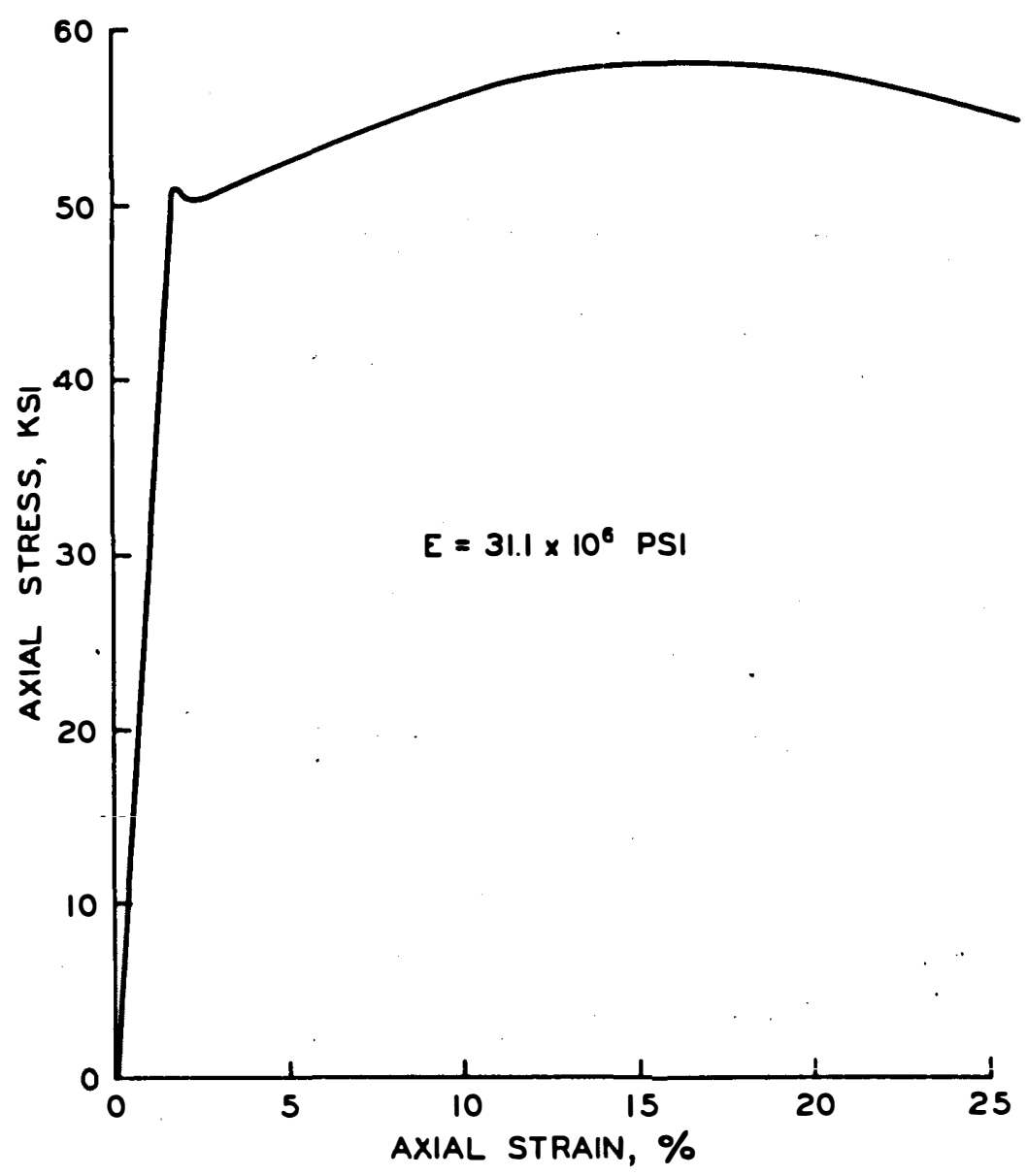

Figure 7. Average stress-strain relationship for the galvanized steel strips 
stress-strain curve with modulus of elasticity $E=31.1 \times 10^{6}$ psi and yield stress $\sigma_{\mathrm{y}}=51 \mathrm{ksi}$. The Poisson's ratio $v$ needed for the $\mathrm{FE}$ analysis was assumed equal to 0.28 .

\section{Elastic Behavior of Skin Element}

16. The skin element was made of Alcoa Tll high-strength aluminum panels, $2 \mathrm{ft}$ wide, $12 \mathrm{ft}$ long, and $1.6 \mathrm{in}$. thick, connected lengthwise to each other by a hinge connector. The physical and elastic properties of the panels are shown below.

$\begin{aligned} \text { Moment of inertia per foot of panel width } & =1.368 \mathrm{in.}^{3} \\ \text { Section modulus per foot of panel width } & =1.396 \mathrm{in.}^{3} \\ \text { Modulus of elasticity } & =10 \times 10^{6} \mathrm{psi} \\ \text { Weight per square foot } & =4.61 \mathrm{lb} \\ \text { Poisson's ratio } & =0.33 \\ \text { Thickness of the panel } & =1.6 \mathrm{in} . \\ \text { Thickness of the sheet } & =0.1 \mathrm{in} . \\ \text { Yield stress } & =35,000 \mathrm{psi}\end{aligned}$

17. The reinforcing elements were fixed to the skin element through a connector as shown in Figure 8. The connector consisted of double angles, each of which was $1-1 / 2$ by 3 by $1 / 4$ in. and 12 in. long, used to grip the reinforcing strip and tie it to the skin element by two 1/4-in. bolts. This type of connection was simple and adequate as long as the skin element exhibited very small or no bending deformations.

\section{Behavior of Interface Elements}

18. The interface element formulation introduced by Goodman and his coworkers ${ }^{7}$ was incorporated in the FE program used in this study. The constitutive behavior of the interface elements was based on the hyperbolic shear stress-displacement model originally formulated by Duncan and Chang ${ }^{6}$ (Appendix A) and summarized by the following equations: 


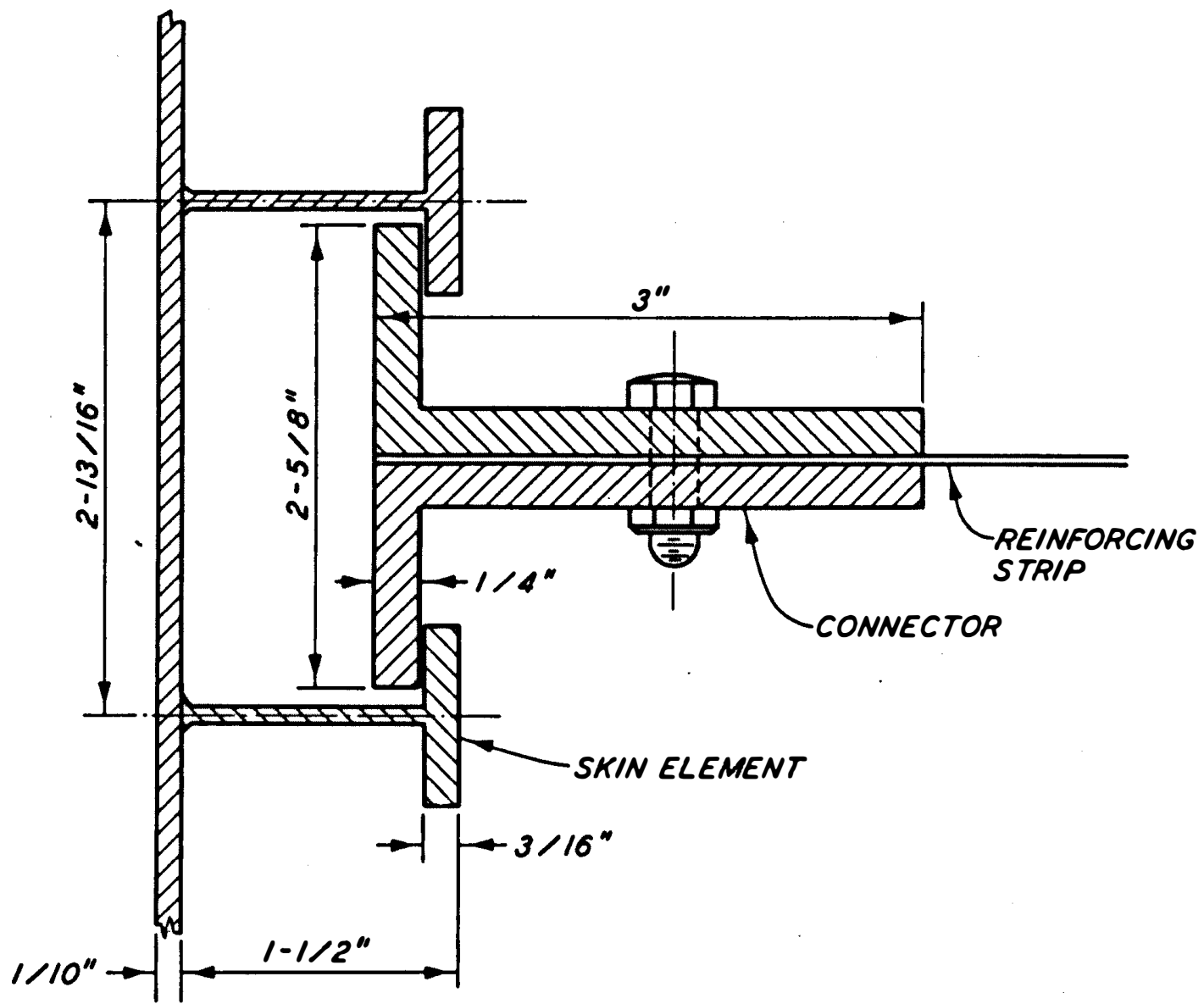

Figure 8. Details of the connector tying the reinforcing strip to the skin element

$$
\begin{gathered}
K_{s t}=\left(1-\lambda_{2}\right)^{2} K_{i} . \\
K_{i}=K_{j} \gamma_{w}\left(\frac{\sigma_{n}}{P_{a}}\right)^{m} \\
\lambda_{2}=\frac{R_{f} \tau}{C_{a}+\sigma_{n} \tan \delta} .
\end{gathered}
$$

where

$$
\begin{aligned}
K_{s t} & =\text { tangent shear } \text { stiffness } \\
K_{i} & =\text { initial shear stiffness }
\end{aligned}
$$




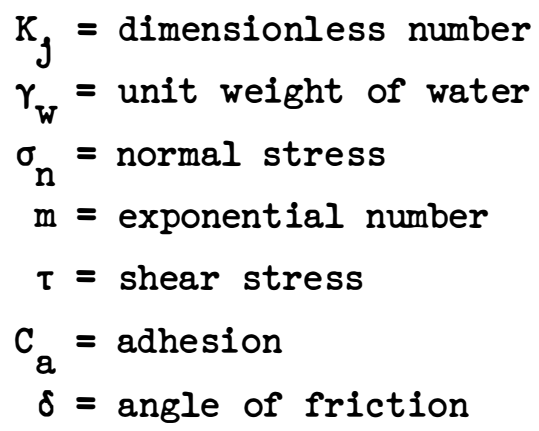

The normal stiffness of the interface element is assumed to behave elastically and, given a high value of $10^{8}$ psf', to inhibit mutual penetration of the materials adjacent to the interface element. The tangent shear and normal stiffnesses were each set to a small residual value $K_{r}$ of $10 \mathrm{psf}$ if the normal stress of the interface element became tensile, permitting voids to develop in the interface. The shear stiffness is also reduced to the residual shear stiffness $K_{r}$ if the shear stress at the interface equals or exceeds the Mohr-Coulomb strength.

Interface behavior

between reinforcing strip and sand

19. The nonlinear shear stress-displacement relationship between the sand and the reinforcing was determined, prior to the field test, using a specially designed shear box. The testing device, shown in Figure 9, is similar to the direct shear box except that the lower frame was replaced by a sheet of the galvanized steel glued to a wooden block.

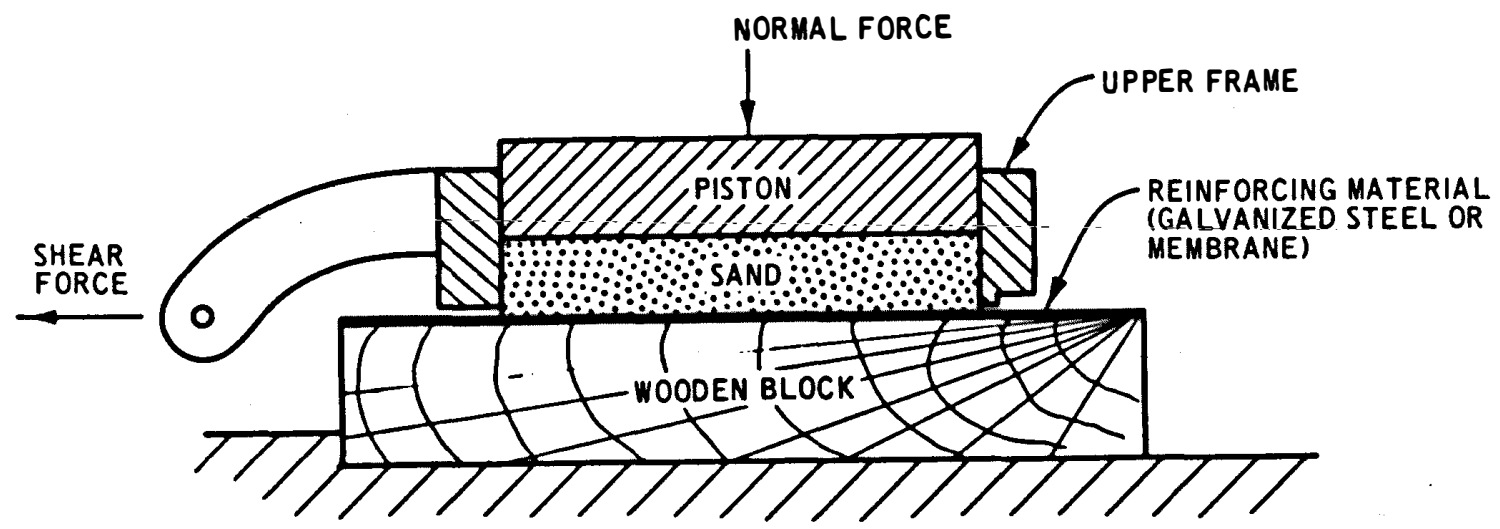

Figure 9. Modified shear box for determining skin friction angle between the sand and the reinforcing material 
The sand was compacted to a dry density of 101.7 pcf. Three direct shear tests were conducted with normal stresses of 10, 50, and 100 psi, respectively, at a shear deformation rate of $0.5 \mathrm{in}$. per min.

20. The shear stress-deformation relationship between the sand and the galvanized steel is shown in Figure 10; these curves provide a reasonably accurate determination of the initial shear stiffness $K_{i}$. The ultimate shear stress $\tau_{u l t}$ was obtained from the inverse of the slope of the linearized shear stress-deformation relationship as shown in Figure 1l. The failure ratio $R_{f}$ was obtained by dividing the peak shear stress $\tau_{\max }$, as measured from Figure 10, by the ultimate shear stress $\tau_{u l t}$; for these tests the value $R_{f}$ was approximately equal to unity. The angle of friction $\delta$ and the adhesion $C_{a}$ were obtained by plotting the shear stress at failure $\tau_{\max }$ versus $\sigma_{n}$ as shown in Figure 12. A summary of the parameters needed for the hyperbolic shear stress-displacement behavior of the interface elements between the sand fill and the galvanized steel is presented below.

$\begin{array}{rrrcccc}\begin{array}{c}\sigma_{n} \\ \text { psi }\end{array} & \begin{array}{c}\tau_{\max } \\ \text { psi }\end{array} & \begin{array}{c}\mathrm{K}_{i} \\ \mathrm{psi}\end{array} & \begin{array}{c}\mathrm{C}_{\mathrm{a}} \\ \mathrm{psi}\end{array} & \begin{array}{c}\delta \\ \text { degrees }\end{array} & \underline{\mathrm{R}_{\mathbf{f}}} \\ 10 & 3.06 & 81 & 0 & 18 & 1.0 \\ 50 & 11.95 & 444 & 0 & 18 & 1.0 \\ 100 & 32.09 & 1020 & 0 & 18 & 1.0\end{array}$

21. The influence of stress level was accounted for by plotting the initial shear stiffness $K_{i}$ versus $\left(\sigma_{n} / P_{a}\right)$ as shown in Figure 13. The experimental data fell on a straight line on the logarithmic scale, thus enabling accurate determination of the exponential parameter $m$ and the dimensionless number $K_{f}$ defined in Equation $2 b$. For the interface element between the steel strip and the surrounding sand, $m$ is equal to 1.1 and $K_{j}$ is equal to 3280 .

Interface behavior

between skin element and sand

22. No direct shear test was conducted to examine the interface behavior between the skin element and the sand fill. However, the nonlinear parameter obtained previously for the sand on galvanized steel 


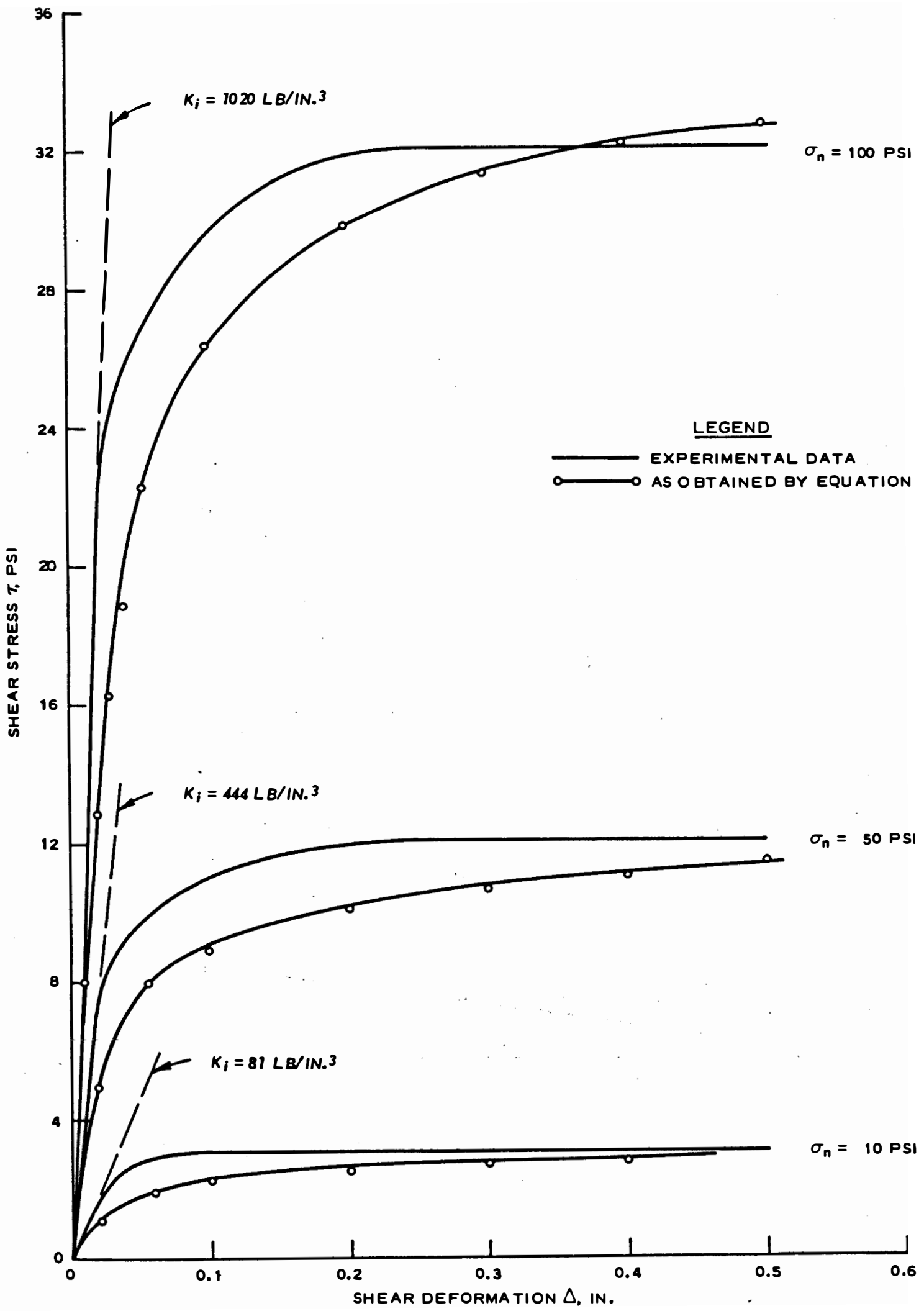

Figure 10. Shear stress-deformation relationship between the sand and the galvanized steel strips 


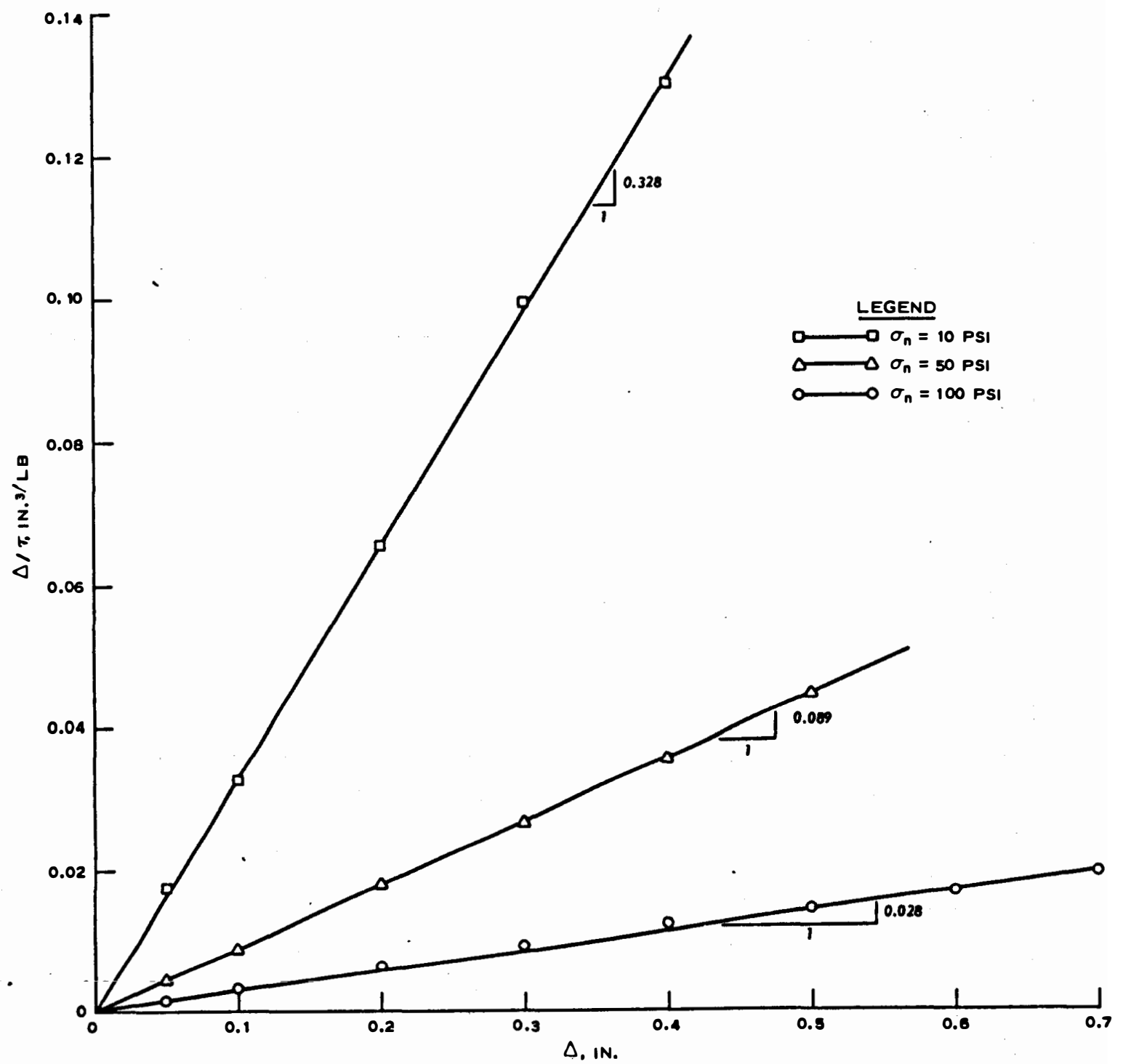

Figure 11. Linearized shear stress-deformation relationship for sand on galvanized steel 


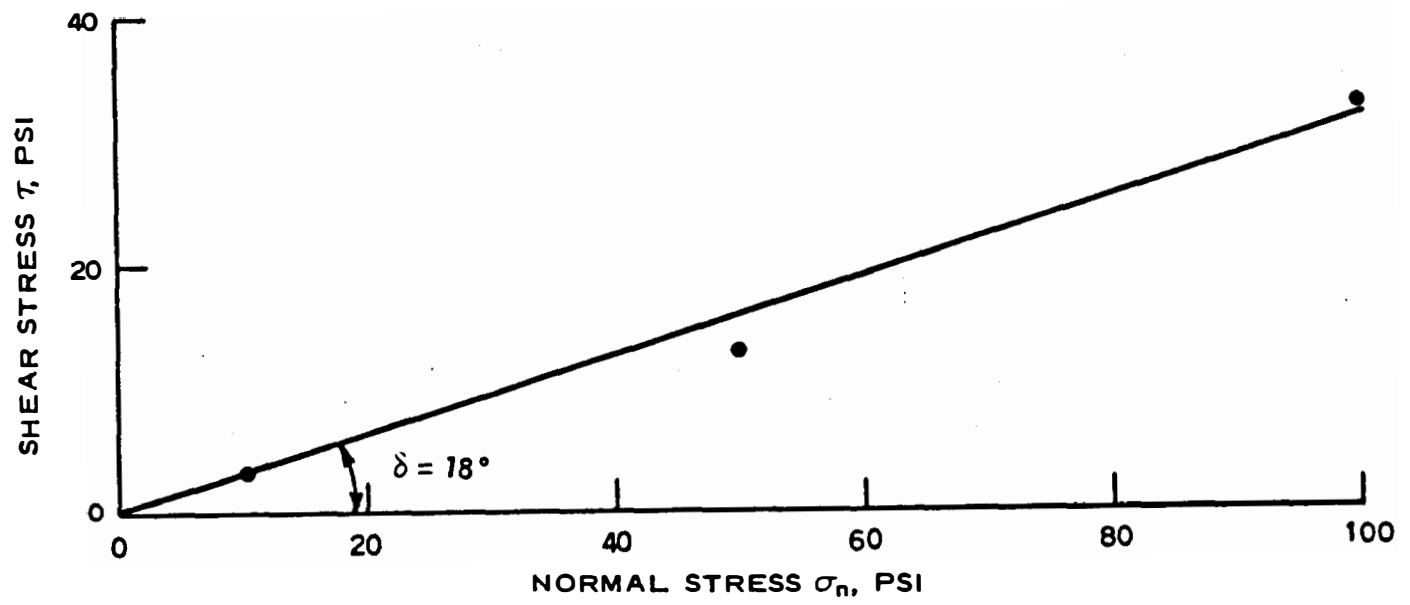

Figure 12. Mohr-Coulomb envelope for sand on galvanized steel 


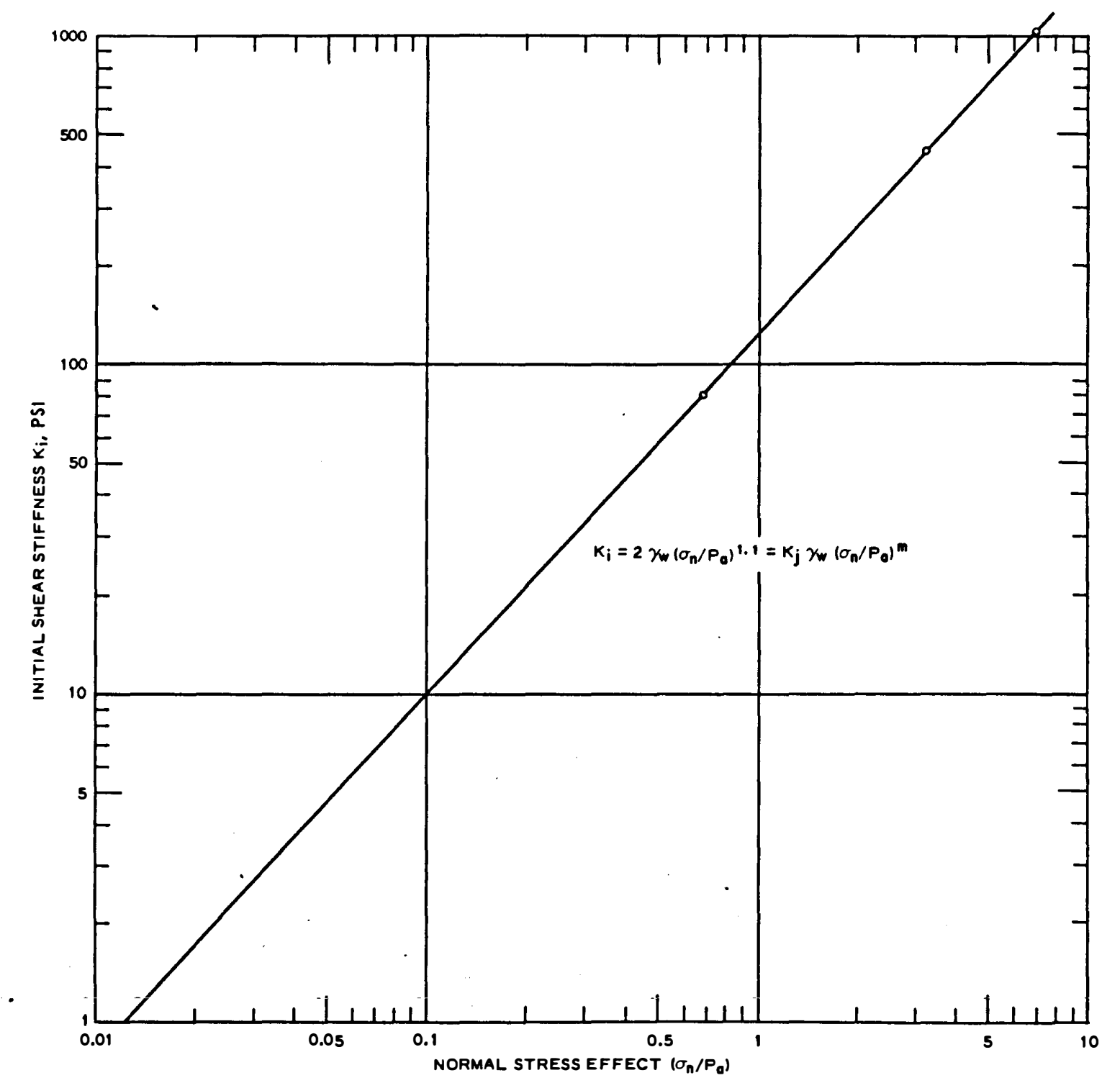

Figure 13. Variation of $K_{i}$ versus $\left(\sigma_{n} / P_{a}\right)$ for sand on galvanized steel 
was used to describe the interface behavior between the skin element and the sand.

Interface behavior between sand and natural soil

23. The nonlinear constitutive equation presented in Equation 2 was used to describe the interface behavior between the sand fill and the surrounding natural ground. Three direct shear tests in which the lower part of the shear box was filled with the $\mathrm{ML}$ soil and the upper part was filled with compacted sand were conducted, and the linearized shear stress-displacement relationship is presented in Figure 14. The figure shows that the experimental points deviate slightly from the straight line, which indicates that the hyperbolic representation is only an approximation for the behavior of this material. The MohrCoulomb failure envelope for sand on silt, presented in Figure 15, showed an angle of friction of $34 \mathrm{deg}$ and a small adhesion of 0.05 psi. 24. The influence of the stress level on the behavior of the interface elements between the sand and the natural ML soil was accounted for by plotting the initial shear stiffness $K_{i}$ versus $\left(\sigma_{n} / P_{a}\right)$ as shown in Figure 16. The figure shows that the experimental points deviate significantly from the ideal straight line; however, the best fit line was used for evaluating $m$ and $K_{j}$. A sumary of the parameters needed for the nonlinear constitutive equation for the interface element between the sand and the natural $\mathrm{ML}$ soil is presented below.

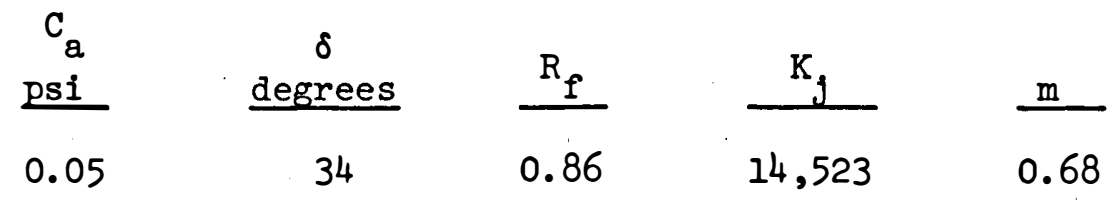

25. Comparison between the shear stress-deformation curves obtained by experimental tests and those generated by the hyperbolic formulation, shown in Figure 17, indicates a reasonable agreement between the two respective curves. 


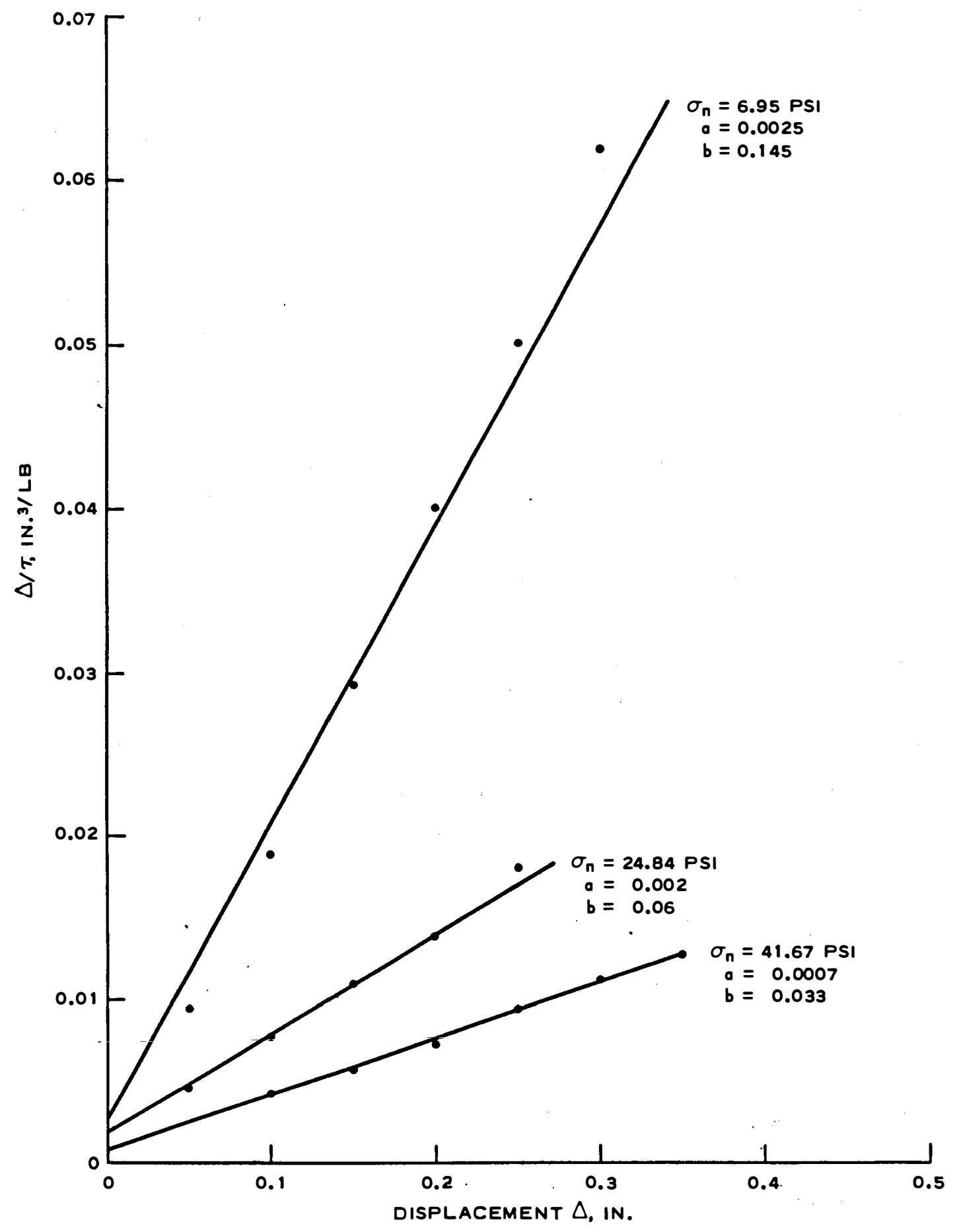

Figure 14. Linearized shear stress-displacement relationship for sand on silt 


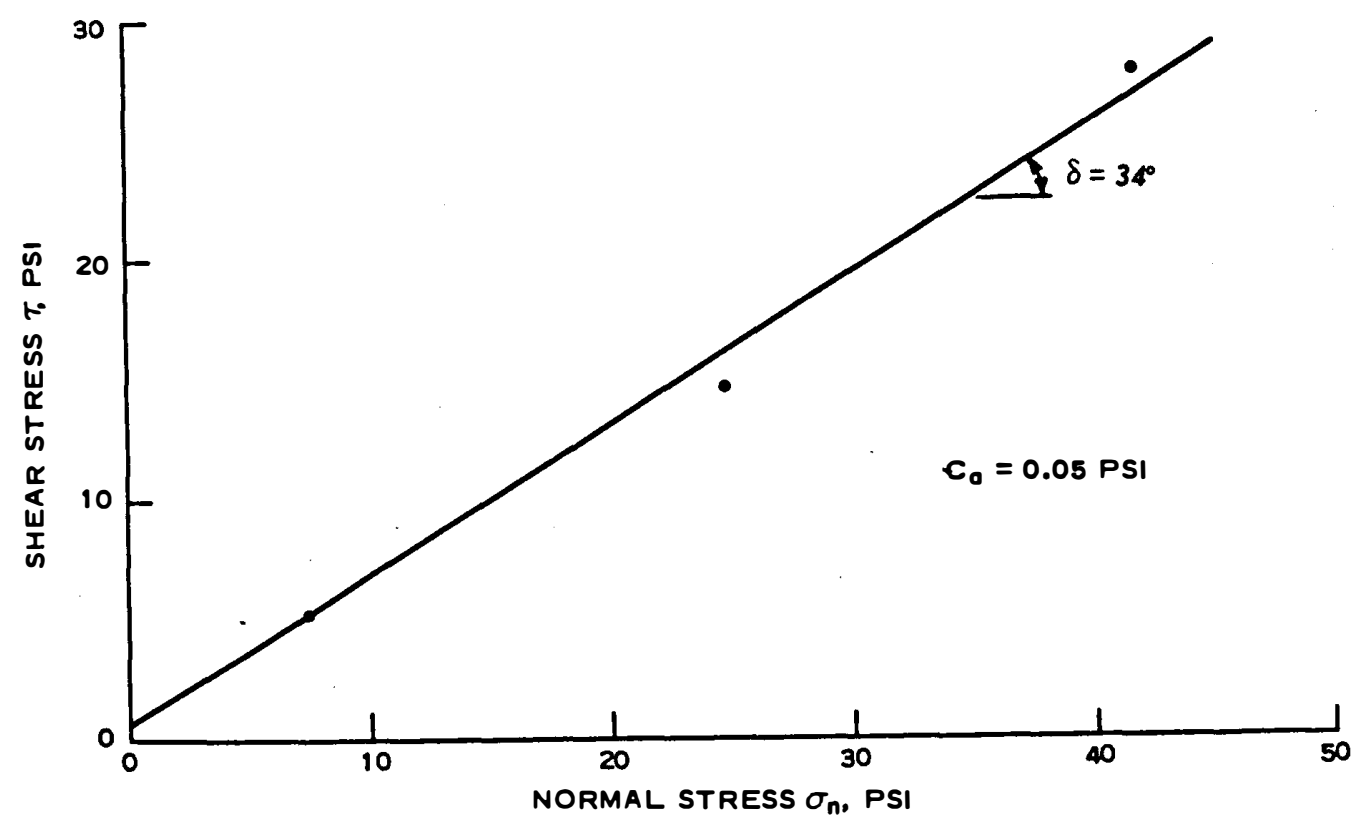

Figure 15. Shear stress versus normal stress at failure for sand on silt 


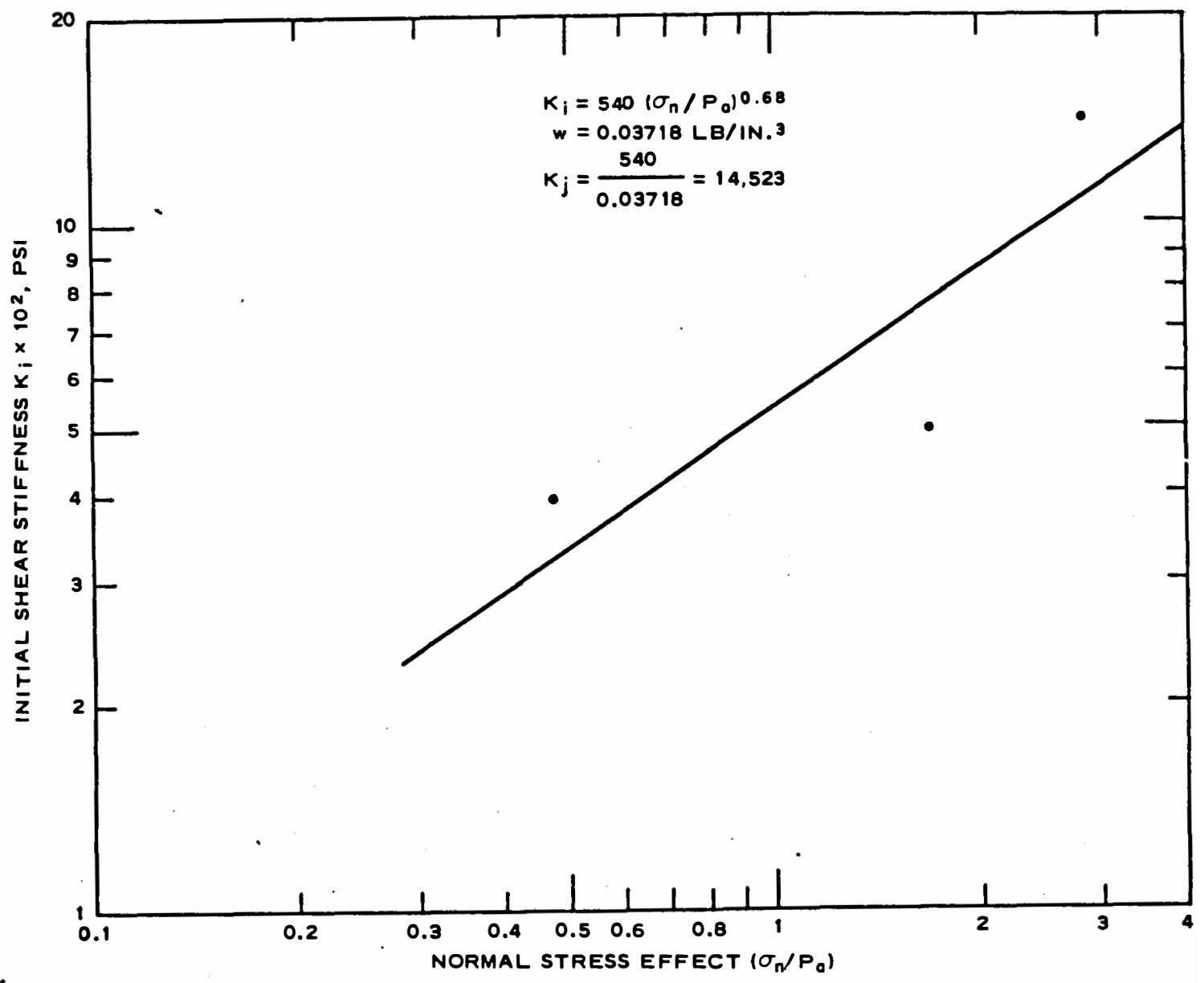

Figure 16. Variation of initial shear stiffness with respect to $\left(\sigma_{n} / P_{a}\right)$ for interface element between the sand fill and the natural ML soil 


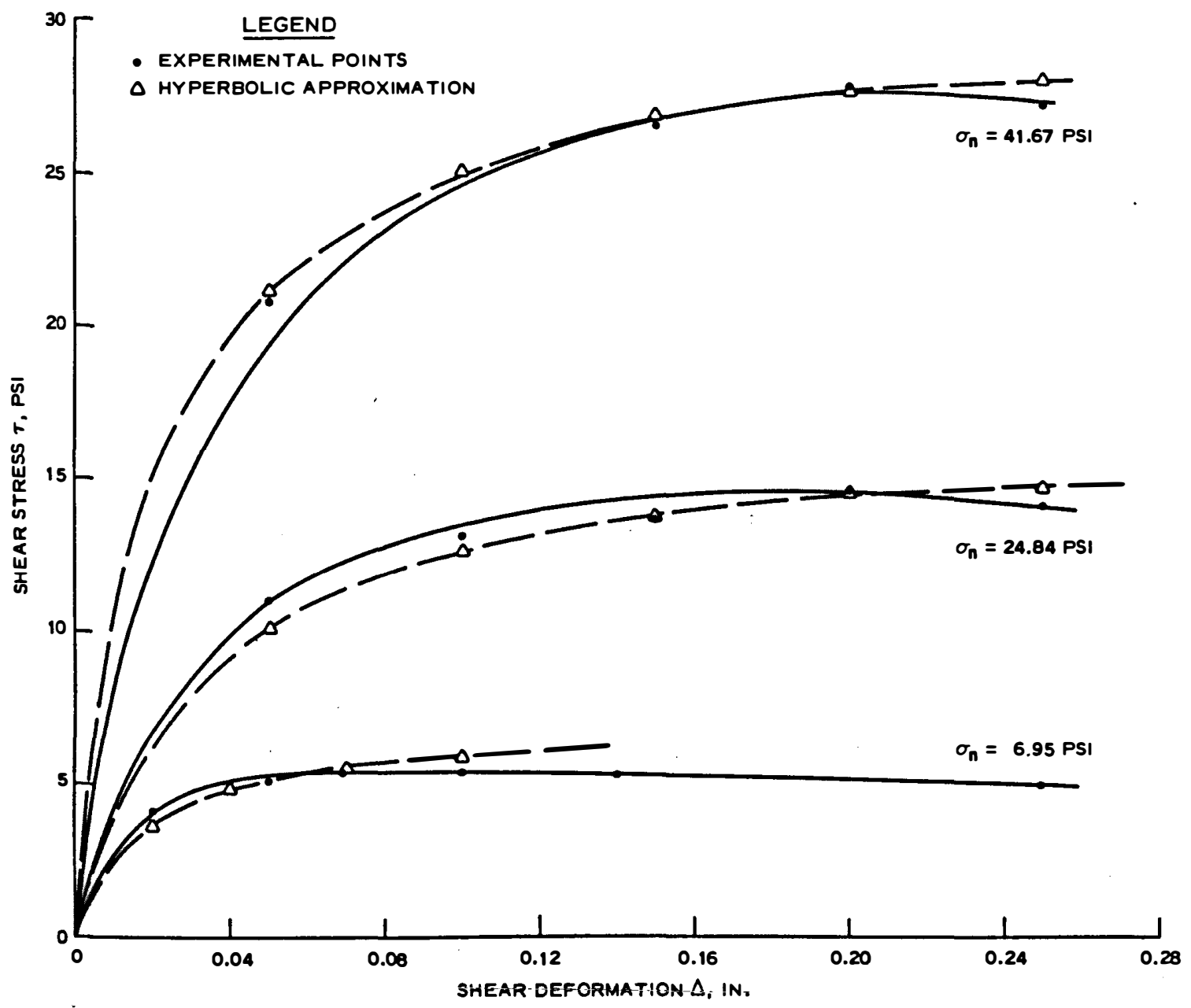

Figure 17. Shear stress-deformation relationship along plane between the sand fill and the $\mathrm{ML}$ soil 
26. The reinforced earth wall is a complicated $3 \mathrm{D}$ problem, the complexity of which is compounded by the introduction of the steel strips as a reinforcing element. The solution of such a problem requires a substantial amount of human effort and computer time. In order to arrive at a solution with reasonable time and cost, it is necessary to introduce a certain amount of idealization and simplification with respect to geometry and modeling of material properties.

\section{Idealization as 2D Problem}

- Modeling of reinforcing strip

27. The 3D reinforced earth wall was idealized as a $2 \mathrm{D}$ plane strain problem by assuming that the reinforcing strips (see Figure 1) are replaced by a plate extended to the full width and breadth of the wall. These plates are illustrated in mesh I (Figure 18) and mesh II (Figure 19) which were developed for this study. Assuming that the major response of the strips is provided by an axial stiffness, the total axial stiffness of the reinforcing strips $S$ of the wall is:

$$
S=\sum_{j=1}^{n} \frac{A_{j} E_{j}}{L_{j}}=n \frac{A_{s} E_{s}}{L_{s}}
$$

where

$$
\begin{aligned}
\mathrm{n} & =\text { total number of strips in each row } \\
\mathrm{A}_{\mathrm{S}} & =\text { cross-sectional area of the reinforcing strip } \\
\mathrm{E}_{\mathrm{S}} & =\text { modulus of elasticity of the galvanized steel } \\
\mathrm{L}_{\mathrm{S}} & =\text { length of the reinforcing strip }
\end{aligned}
$$

28. The equivalent stiffness of the plate that substitutes for each row of steel strips $S_{e}$ may be defined as

$$
S_{e}=\frac{A_{e} E_{e}}{L_{e}}
$$




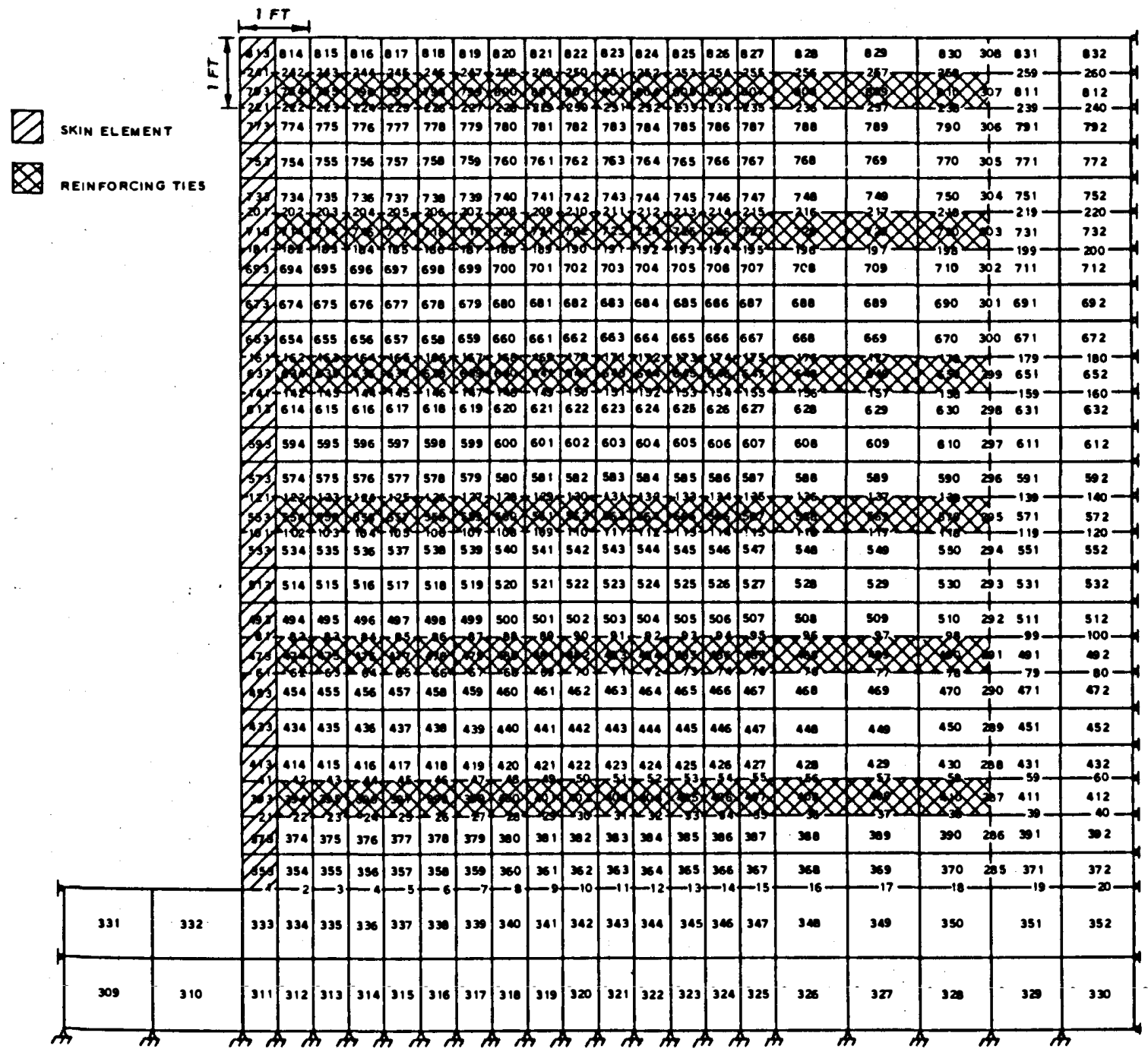

Figure 18. FE mesh I employed in the analysis of the reinforced earth wall 


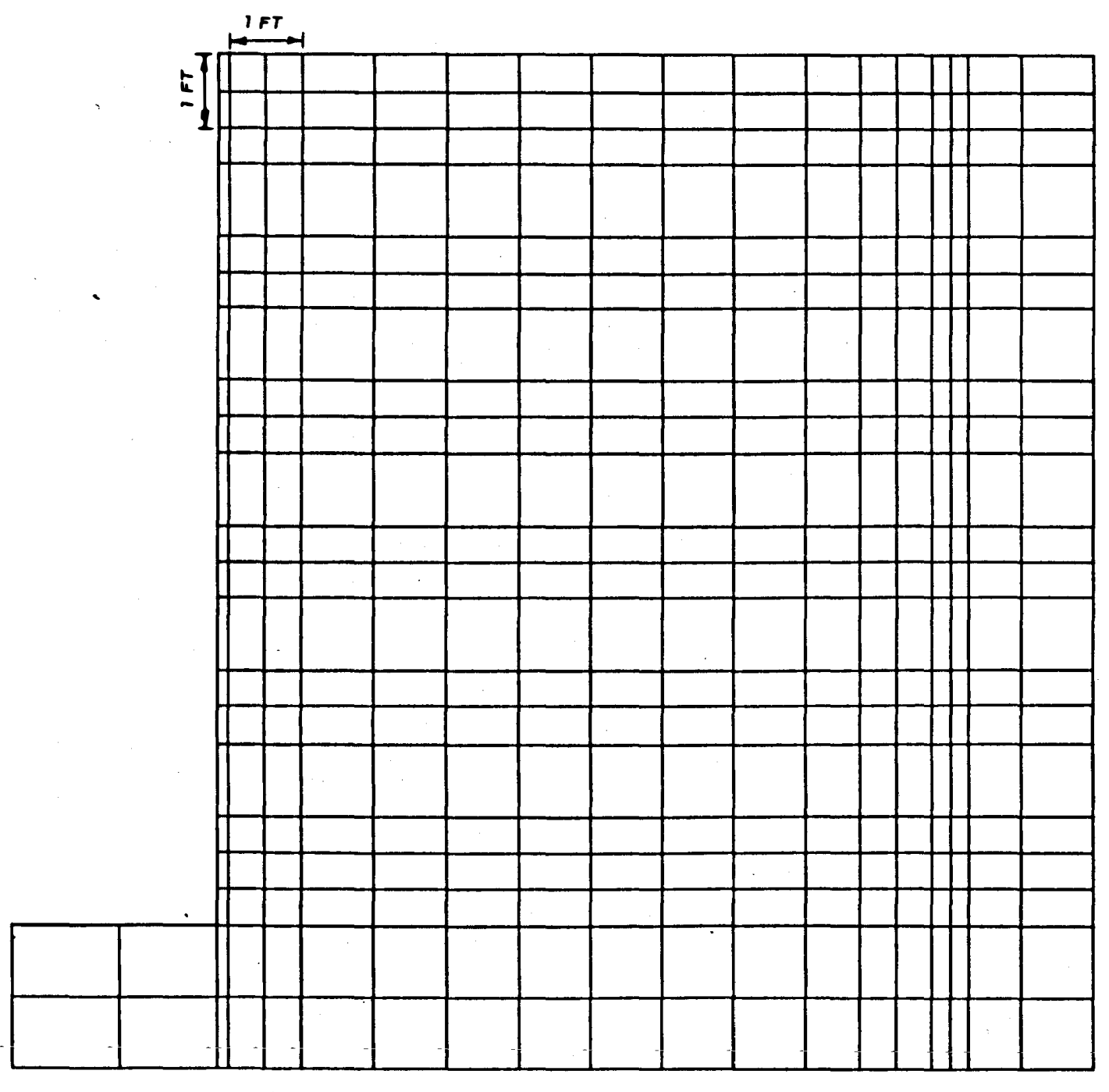

Figure 19. FE mesh II for the reinforced earth wall 
where

$A_{e}=$ equivalent cross-sectional area of the steel strips

$\mathrm{E}_{e}=$ equivalent modulus of the steel strips

$\mathrm{L}_{e}=$ equivalent length of the steel strips

28. Because the stiffness $S$ and the equivalent stiffness $S_{e}$ should be the same and also because the length $L_{s}$ and the equivalent length $L_{e}$ remain the same, thus by equating Equations 3 and 4 , the equivalent stiffness $E_{e}$ can be determined as

$$
E_{e}=\frac{n A_{s} E_{s}}{A_{e}}
$$

29. For the prototype reinforced earth wall the cross-sectional area of the reinforcing strip was $0.096 \mathrm{sq}$ in., the modulus of elasticity of the galvanized steel was $31.1 \times 10^{6} \mathrm{psi}$, and the number of strips in each row was 6 . The thickness of the equivalent reinforcing strip elements, as shown in mesh I (Figure 18), was 6 in. and as shown in mesh II (Figure 19), $0.024 \mathrm{in.} \mathrm{The} \mathrm{width} \mathrm{of} \mathrm{the} \mathrm{equivalent} \mathrm{plate} \mathrm{for}$ both meshes (i.e. length of the reinforced earth wall) was $16 \mathrm{ft}$. Substituting the appropriate values in Equation 5, the magnitude of $\mathrm{E}_{\mathrm{e}}$ can be determined.

Mesh I: $\quad E_{e}=\frac{6 \times 0.096 \times 31.1 \times 10^{6}}{0.5 \times 16}=2.24 \times 10^{6} \mathrm{psf}$

Mesh II: $\quad E_{e}=\frac{6 \times 0.096 \times 31.1 \times 10^{6}}{0.002 \times 16}=5.598 \times 10^{8} \mathrm{psf}$

The unit weight of the equivalent reinforcing strips of mesh $I$ was assumed identical with that of the sand backfill because of the very small cross-sectional area of the actual reinforcing strips. The unit weight of the equivalent reinforcing strips in mesh II was taken as 492 pcf, which is the unit weight of the actual strips; the very small area of these strips should cause little additional contribution to the stresses from gravity using mesh II. 


\section{Modeling of skin element}

30. The behavior of the skin element, like that of the rest of the reinforced earth mass, was treated as a plane strain problem whose major response is provided by bending. The aluminum panels that represent the skin element, as shown in Figure 1, were replaced by an equivalent beam element of similar deflection response depending on the dimensions of the skin element in the FE meshes, Figures 18 and 19. The equation used to satisfy equal bending deformation response between the prototype and the model was:

$$
\frac{E_{a} I_{a}}{L_{a}}=\frac{E_{e} I_{e}}{L_{e}}
$$

where

$$
\begin{aligned}
& E_{a}=\text { modulus of elasticity of the aluminum panel } \\
& I_{a}=\text { moment of inertia of the aluminum panel per unit width } \\
& L_{a}=\text { length of the beam }\left(S_{2}\right. \text { ) between any two rows of reinforcing } \\
& \text { strips (see Figure } l \text { ) } \\
& E_{e}=\text { equivalent modulus of elasticity } \\
& I_{e}=\text { equivalent moment of inertia per unit width } \\
& L_{e}=\text { equivalent length of the beam } \\
& 31 \text {. Since the beam lengths of the skin element and its model are }
\end{aligned}
$$
the same (i.e., $L_{a}=L_{e}$ ), the equivalent modulus of elasticity for the skin element can be expressed by:

$$
E_{e}=E_{a} \frac{I_{a}}{I_{e}}
$$

From paragraph 16, the modulus of elasticity and the moment of inertia are $10 \times 10^{6} \mathrm{psi}$ and $1.368 \mathrm{in} .^{4}$, respectively. The depth of the equivalent beam, as shown in Figure 18 for mesh I, is 6 in.; therefore, the equivalent moment of inertia $I_{e}$ is equal to. 216 in. ${ }^{4}$. Substituting the values of $E_{a}, I_{a}$, and $I_{e}$ in Equation 7 , the magnitude of $E_{e}$ for mesh I can be obtained as follows:

$$
E_{e}=\frac{10 \times 10^{6} \times 1.368}{216}=6.33 \times 10^{4} \mathrm{psi}\left(9.13 \times 10^{6} \mathrm{psf}\right)
$$


The magnitude of $\mathrm{E}_{\mathrm{e}}$ for mesh II (Figure 19) with skin element thickness of 1.6 in. was $3.34 \times 10^{6}$ psi $\left(4.8 \times 10^{8}\right.$ psf).

32. The aluminum panels of the skin element were hinged rather than bonded together into an elastically rigid unit; the actual modulus of the skin element may consequently have been substantially less than that assumed for the $\mathrm{FE}$ analyses using meshes $\mathrm{I}$ and II.

33. Two iterations were made for computation of stresses during each construction and loading sequence. The first iteration indicated the appropriate modulus (based on input material properties) to use for computation of the stresses during the second iteration.

\section{FE Mesh Design}

34. In addition to idealizing the reinforced earth wall as a 2D problem, there are a number of other factors which affect the design of the FE mesh. Some of these factors are:

a. Design of elements required to obtain a satisfactory result.

b. Boundary conditions.

c. Number of construction and loading sequences.

d. Location of interface elements.

Design of elements

35. It is always desirable to use a minimum number of elements that achieve a satisfactory degree of accuracy so that the computer time and hence computation cost are minimum. However, for a given number of elements, the degree of accuracy in simulating a particular behavior depends upon the correlation between the displacement pattern assumed and the displacement of the actual events. Because of the uncertainties regarding the assumed displacement and the preliminary nature of this study, simple meshes using relatively large numbers of rectangular elements, as shown in Figures 18 and 19, were developed to improve accuracy. 36. The elements in mesh I, Figure 18, were square to minimize distortion of results that might occur if the aspect ratio is different from unity. The elements in mesh II were reduced in total number 
compared to mesh I to increase computation efficiency and dimensions were adjusted to closely simulate actual dimensions of the components of the wall.

Boundary conditions

37. The boundaries should be located so that they will have negligible effect on the main structure to be analyzed. In view of the preliminary nature of this analysis, the boundaries were kept at a distance of $2 \mathrm{ft}$ from the reinforced earth mass. No calculation was used to determine the influence of the boundary conditions on the FE results.

38. The left and right vertical boundaries were confined laterally and the bottom horizontal boundary was confined both laterally and vertically. During each construction sequence of the wall, the lateral displacement was set to zero to simulate actual construction in which the lateral displacements of the skin element were restricted. Construction and loading sequences

39. Twelve buildup increments 1 ft high each were used to construct the wall described by mesh $I$, while six buildup increments 2 ft high were used to construct the wall described by mesh II. Concentrated loads following construction were placed on each nodal point at the top of the wall mesh to cause surface pressures of 250 psf per increment. Six increments were applied to reach the failure condition of $1500 \mathrm{psf}$ observed with the actual wall.

Location of interface elements

40. The interface elements within the FE meshes are presented in Figures 18 and 19. These interface elements increase flexibility in accounting with the interaction effects between the different components of the wall such as slippage and separation between the different components. Mesh. I contains vertical interface elements between the skin element and backfill material and between the back face of the wall and the original in situ earth. Horizontal interface elements are located between the reinforcing strips and backfill material and between the backfill and original ground surface of the wall. Mesh II contains vertical interface elements between the back face of the wall and the 
original in situ earth and horizontal interface elements between the reinforcing strips and backfill material.

\section{Examination of the FE Mesh}

41. Two FE analyses were performed using mesh $I$ and mesh II in order to determine the influence of the shape of the FE mesh on the results. The results of the FE analyses obtained from both meshes were compared and correlated with field measurements at the end of construction as well as prior to failure. End of construction (EC) refers to completion of construction of the reinforced earth wall; prior to failure (PF) refers to placement of 1500 psf of surcharge load on the top surface of the wall.

Tensile stress distribution in reinforcing strips

42. The tensile stress obtained by the FE method, which is based on a reinforcing plate covering the entire area at a given reinforced elevation of the wall, was converted to tensile stress carried by the reinforcing strips as actually placed in the field by the following expression:

$$
\sigma_{t}=\frac{{ }^{t} e^{W} e}{N t W} \sigma_{t e}
$$

where

$$
\begin{aligned}
\sigma_{t} & =\text { tensile stress in the reinforcing strip } \\
t_{e} & =\text { equivalent thickness of the reinforcing tie in the } \mathrm{FE} \text { mesh } \\
\mathrm{W}_{e} & =\text { equivalent width of the reinforcing tie in the } \mathrm{FE} \text { mesh } \\
\mathrm{N} & =\text { number of reinforcing ties in each reinforced elevation } \\
t & =\text { actual thickness of the reinforcing tie } \\
\mathrm{W} & =\text { actual width of the reinforcing tie } \\
\sigma_{t e} & =\text { equivalent tensile stress computed by the } \mathrm{FE} \text { analysis }
\end{aligned}
$$

The parameters expressed in Equation 8 for mesh I and mesh II are: 


\begin{tabular}{|c|c|c|}
\hline Parameter & Mesh I & Mesh II \\
\hline$t$ & $0.024 \mathrm{in.}$ & $0.024 \mathrm{in.}$ \\
\hline W & $4.00 \mathrm{in.}$ & $4.00 \mathrm{in.}$ \\
\hline $\mathrm{N}$ & 6 & 6 \\
\hline$t_{e}$ & $6.00 \mathrm{in.}$ & $0.024 \mathrm{in}$ \\
\hline $\mathrm{w}_{\mathrm{e}}$ & $192.0 \mathrm{in.}$ & $192.0 \mathrm{in.}$ \\
\hline
\end{tabular}

43. Comparisons of tensile stresses obtained from the FE method using mesh I and mesh II and those obtained from actual measurement at the end of construction and prior to failure are shown in Figures 20 and 21, respectively. Figure 20 shows little difference in results between mesh I and mesh II at the end of construction. The tensile stress distribution from the FE analysis assumes a parabolic shape similar to that obtained from actual measurements for the tie at elevation $1 \mathrm{ft}$

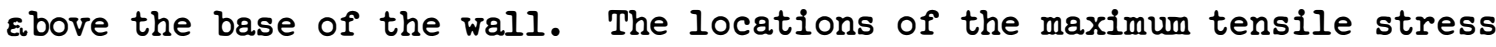
as obtained from the FE analysis agreed well with those measured in the field.

44. The tensile stress distribution along the reinforcing ties prior to failure, Figure 2l, indicates that the FE results of mesh II are slightly higher than those from mesh I. However, the shapes of the tensile stress distribution curves for mesh II are much closer to actual field data than those obtained for mesh $I$. These results indicate that the square elements as represented in mesh I reduce the maximum tensile stress as well as the curvature of the tensile stress distribution curve.

Lateral pressure distribution

45. The lateral pressure distributions along a vertical plane $1.25 \mathrm{ft}$ from the skin element as obtained from the FE analyses of mesh I and mesh II are shown in Figure 22. These results indicate that while the lateral pressures at the end of construction are slightly higher for mesh I than for mesh II, the trend reverses itself prior to failure. The results of the FE analyses for both $\mathrm{EC}$ and $\mathrm{PF}$ cases are approximately similar but somewhat higher than those obtained from the Rankine active earth pressure theory. The PF lateral pressure near the top of 


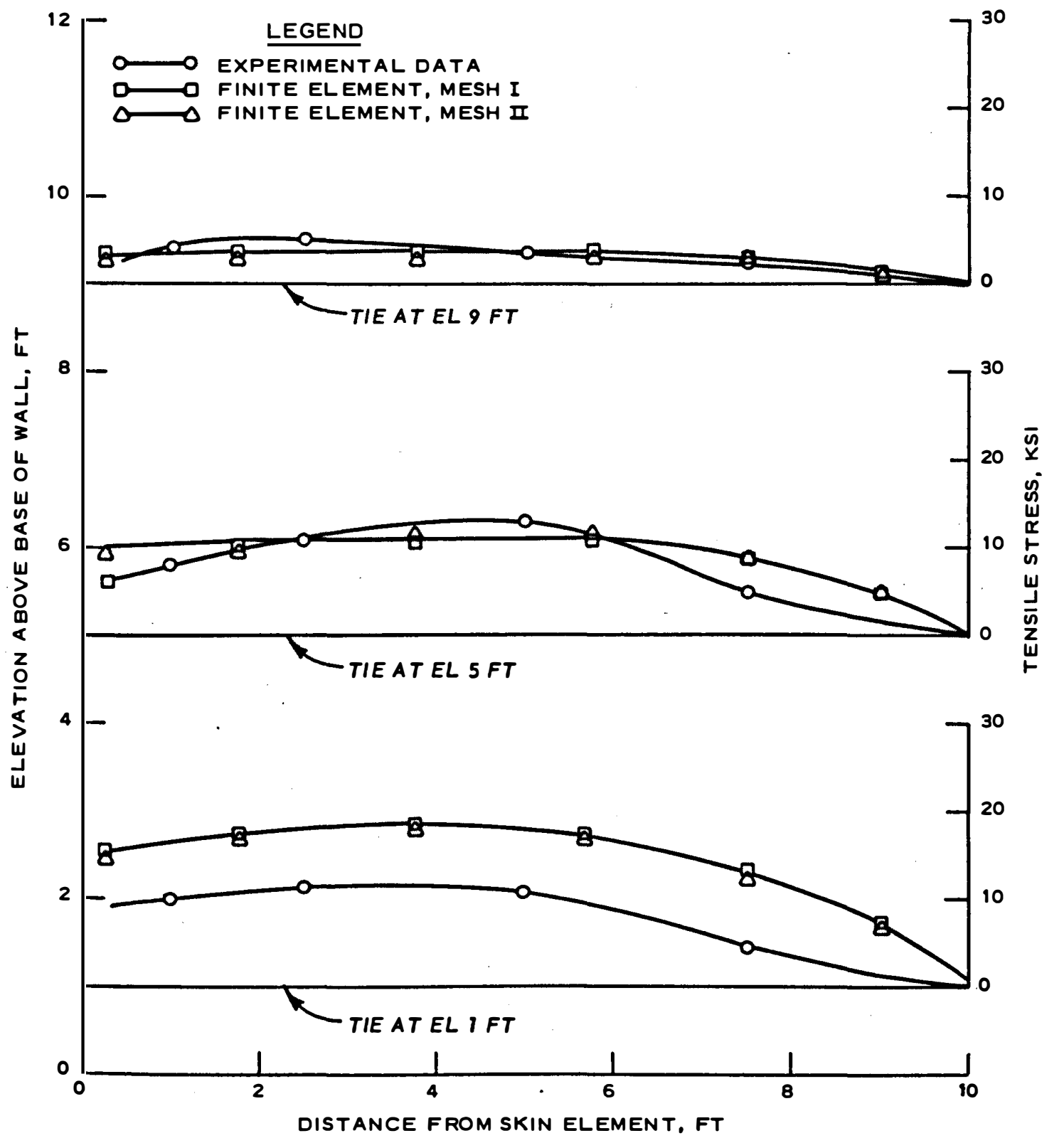

Figure 20. Influence of FE mesh on tensile stress distribution along the instrumented reinforcing strips at end of construction 


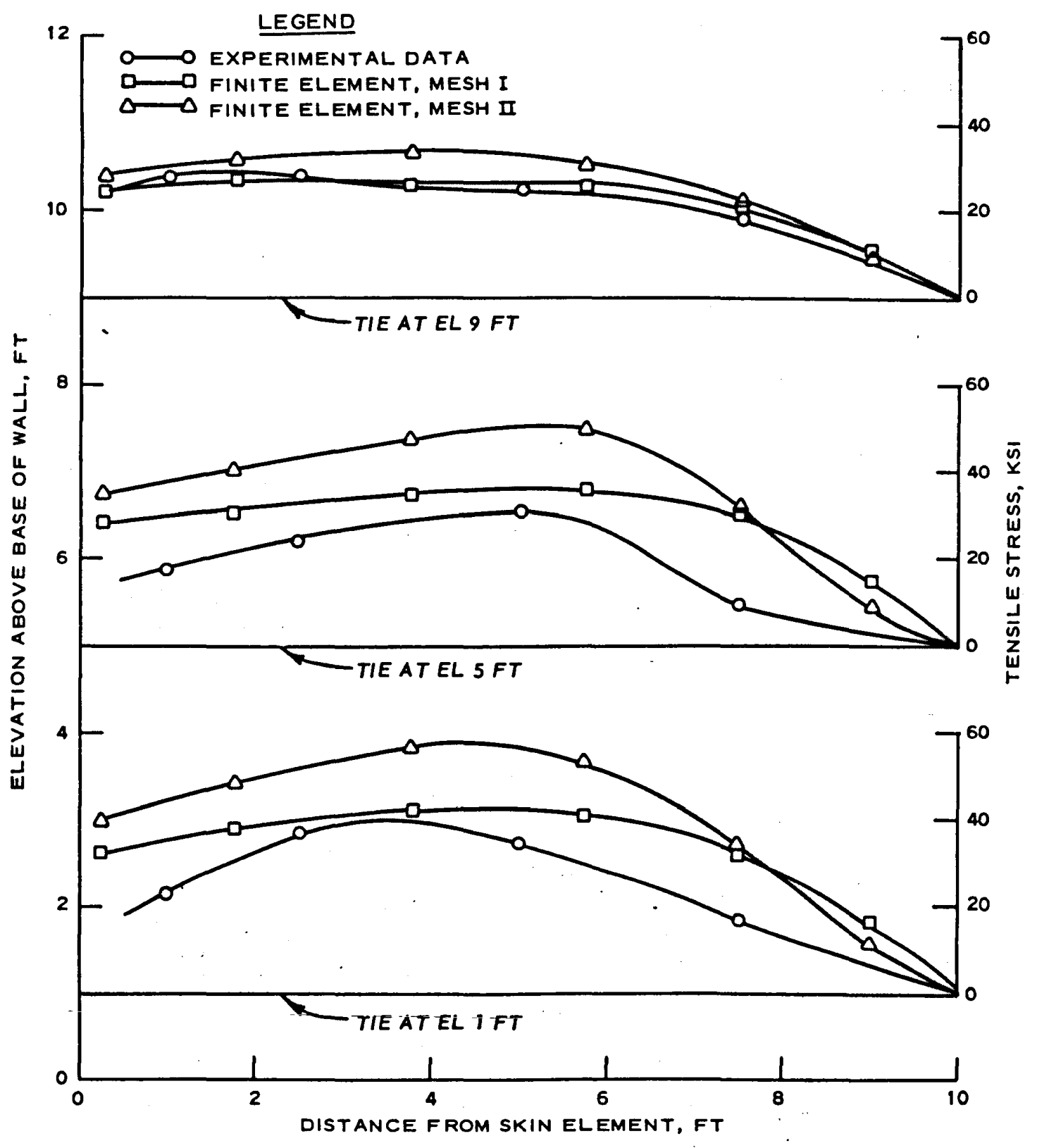

Figure 21. Influence of FE mesh on tensile stress distribution along the instrumented reinforcing strips prior to failure 


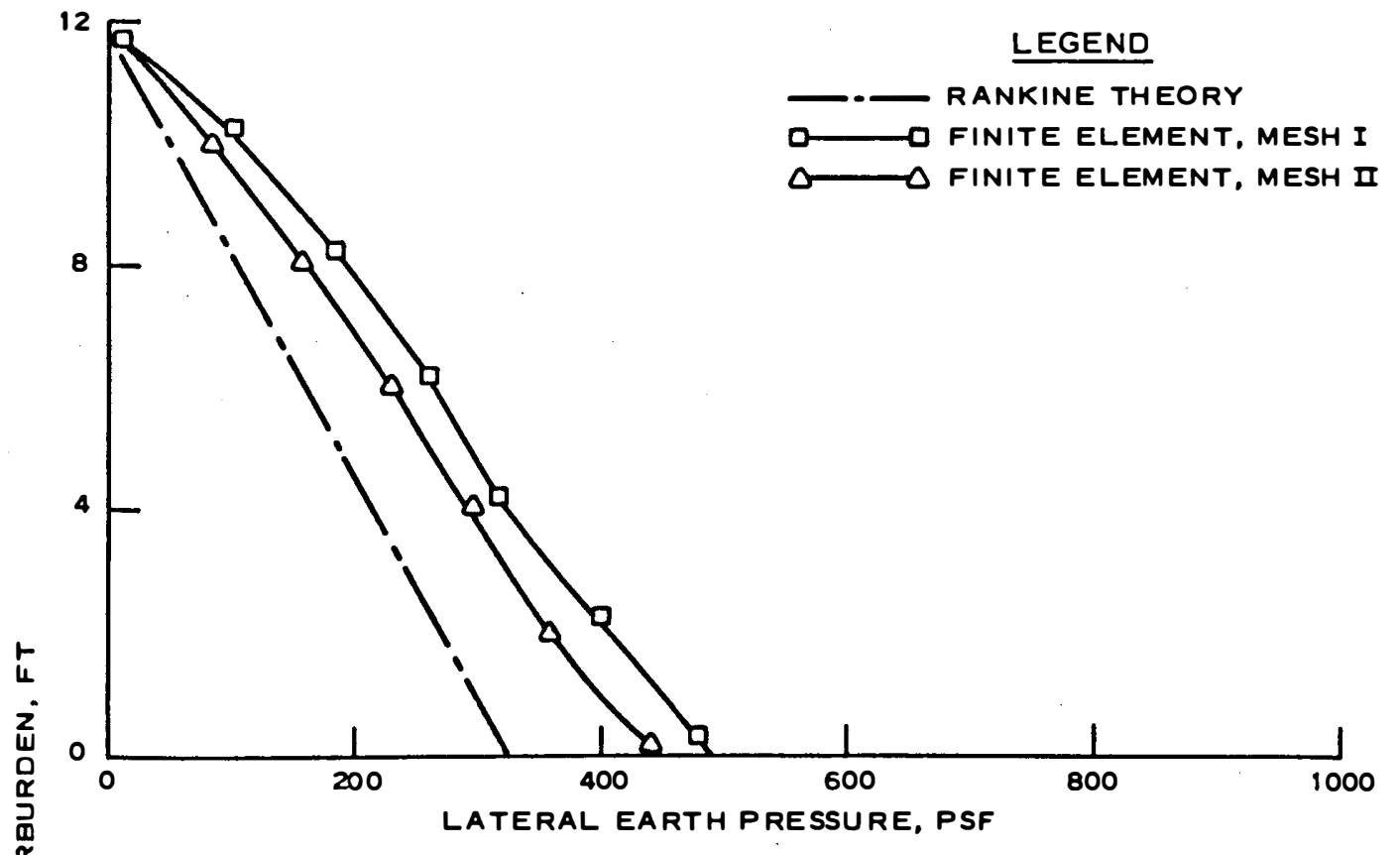

\section{a. END OF CONSTRUCTION}

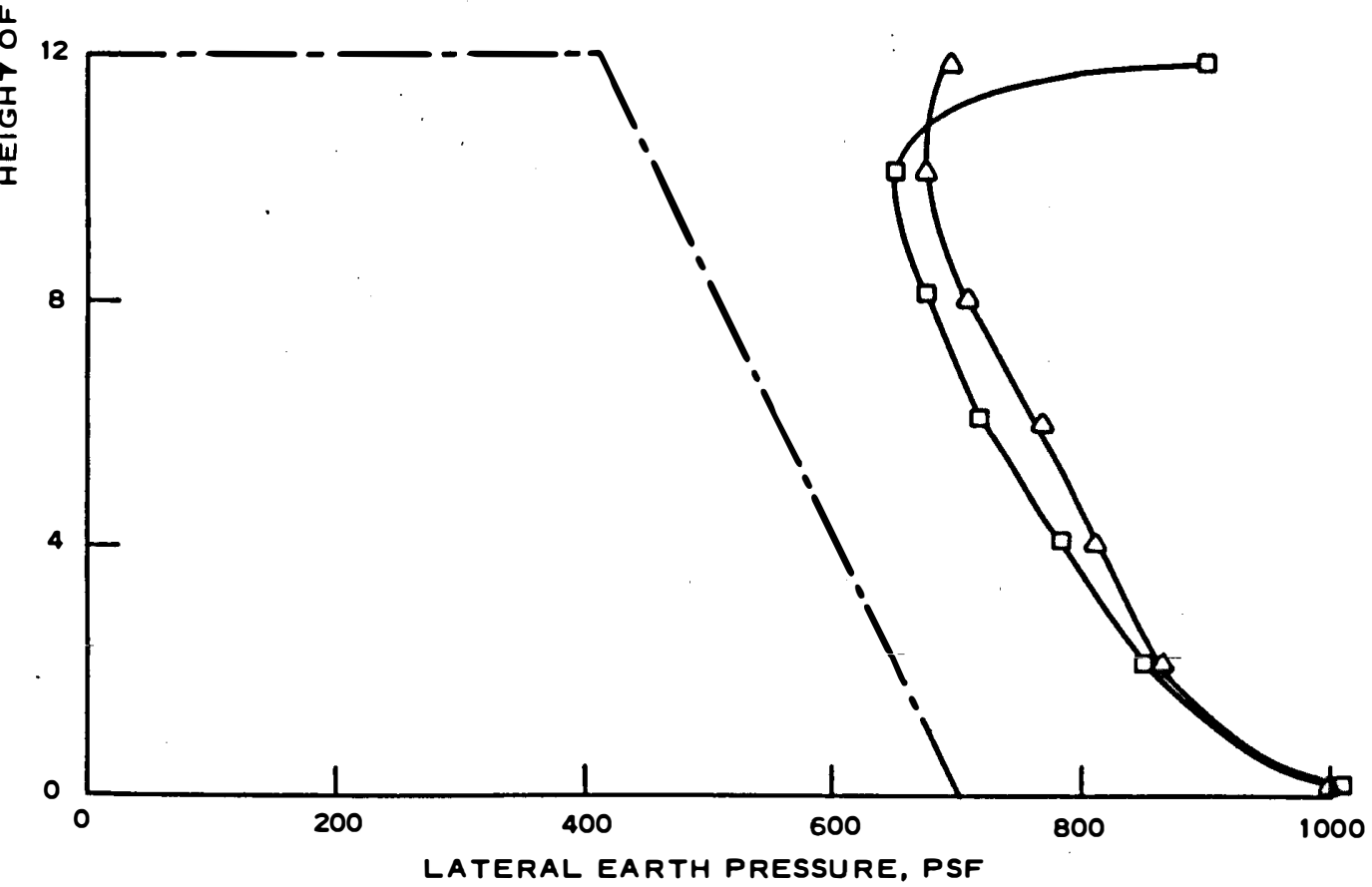

b. PRIOR TO FAILURE

Figure 22. Influence of FE.mesh on lateral pressure acting on vertical plane $1.25 \mathrm{ft}$ from skin element 
the wall as obtained from the FE analysis is greatly increased for mesh $I$, a weakness in the FE program.

46. From the foregoing, it appears that both mesh I and mesh II provided approximately the same results, indicating that the use of square elements of aspect ratio of 1.0 did not significantly improve the results. Furthermore, fewer elements are contained in mesh II, significantly reducing computation and increasing accuracy. Therefore, mesh II was adopted for the actual FE analysis of the reinforced earth wall. 
47. Reliable FE analysis of the reinforced earth wall requires accurate information on material properties, proper modeling of deformation and failure mechanisms, and proper modeling of the interaction effects between the components of the wall. The previously described models of material behavior (Part II) and idealization of the wall by the computer code (Part III) provide only a rough approximation of the actual field situation. The results of this analysis and comparisons with field observation will consequently be used to help determine more appropriate parameters for material properties of the components of the wall and improved models that may better represent field behavior.

48. An important assumption needed to obtain the FE plane strain solution is that the reinforcing strips cover the entire length of the wall. Such an assumption increases the shear resistance between the reinforcing element and the surrounding sand by a magnification factor $m_{f}$, where $m_{f}$ (see Figure 1 ) is the ratio of the horizontal crosssectional area of the wall to the total area of the reinforcing strips at that elevation. Thus,

$$
m_{f}=\frac{L \cdot L^{\prime}}{N \cdot L \cdot W}=\frac{10 \times 16}{6 \times 10 \times 0.333}=8
$$

Therefore, the increase in the shear stress at the interface element of mesh II due to the computer code is compensated for by reducing the shear stresses in Equation 2 by $m_{f}$. Thus, the constitutive equation for the interface element used in the actual $\mathrm{FE}$ analysis is:

$$
\begin{aligned}
K_{s t} & =\left(1-\lambda_{2}\right)^{2} K_{i} \\
K_{i} & =\frac{K_{f}}{m_{f}} \gamma_{w}\left(\frac{\sigma_{n}}{P_{a}}\right)^{n}
\end{aligned}
$$




$$
\lambda_{2}=\frac{R_{f} \tau}{\frac{C_{a}}{m_{f}}+\sigma_{n} \tan \left(\frac{\delta}{m_{f}}\right)}
$$

Therefore, the material parameters input in the code are $K_{j}=410$ and $\phi=3$ deg.

49. It must be noted that Equation 10 can only provide a crude simplification of the real behavior between the reinforcing strips and the surrounding soil. More study is needed to provide a better constitutive model to describe the behavior of the interface elements. In Equation 10 the tangent shear stiffness $K_{s t}$ is set to a small residual value $K_{r}$ of 10 psf whenever the shear stress at the interface element exceeds a Mohr-Coulomb strength envelope with cohesion equal to $c_{a} / m_{f}$ and an angle of friction equal to $\delta / \mathrm{m}_{\mathrm{f}}$.

50. The ribs of the skin element, Figure 8 , are extended only along the length of the wall; thus, they contribute very little to the bending resistance of the skin element in the vertical direction. The moment of inertia used in the calculation is that for the aluminum sheet of 0.1-in. thickness rather than that of the integral aluminum panel.

\section{FE Analysis}

51. Two FE analyses were performed using mesh II. - In the first analysis, case $\mathrm{C}_{1}$, the toe of the wall represented by point $\mathrm{A}$ of Figure 2 was assumed fixed. In the second $\mathrm{FE}$ analysis, case $\mathrm{C}_{2}$, point $\mathrm{A}$ was assumed free to move in any direction. It must be noted that under field conditions point $A$ is neither fixed nor free and the true answer may be between the two extreme cases. The lateral pressures exerted by the backfill and surcharge loading following construction, lateral movement of the skin element, and the tensile stress and deformation behavior of the reinforcing strips are given below. Comparisons are made with field observations for the EC and PF cases. Distribution of lateral pressure

52. The distributions of lateral pressure along a vertical plane 
I ft from the wall face determined from the FE analysis for the freeand fixed-end cases are compared with field observations. Figure 23 shows the variation of the lateral pressure as a function of the height of the wall at the end of construction. The differences in results between cases $C_{1}$ and $C_{2}$ at the end of construction are negligible except at the base of the wall where the fixed end, case $C_{1}$, showed higher lateral pressure than the free end, case $C_{2}$. The results of the FE analysis at the end of construction for $C_{1}$ and $C_{2}$ cases are somewhat higher than those determined by Rankine theory and those obtained by field measurements.

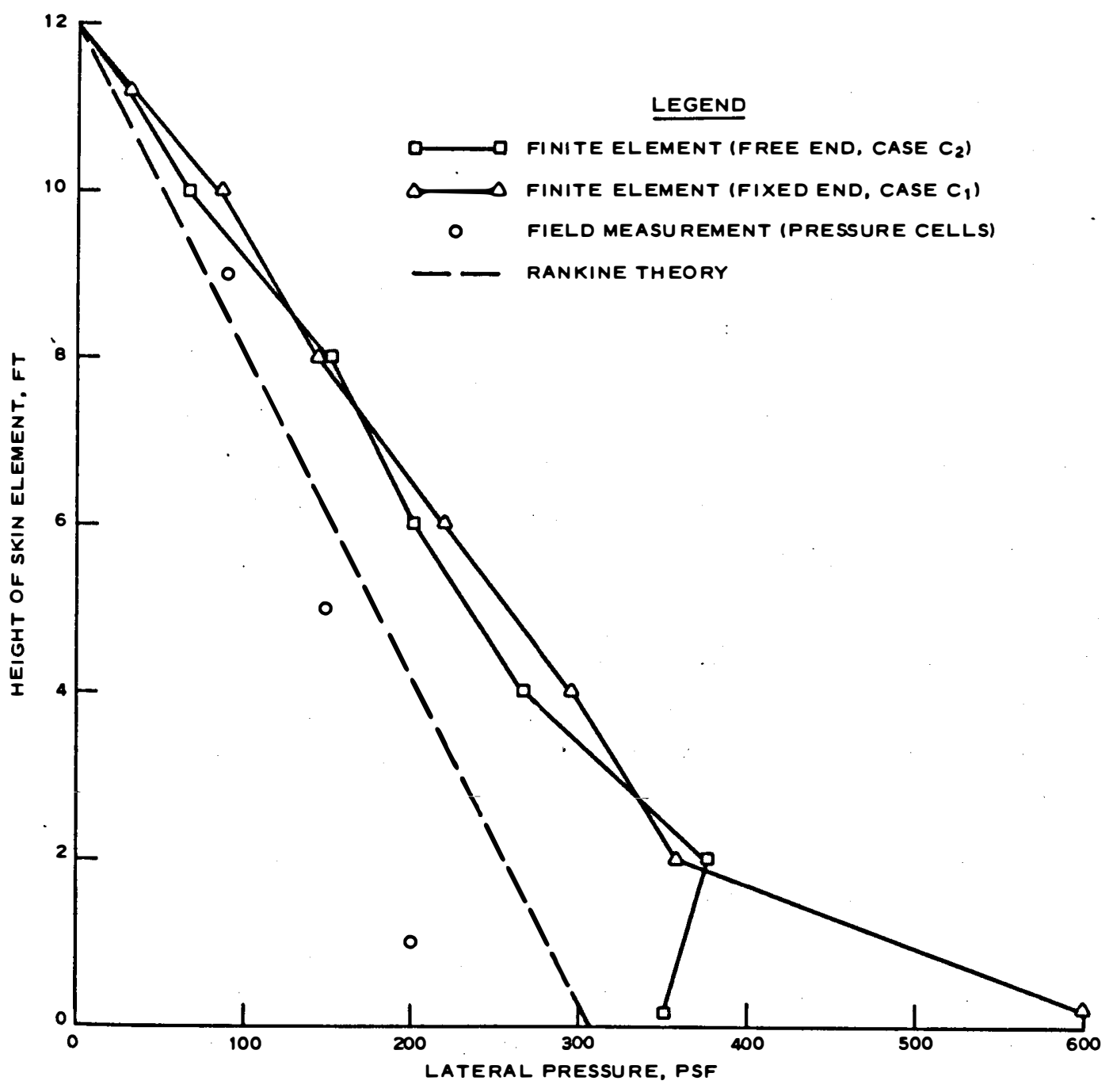

Figure 23. Pressure distribution at vertical plane 1 ft from skin element at end of construction 
53. Field measurements for lateral pressures, Figure 23, were obtained directly from readings of earth pressure cells placed along the center line of the wall 1 ft from the skin element, and also from those stresses generated in the instrumented reinforcing strips within a segment of the wall bounded by $\mathrm{S}_{x} \mathrm{~S}_{z}$, Figure l, surrounding the strip. The excessive lateral pressures determined by the FE analysis may be attributed to deficiencies in the computer code and to the poor modeling of the skin element. It must be noted that the panels of the skin element were connected together by horizontal hinged joints, Figure l, rather than continuous bonded joints as assumed in the FE analyses. The crude approximation of the tangential shear stiffness in the interface elements between the reinforcing strips and backfill material could also have contributed to the difference in the results.

54. Figure 24 shows the FE results for lateral pressures along a vertical plane $1 \mathrm{ft}$ from the skin element prior to failure. The results indicate that the lateral pressures obtained for the fixed end, case $C_{1}$, are significantly higher than those obtained for the free end, case $\mathrm{C}_{2}$ - Both analyses deviated significantly from the linear distribution of Rankine active earth pressure theory but agreed well with field measurement at the upper portion of the reinforced earth wall. It is very difficult to tell which FE analysis agrees with field conditions at the middle portion of the wall since the pressure cell reading agreed very well with case $C_{1}$ while lateral pressure calculated from the tensile stress of the instrumented strips agreed with case $C_{2}$. At the lower part of the wall it is clear that the $\mathrm{FE}$ analysis of case $\mathrm{C}_{1}$ provides better agreement with field measurement than does that of case $\mathrm{C}_{2}$.

55. Significant scatter in the results of the $\mathrm{FE}$ analyses was observed from one vertical plane to the other; the scatter became appreciably worse closer to the skin element. . The scatter in results is not well understood but was probably influenced by the interaction effects between the reinforcing strips, skin element, and the backfill material. 


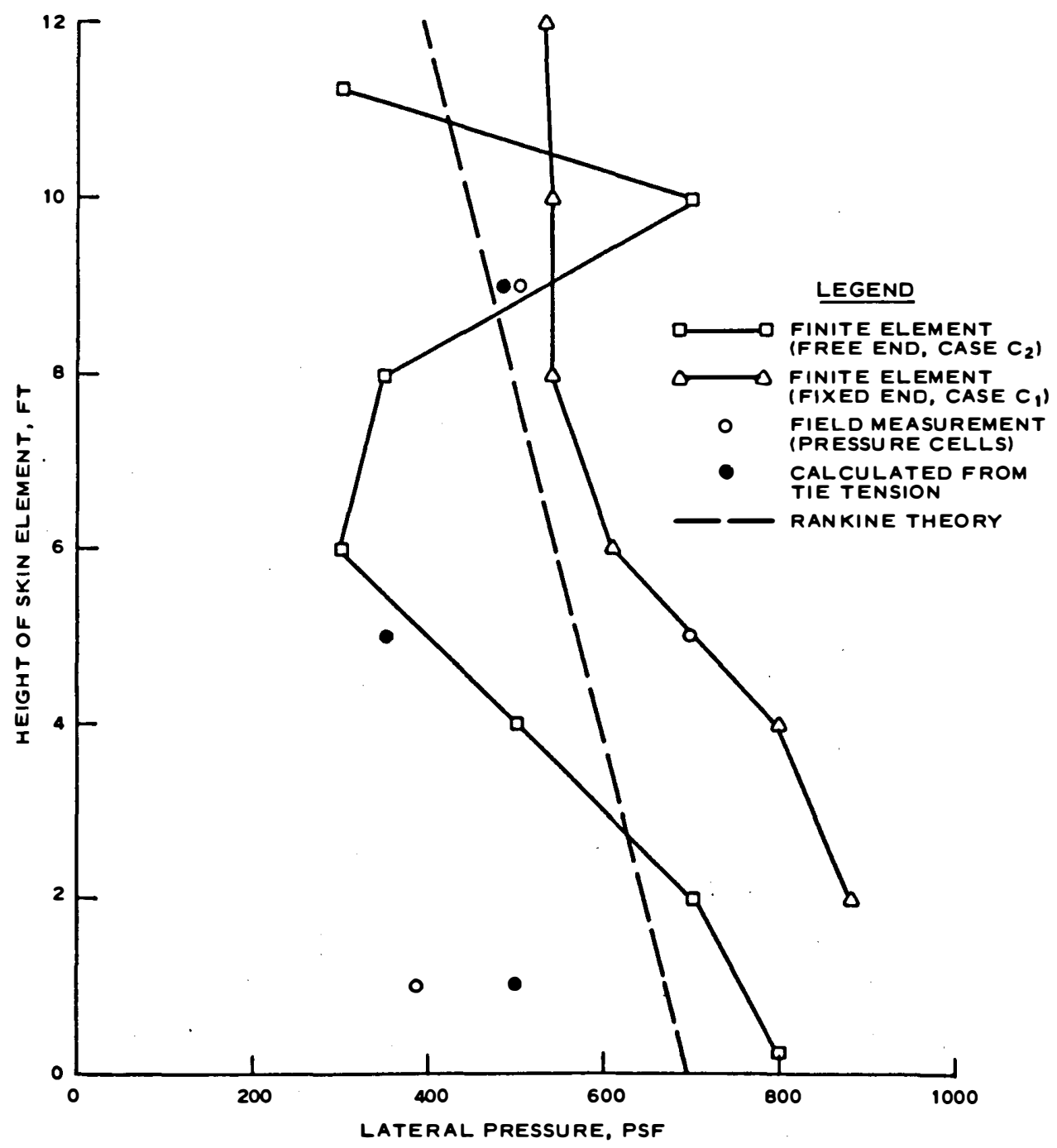

Figure 24. Pressure distribution at vertical plane $1 \mathrm{ft}$ from skin element prior to failure

Distribution of tensile

strain in reinforcing strips

56. The reinforcing strips located at elevations of 1,5 , and $9 \mathrm{ft}$ along the center line of the wall were instrumented with full SR-4 bridges on both surfaces at points $1,2.5,5$, and $7.5 \mathrm{ft}$ from the face of the skin element. The measured strains at the top and bottom of each instrumented point were averaged to eliminate the effect of bending strains; the average strain was considered equal to the tensile strain at that point in the reinforcing strip. Only the strains at the end of construction and prior to failure are presented. For the FE analysis 
the strains were calculated from the average deformations of the nodal points of each element in the instrumented strips. It has been noticed that in certain cases the deformation for the two nodal points at the lower face of the element were unbearably excessive; in such case, only the deformations of the two nodal points at the upper face of the element were considered.

57. Comparisons of tensile strains from the $F E$ analyses for the free-end and fixed-end cases and the actual strain gage measurements of the field test at the end of construction are presented in Figure 25. The figure indicates that the FE results for the free-end condition, case $C_{2}$, are slightly higher than those for the fixed-end condition, case $C_{1}$, but much closer to actual field measurements. The FE analysis indicated that the maximum strain in each reinforcing strip occurred at points closer to the skin element than those obtained from actual measurement. In general, the maximum tensile strains at the end of construction for case $\mathrm{C}_{2}$ are in better agreement with field results than those obtained from case $C_{1}$.

58. The trend of the results at the end of construction differed significantly from those obtained prior to failure of the wall. Strains determined from the FE analysis prior to failure, shown in Figure 26, indicated a maximum strain value close to the skin element that decreased gradually until it vanished at the free end of the reinforcing strips. The results, unlike the end of construction condition, showed higher strains for case $C_{2}$ than for case $C_{i}$. For the strips at elevation $5 \mathrm{ft}$ above the base, both $C_{1}$ and $C_{2}$ cases showed similar values and their maximum values were in good agreement with that obtained from field measurement.

Distribution of tensile stress in reinforcing strips

59. The in situ tensile stress distribution along the reinforcing strips of the reinforced earth wall was calculated from the strain gage readings and the modulus of elasticity of the galvanized steel using modulus of elasticity $E=31.1 \times 10^{6} \mathrm{psi}$. Therefore, the variation in the field tensile stress distribution is similar to the variation in 


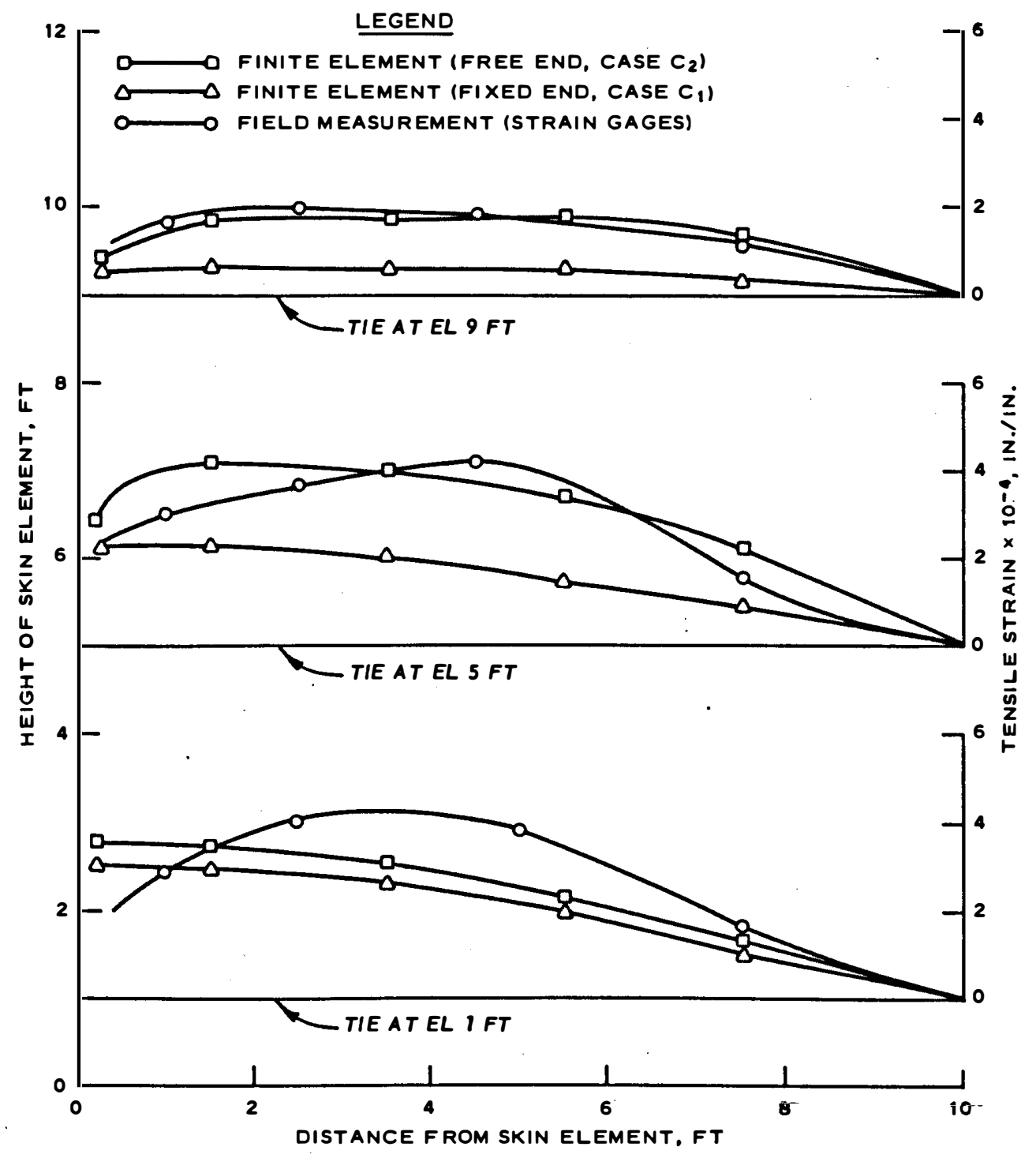

Figure 25. Tensile strain distribution along instrumented ties at end of construction 


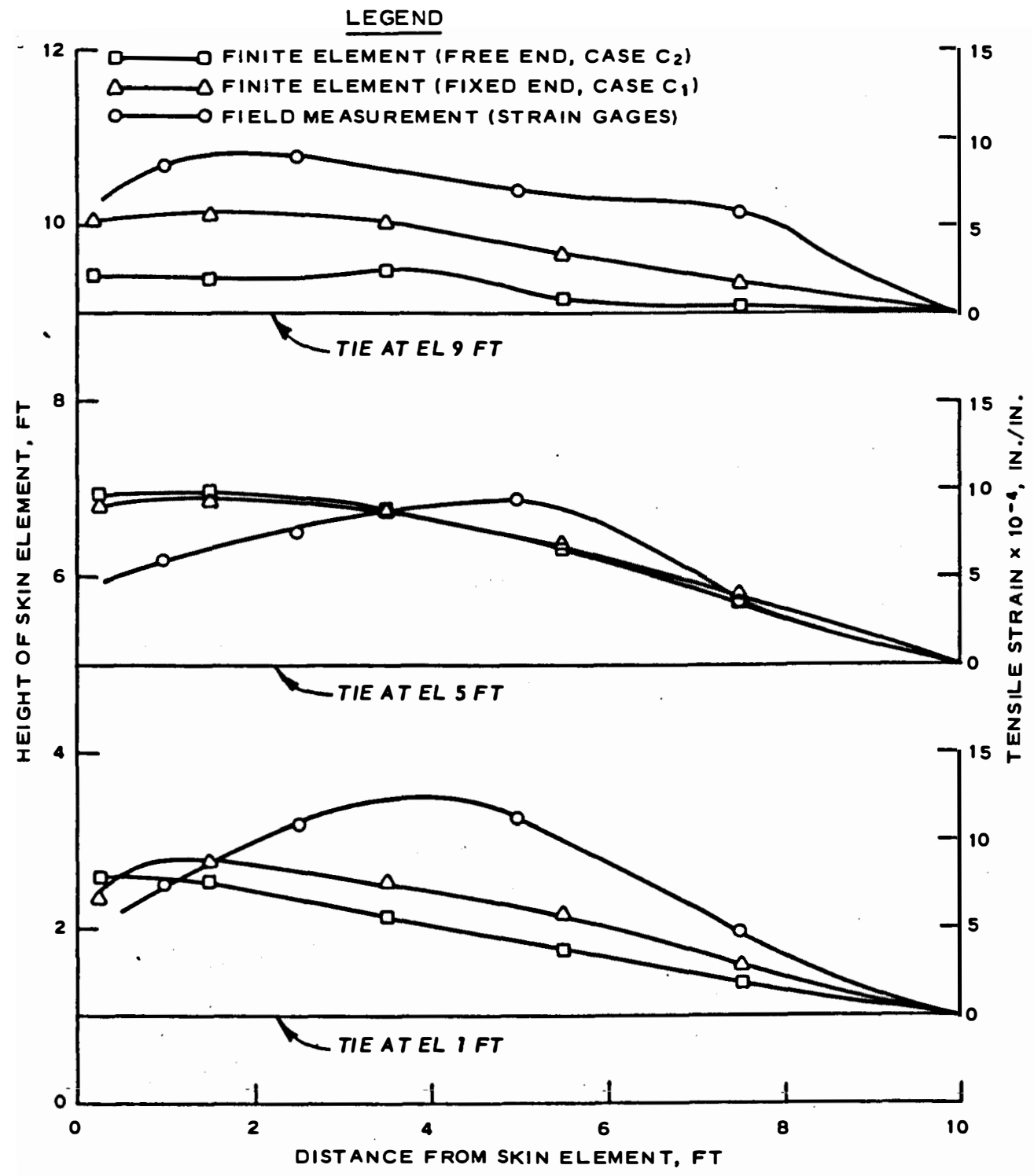

Figure 26. Tensile strain distribution along instrumented ties prior to failure 
tensile strain distribution as long as the stresses in the reinforcing strips are within the elastic range. The tensile stress at any point for the FE analysis was obtained from the equivalent tensile stresses using Equation 8. Comparisons of the tensile stress distribution along the instrumented strips at the end of construction between the FE analysis and field test results are presented in Figure 27. The figure shows that the FE results for the free-end case and the fixed-end case are identical, but somewhat different from field measurements. The maximum

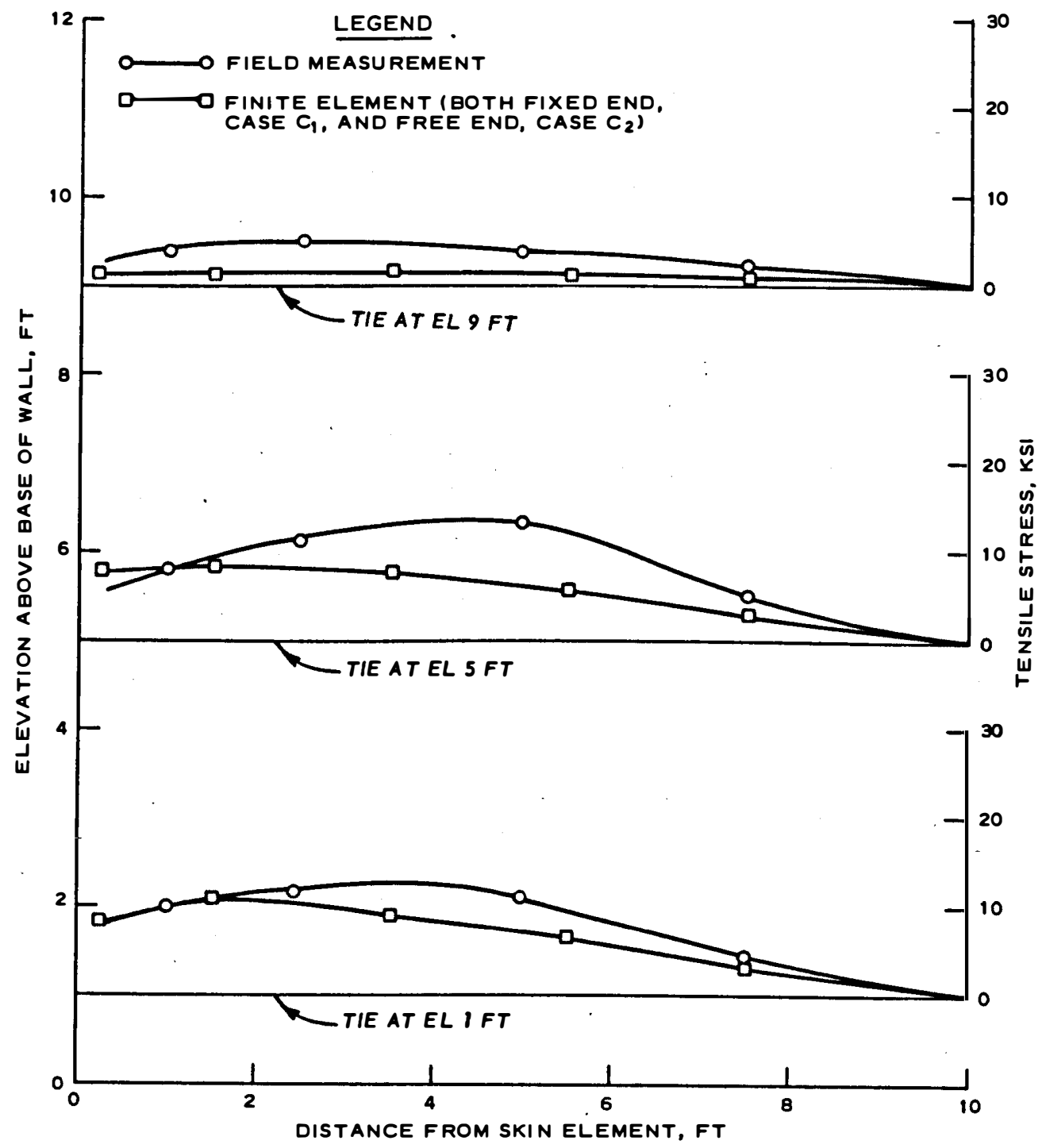

Figure 27. Tensile stress distribution along instrumented ties at end of construction 
tensile stress for the FE analysis occurred at a point much closer to the skin element than that observed in the field. Both the FE results and the field data show a gradual decrease in the tensile stress from the maximum until it reached zero at the free end of the reinforcing strip.

60. Comparisons of results between the tensile stress prior to failure for the FE analysis and actual field observations are presented in Figure 28. The figure shows that the tensile stresses obtained from

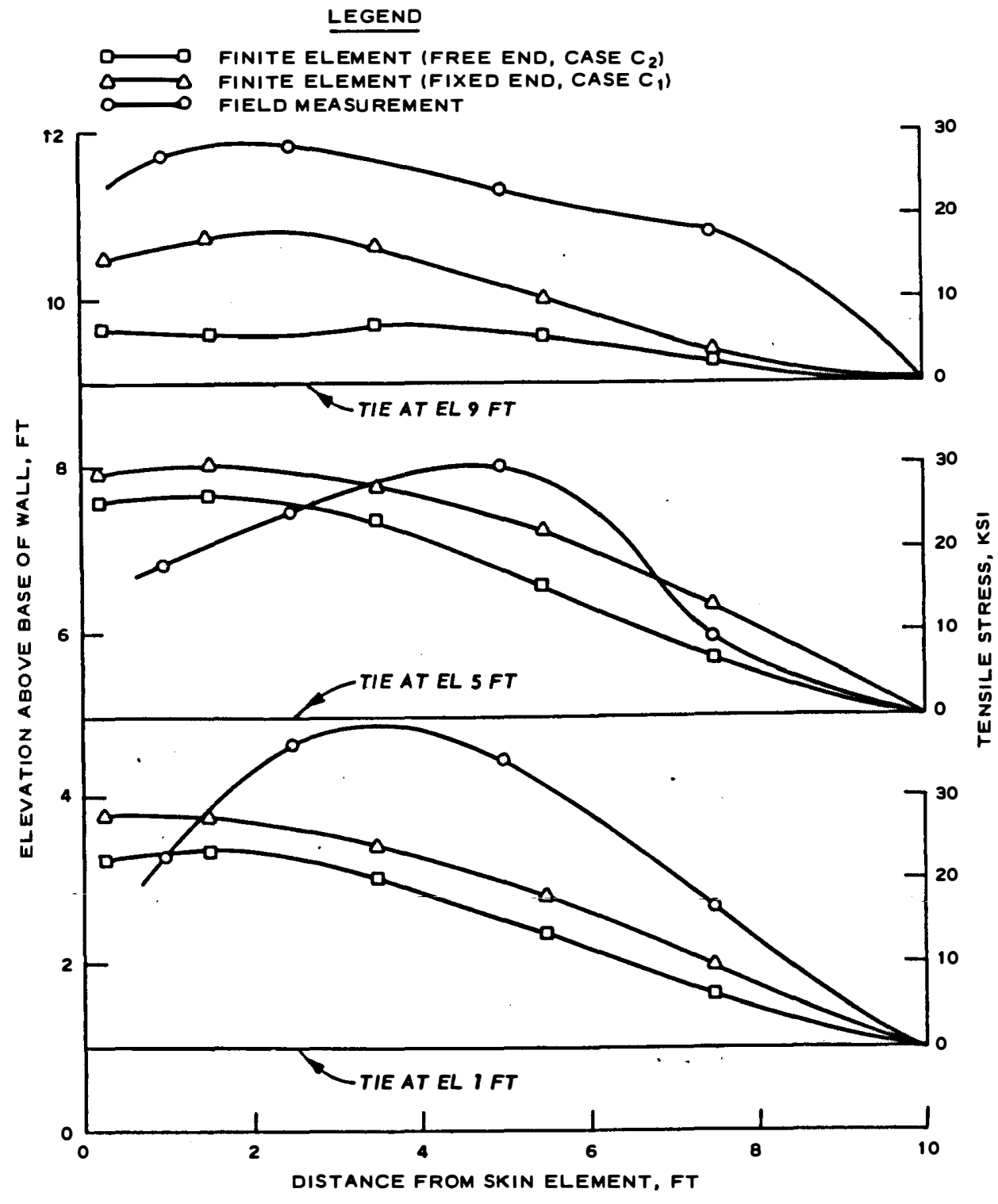

Figure 28. Tensile stress distribution along instrumented ties prior to failure 
the FE analysis are generally lower than those obtained from field measurements and the results for the fixed-end condition, case $C_{1}$, are higher than those for the free-end condition, case $C_{2} \cdot F E$ analysis results also show that the maximum tensile stresses occurred at a point much closer to the skin element than those obtained from field measurement. Reasons for the differences between the FE results and field observations are not known with certainty; however, deficiencies in the computer code and modeling, difficulty in determining the actual stiffness of the skin element, and lack of precise constitutive equations for describing behavior for the materials are considered major contributing factors.

Lateral movement of skin element

61. The reinforced earth wall was constructed such that each section of aluminum paneling added to form the skin element was held in place to prevent lateral movement while the corresponding layer of backfill was added. Field observations indicated negligible deformations at the end of construction, but the skin element deformations became substantial prior to failure, as shown in Figure 29, with maximum deformation of $3.4 \mathrm{in.} \mathrm{at} \mathrm{the} \mathrm{top} \mathrm{of} \mathrm{the} \mathrm{wall.} \mathrm{Comparison} \mathrm{between} \mathrm{the} \mathrm{FE} \mathrm{analy-}$ ses and the field observations, based on the accumulative deformation from one panel to the next, shows good agreement between the field observations and FE results for the fixed-end condition, case $C_{1}$. For the free-end condition, case $\mathrm{C}_{2}$, the $\mathrm{FE}$ analysis showed excellent agreement with field observations at the lower half of the wall; however, at the upper half of the wall the FE results deviated significantly from actual observations and indicated compression.

\section{Concluding Remarks on the FE Analysis}

62. Because of the preliminary nature of this study and the complex interaction between the various components of the reinforced earth wall, it is considered unlikely that total agreement between the FE analyses and field measurements could be obtained. However, it is shown that the boundary conditions of the wall play a significant role in the 


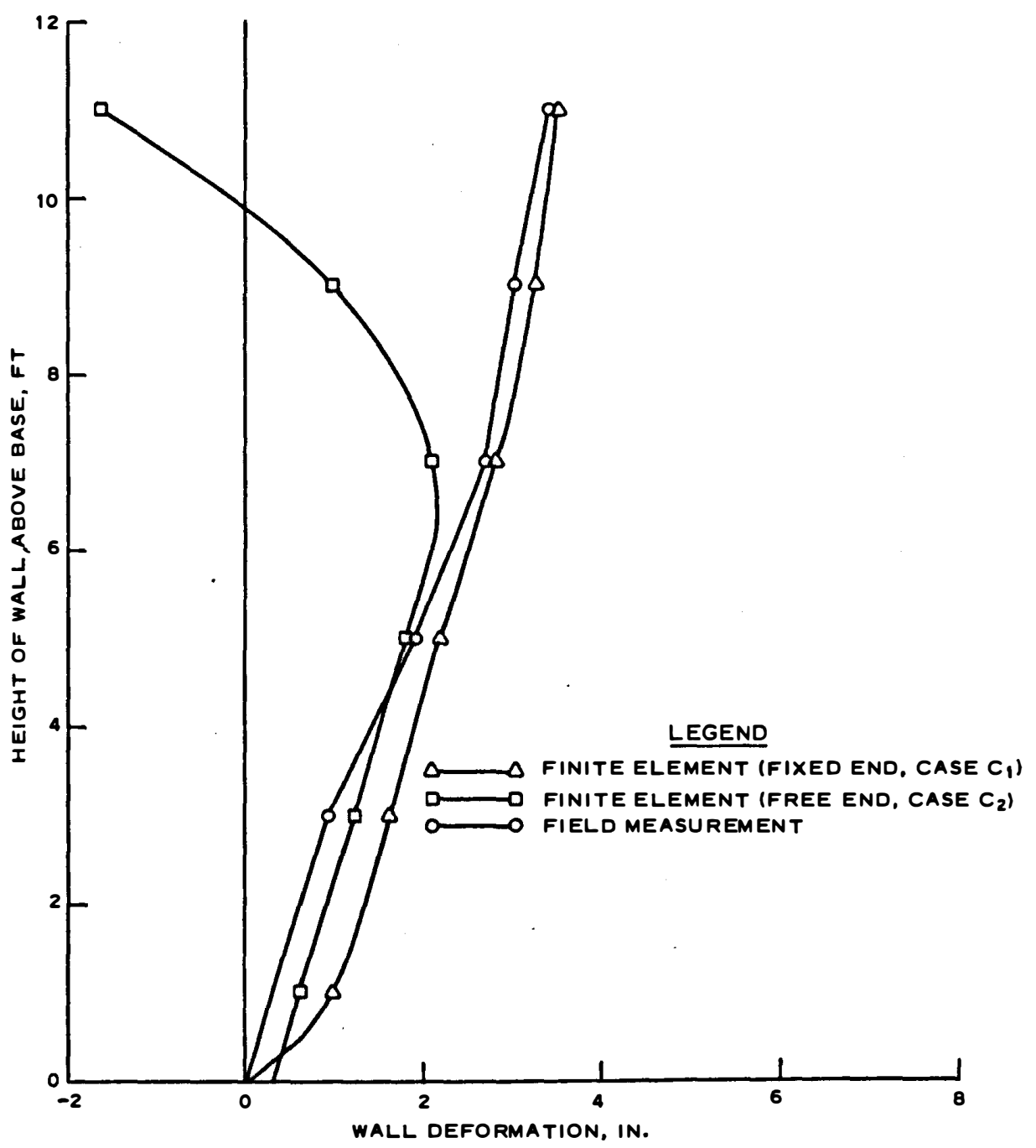

Figure 29. Accumulated lateral skin element deformation prior to failure

FE results. In certain aspects such as the deformation of the skin element, the fixed-end condition showed better agreement with field observations, while in other aspects such as the tensile strain in the reinforcing strips, the free-end condition showed better agreement. Other problems, such as improving the computer code, obtaining better constitutive equations for modelling material properties, and better representation of the skin element stiffness used in the calculation, need further development before a total agreement can be achieved. 


\section{PART V: PARAMETRIC STUDY}

\section{General Objectives}

63. In the previous part of this report it was shown that there are some differences between results of the FE analysis and those obtained from field observation. The differences were attributed to many factors, some of which were discussed previously. Variables which may influence the performance of a reinforced earth wall are also numerous. The influence of the following variables on the tensile stress distribution along the instrumented reinforcing strips was evaluated using the $\mathrm{FE}$ analysis: (a) friction between the reinforcing strips and the fill material; (b) end conditions of the skin element; (c) stiffness of the skin element; and (d) length of the reinforcing strips.

Influence of friction between

reinforcing strip and fill material

64. Equation 2 represents the constitutive equation which is used to describe the stress-deformation relationship between the galvanized steel and the concrete sand used. Analysis of the test results presented in Figures 12 and 13 indicated that $\delta=18$ deg and $\mathrm{K}_{\mathrm{j}}=3280$. These parameters were reduced by a magnification factor $\mathrm{m}_{\mathrm{f}}=8$ when used in the $\mathrm{FE}$ code to obtain tensile stress distribution for cases $C_{1}$ and $C_{2}$, shown in Figures 27 and 28 . In order to determine the influence of friction between the reinforcing strips and the fill material, FE runs were performed using the same parameters employed in cases $C_{1}$ and $C_{2}$ except that $\delta$ and $K_{j}$ were not reduced. The tensile stress distributions for the fixed-end condition, case $C_{3}$, and the free-end condition, case $C_{4}$, are presented in Figures 30 and 31 , respectively. Comparison between Figures 30 and 31 for the unreduced interface friction and Figures 27 and 28 for the reduced interface friction indicates that the increase in the interface friction increases the tensile stress in the reinforcing strips; the increase in stress is much higher for the free-end condition, case $\mathrm{C}_{4}$, than for the fixed-end condition, case $\mathrm{C}_{3}$. Based on this analysis it 


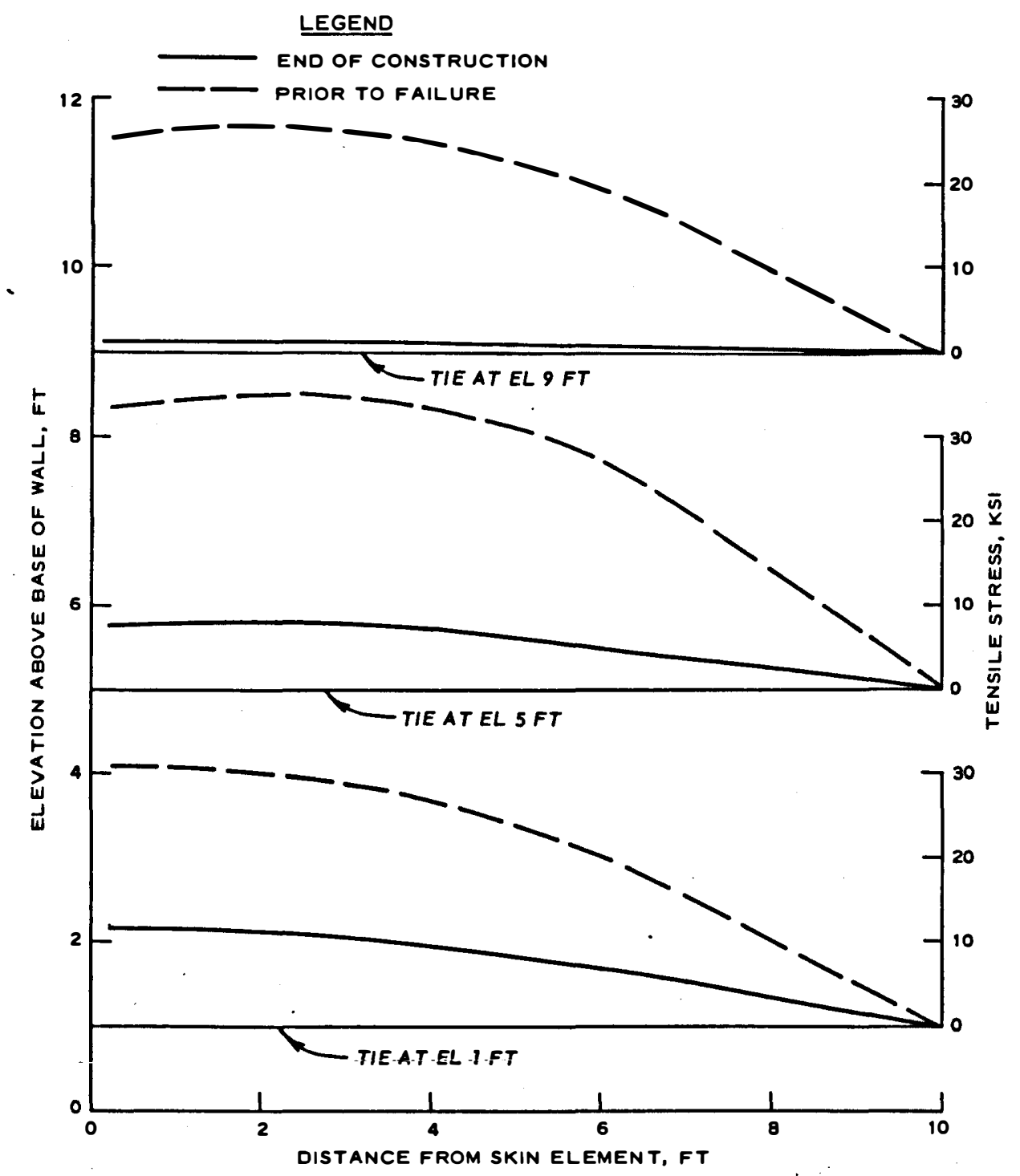

Figure 30. Tensile stress distribution along instrumented reinforcing strips at end of construction and prior to failure for case $C_{3}$ (fixed-end condition) 


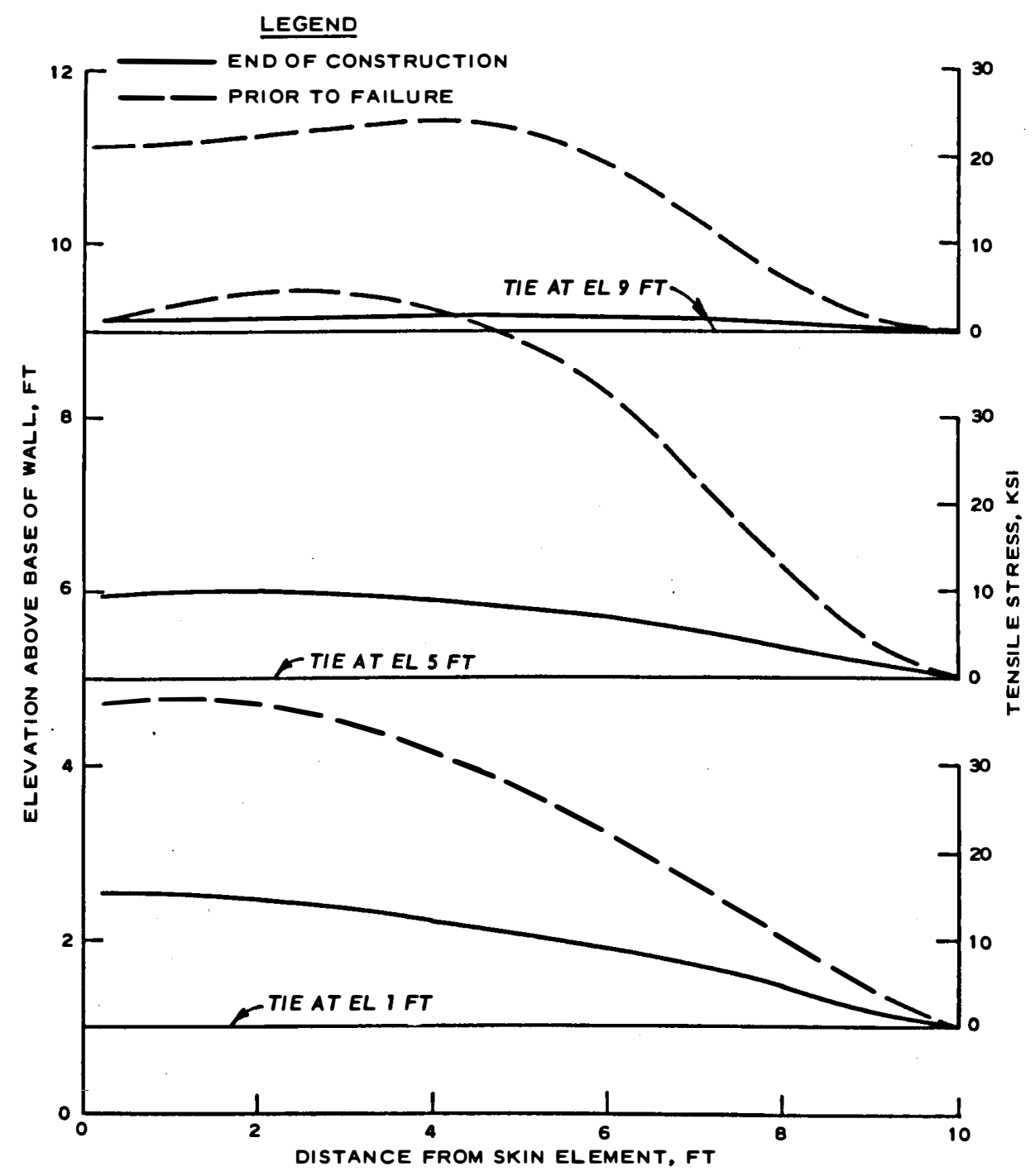

Figure 31. Tensile stress distribution along instrumented reinforcing strips at end of construction and prior to failure for case $\mathrm{C}_{4}$ (free-end condition) 
can be concluded that the increase in the interface friction between the reinforcing strips and the surrounding fill increases the maximum tensile stresses.

Influence of end conditions of skin element

65. Two boundary conditions of the skin element were investigated to determine their influence on the tensile stress distribution within the reinforcing strips. In the first analysis the lower point of the skin element was assumed fixed, cases $\mathrm{C}_{1}$ and $\mathrm{C}_{3}$, and in the second analysis, the lower point was assumed free, cases $C_{2}$ and $C_{4} \cdot$ Comparison between cases $C_{1}$ and $C_{2}$, shown in Figure 28, indicates that the fixed-end condition yielded higher tensile stresses in the reinforcing strips than that for the free-end condition. However, comparison between cases $\mathrm{C}_{3}$ and $\mathrm{C}_{4}$, where the interface friction between the reinforcing strips and the fill material was not reduced, shows that the free-end condition induced higher tensile stresses than the fixed-end condition. Therefore, it is not possible to draw definite conclusions on the basis of boundary condition of the skin element alone since the interface stress between the reinforcing strips and the surrounding fill plays a major role in dictating the magnitude and distribution of the tensile stresses. Influence of skin element stiffness

66. In the previous FE runs the stiffness of the skin element was based on the moment of inertia $I_{x}$ of the metal sheet at the back of the aluminum panel, on the assumption that the T ribs (see Figure 2), which were placed in the horizontal direction, did not influence the stiffness of the skin element. Knowing that the thickness of the metal sheet is 0.1 in., the moment of inertia $I_{x}$ per foot of the skin element is 0.0022 in. $^{3}$ To evaluate the influence of skin element stiffness on the tensile stress along the reinforcing strips, another FE analysis, case $\mathrm{C}_{5}$, was conducted. Case $\mathrm{C}_{5}$ was similar to case $C_{4}$ in every respect except that the moment of inertia in case $C_{5}$ was 1.368 in., 3 which is the moment of inertia per foot of panel as shown in paragraph 16, rather than $0.0022 \mathrm{in.}^{3}$, which is the $I_{x}$ for the aluminum 
sheet only. The tensile stress distribution along the instrumented strips at the end of construction and prior to failure for case $\mathrm{C}_{5}$ is shown in Figure 32. Comparison between results for case $C_{5}$ and those of case $C_{4}$, shown in Figure 31, indicates that the magnitudes of the maximum tensile stress are not significantly influenced by the stiffness of the skin element. However, maximum tensile stresses for low skin element stiffness, case $C_{4}$, occurred at points much closer

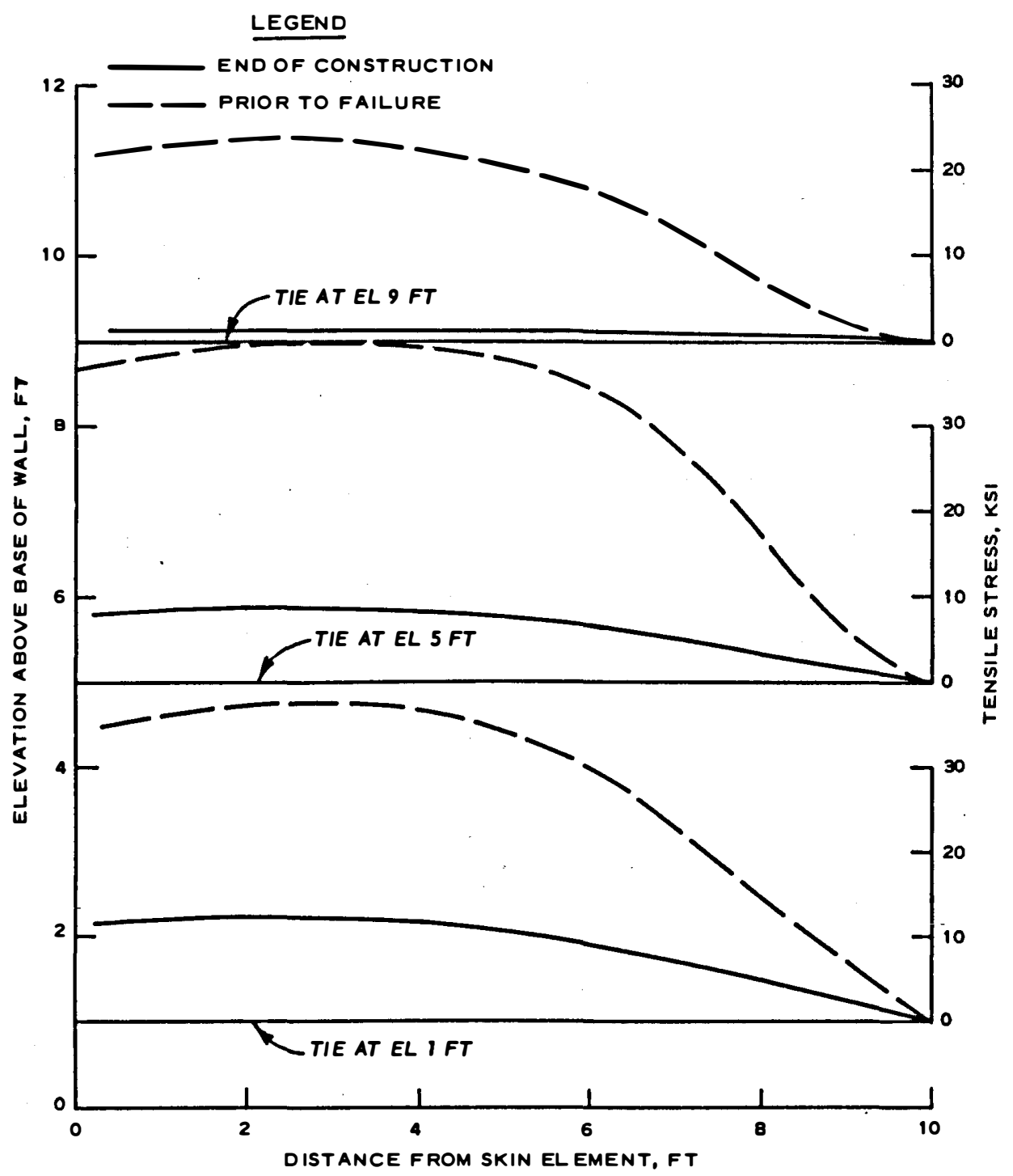

Figure 32. Tensile stress distribution along instrumented reinforcing strips at end of construction and prior to failure for case $C_{5}$ 
to the face of the wall than those for high skin element stiffness, case $\mathrm{C}_{5}$. Therefore, it can be concluded that the stiffness of the skin element slightly changes the shape of the tensile stress distribution along the reinforcing strip but not the magnitude of the maximum stress.

Influence of length

of reinforcing strips

67. The influence of the length of the reinforcing strips on the magnitude and distribution of tensile stresses was examined by increasing the length of the reinforcing strips and the depth of the wall from $10 \mathrm{ft}$ for case $\mathrm{C}_{3}$ to $20 \mathrm{ft}$ for case $\mathrm{C}_{6}$ (Figure 33). All other parameters between cases $\mathrm{C}_{3}$ and $\mathrm{C}_{6}$ were identical. Comparison between Figure 33, case $\mathrm{C}_{6}$, and Figure 30 , case $\mathrm{C}_{3}$, indicates that the increase in the length of the tie influenced the distribution but not the magnitude of the maximum tensile stresses along the reinforcing ties at the end of construction. However, for the prior to failure case, maximum tensile stress along the reinforcing strips showed a substantial decrease with increasing length of the strips. Therefore, it can be concluded that the increase in the length of the reinforcing strips tends to decrease the magnitude of tensile stress, and thus less crosssectional area of strips may be required for design purposes.

\section{Concluding Remarks on the Parametric Study}

68. It has been shown that reinforced earth is a complex problem whose complexity arises from different materials with different properties that constitute the reinforced earth mass. The influence of only a few variables was considered in the parametric study. For the cases considered, the magnitudes and locations of maximum tensile stresses are summarized and compared with field data in the following tabulation. It can be seen that none of the FE analyses actually duplicated field conditions. While the magnitude of the tensile stress in case $\mathrm{C}_{3}$ is closest to the field observation, the location of the maximum stresses in case $\mathrm{C}_{5}$ correlates most favorably with the actual field data. 


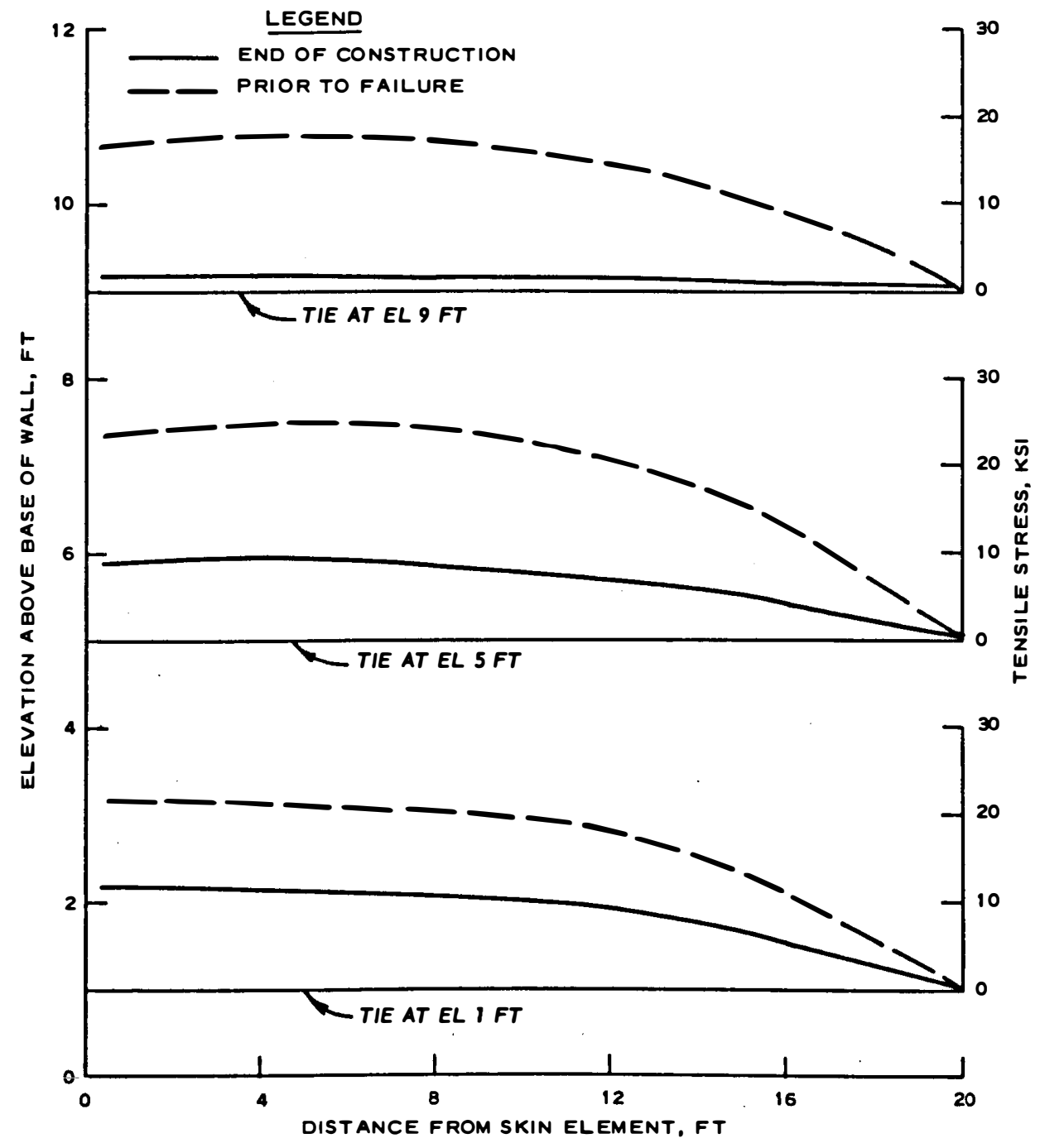

Figure 33. Tensile stress distribution along instrumented reinforcing strips at end of construction and prior to failure for case $\mathrm{C}_{6}$ 
Tie Elevation Above the Foundation

\begin{tabular}{|c|c|c|c|c|c|c|c|c|}
\hline & \multirow[b]{2}{*}{$\begin{array}{c}\text { Friction } \\
\text { Angle } \\
\delta, \text { deg }\end{array}$} & \multirow[b]{2}{*}{$\begin{array}{l}\text { Strip } \\
\text { Length } \\
\underline{L}, \text { It } \\
\end{array}$} & \multicolumn{2}{|c|}{$1.0 \mathrm{ft}$} & \multicolumn{2}{|c|}{$5.0 \mathrm{ft}$} & \multicolumn{2}{|c|}{$9.0 \mathrm{ft}$} \\
\hline & & & $\begin{array}{c}\text { Maximum } \\
\text { Tensile } \\
\text { Stress } \\
\text { psi } \\
\end{array}$ & $\begin{array}{l}\text { Location } \\
\mathrm{ft}\end{array}$ & $\begin{array}{c}\text { Maximum } \\
\text { Tensile } \\
\text { Stress } \\
\text { psi } \\
\end{array}$ & $\begin{array}{l}\text { Location* } \\
\mathrm{ft}\end{array}$ & $\begin{array}{c}\text { Maximum } \\
\text { Tensile } \\
\text { Stress } \\
\text { ps1 } \\
\end{array}$ & $\begin{array}{l}\text { Locat Ion" } \\
\text { ft }\end{array}$ \\
\hline Field test & - & 10 & 39,000 & 2.00 & 30,000 & 4.50 & 29,000 & 3.50 \\
\hline Case & 3 & 10 & 28,700 & 0.75 & 29,410 & 1.50 & 17,220 & 2.50 \\
\hline Case & 3 & 10 & 25,140 & 0.75 & 26,460 & 1.50 & 6,770 & 0.25 \\
\hline $\mathrm{Case}^{\prime} \mathrm{C}_{3}$ & 18 & 10 & 31,040 & 0.75 & 34,980 & 2.50 & 26,260 & 2.50 \\
\hline Case & 18 & 10 & 37,020 & 1.50 & 44,280 & 2.50 & 23,650 & 4.50 \\
\hline Case & 18 & 10 & 37,600 & 2.50 & 39,760 & 3.50 & 23,670 & 2.50 \\
\hline Case & 18 & 20 & 22,260 & 1.50 & 24,510 & 5.00 & 17,650 & 5.00 \\
\hline
\end{tabular}

- The location of the maximum tensile stress was measured relative to the skin element. - . 


\section{Conclusions}

69. An FE study was performed on a reinforced earth wall to investigate the feasibility of using numerical methods in predicting stresses and deformations of the various elements of the wall. The wall used in the $\mathrm{FE}$ analyses was $16 \mathrm{ft}$ long, $10 \mathrm{ft}$ deep, and $12 \mathrm{ft}$ high; the earth backfill was reinforced with galvanized steel strips 4 in. wide, $0.025 \mathrm{in}$. thick, and $10 \mathrm{ft}$ long, spaced at 2 - and 2.5-ft intervals in the vertical and horizontal directions, respectively. Based on the results of the $\mathrm{FE}$ analyses of this study and results collected from laboratory and field tests, the following conclusions are drawn:

a. The one-dimensional interface elements vertically inserted between the foundation soil and the back of the reinforced earth wall are necessary to permit separation between the reinforcing strips and foundation soil such that the tensile stresses developed in the reinforcing strips decrease to zero at the back of the wall as observed from field measurements. Interface elements horizontally inserted between the reinforcing strips and backfill of the wall are necessary to model the slippage and friction forces between the reinforcing strips and backfill.

b. The assumption of using the FE plane strain analysis to solve the 3D problem of a reinforced earth wall by increasing the area of the reinforcing strip, to cover the entire length of the wall, and decreasing the shear resistance between the fill and the reinforcement by the same proportion is a practical and satisfactory assumption.

c. The FE analyses of both fixed-end and free-end skin elements are necessary to obtain good correlation with field data. It is observed that the FE results of tensile stresses along the reinforcing strips and the lateral deformation of the skin element showed better agreement with field observation for the fixed-end condition than for the free-end condition. However, field measurements of strains along the reinforcing strips agreed better with the FE results of the free-end condition than with those obtained from the fixed-end condition. While lateral pressure cell measurements agreed better with FE results of the fixed-end rather than free-end conditions, 
the opposite was observed when comparison was made with lateral earth pressure calculated from tensile stresses in the reinforcing strips.

d. The magnitude and distribution of tensile stresses along the reinforcing strips increase with increasing interface friction between the strip and surrounding fill material, decrease with increasing reinforcing strip length, and show no significant change with change in skin element stiffness.

\section{Recommendations}

70. Based on the findings of this study, it is recommended that the study be expanded as follows:

a. It is desirable to improve the computer code and make it more accurate and efficient by introducing elements that better simulate actual events. The variable node of bending element is recommended because fewer elements may be needed and oscillation observed in results using the isoparametric elements may be reduced or eliminated.

b. Better constitutive equations that not only simulate the behavior of each material in the reinforced earth mass but also describe the interaction between different materials should be developed.

c. More studies are needed to model and improve the behavior of interface elements between the reinforcing strips and surrounding soil.

d. Hinges between panels that form the skin element need to be considered in the FE code. 
1. Al-Hussaini, M. M. and Perry, E. B., "Effect of Horizontal Reinforcement on Stability of Earth Masses," Technical Report S-76-11, Sep 1976, U. S. Army Engineer Waterways Experiment Station, CE, Vicksburg, Miss.

2. Vidal, H., "Reinforced Earth (A New Material for Public Works)," Annales, de l'Institut Technique du Batiment et des Travaux Publics, Vol 19, Nos. 223-224, Series: Materials (30), Jul-Aug 1966, pp 888-938. (Also published as Translation No. 67-12, Dec 1967, U. S. Army Engineer Waterways Experiment Station, CE, Vicksburg, Miss.)

3. Lee, K. L., Adams, B. D., and Vagneron, J. J., "Reinforced Earth Walls," UCLA-ENG-7233, Apr 1972, University of California, Los Angeles, Calif.

4. Clough, G. W. and Duncan, J. M., "Finite Element Analyses of Port Allen and 0ld River Locks," Contract Report S-69-6, Sep 1969, U. S. Army Engineer Waterways Experiment Station, CE, Vicksburg, Miss.; prepared by University of California under Contract No. DACW39-68-C-0040.

5. Radhakrishnan, N. and Jones, H. W., "User Guide for Program UFRAME" (in preparation), U. S. Army Engineer Waterways Experiment Station, $\mathrm{CE}$, Vicksburg, Miss.

6. Duncan, J. M. and Chang, C. Y., "Analysis of Soil Movement Around a Deep Excavation," Journal, Soil Mechanics and Foundation Division, American Society of Civil Engineers, Vol 96, No. SM5, Sep 1970, pp 1655-1681.

7. Goodman, R. E., Taylor, R. L., and Brekke, T. L., "A Model for the Mechanics of Jointed Rock," Journal, Soil Mechanics and Foundation Division, American Society of Civil Engineers, Vol 94, No. SM3, May 1968, pp 637-659.

8. Kondner, R. L., "Hyperbolic Stress-Strain Response: Cohesive Soils," Journal, Soil Mechanics and Foundation Division, American Society of Civil Engineers, Vol 89, No. SMB, Feb 1963; pp 115-143.

9. Janbu, N., "Soil Compressibility as Determined by Oedometer and Triaxial Tests," Proceedings, European Conference on Soil Mechanics and Foundation Engineering, Weisbaden, Vol 1, 1963, pp 19-25. 
APPENDIX A: COMPUTER CODE 


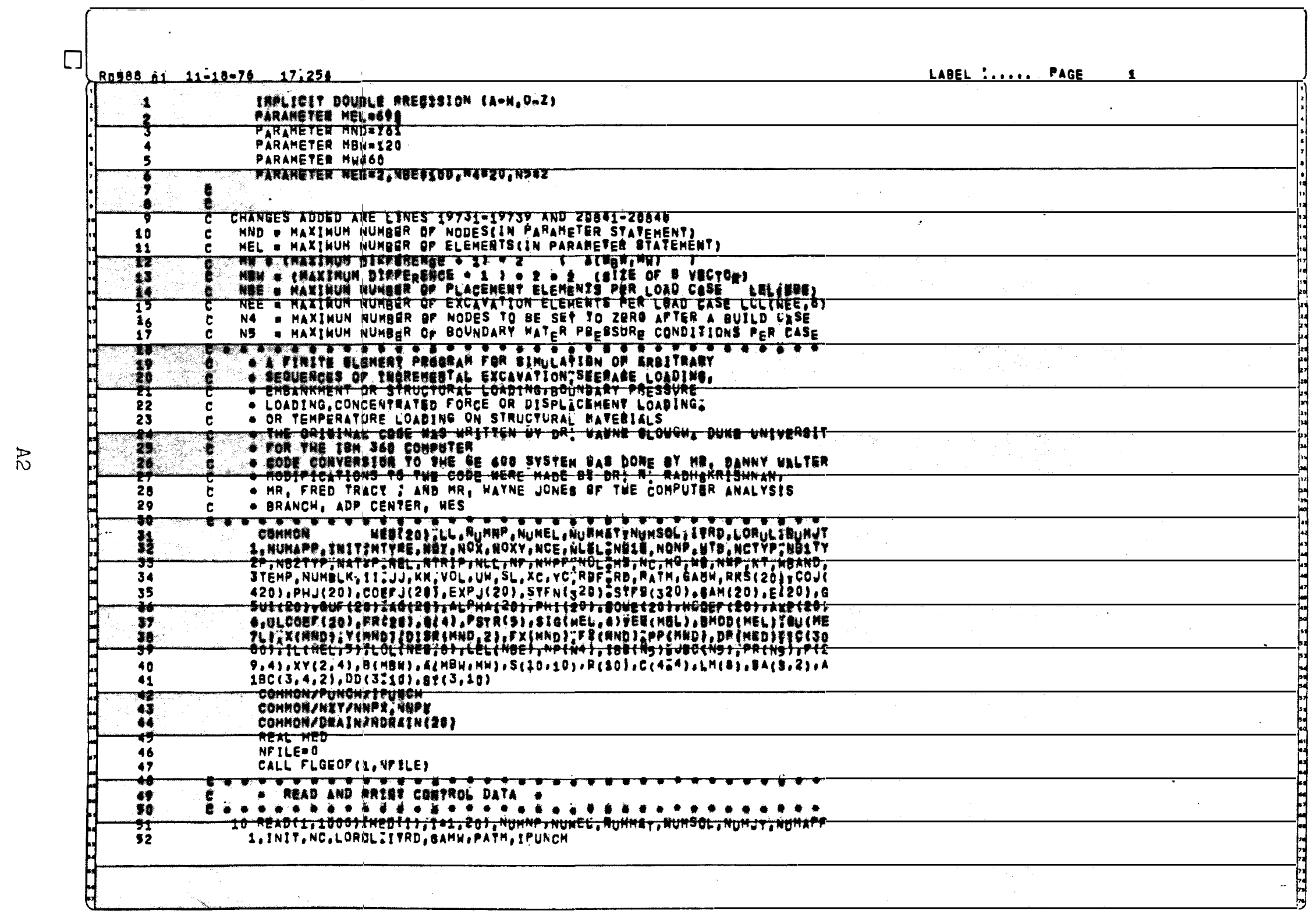




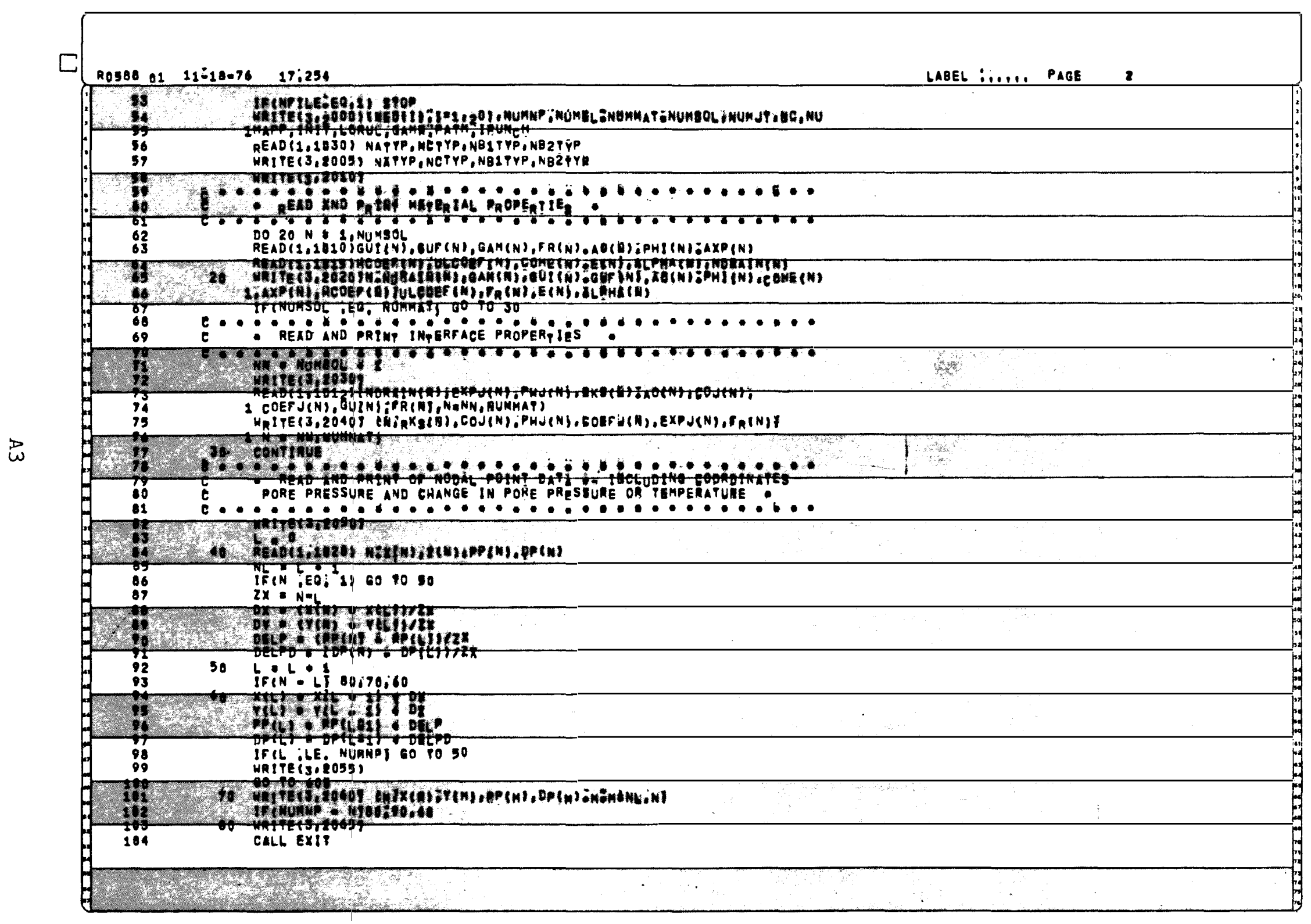




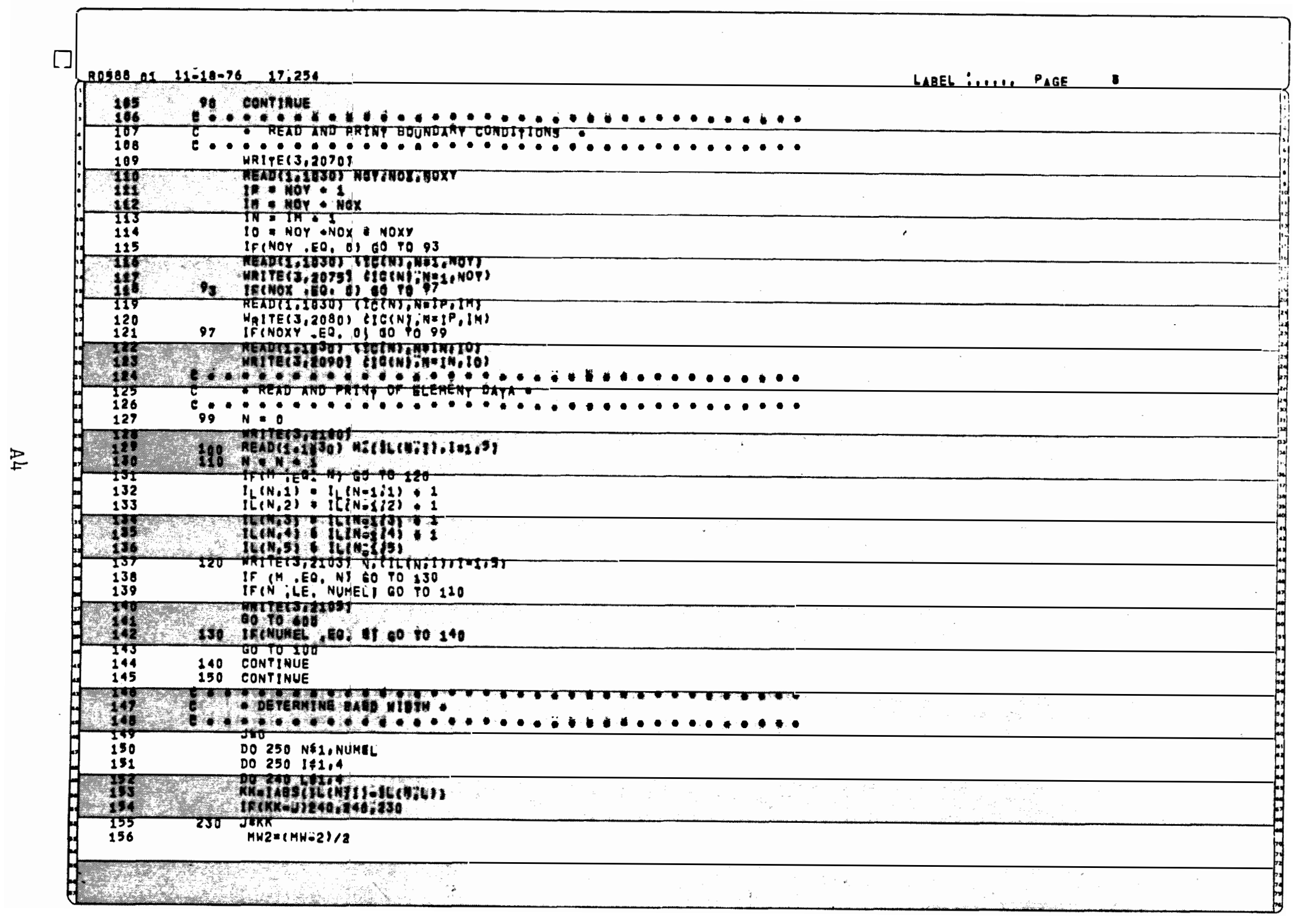




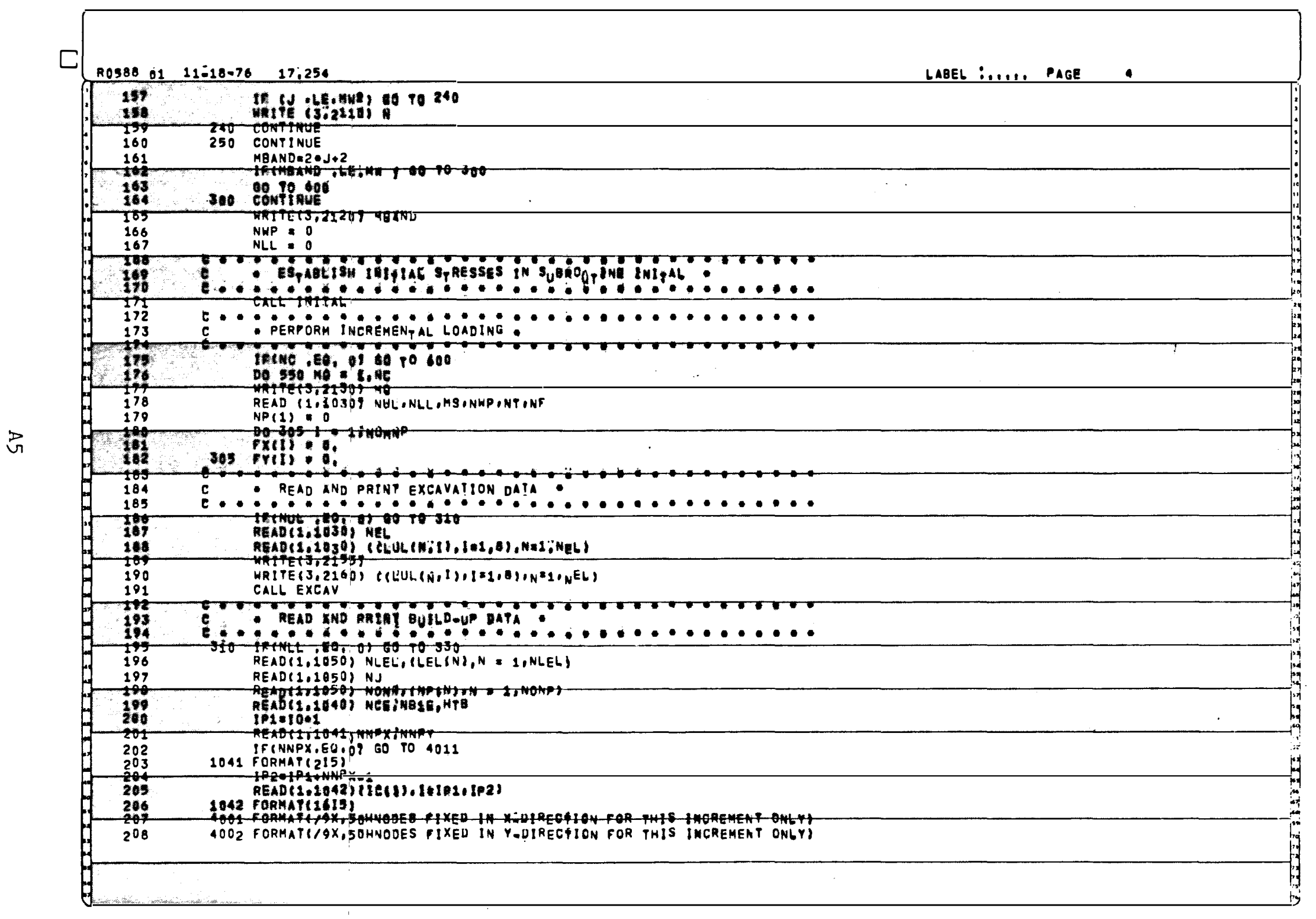




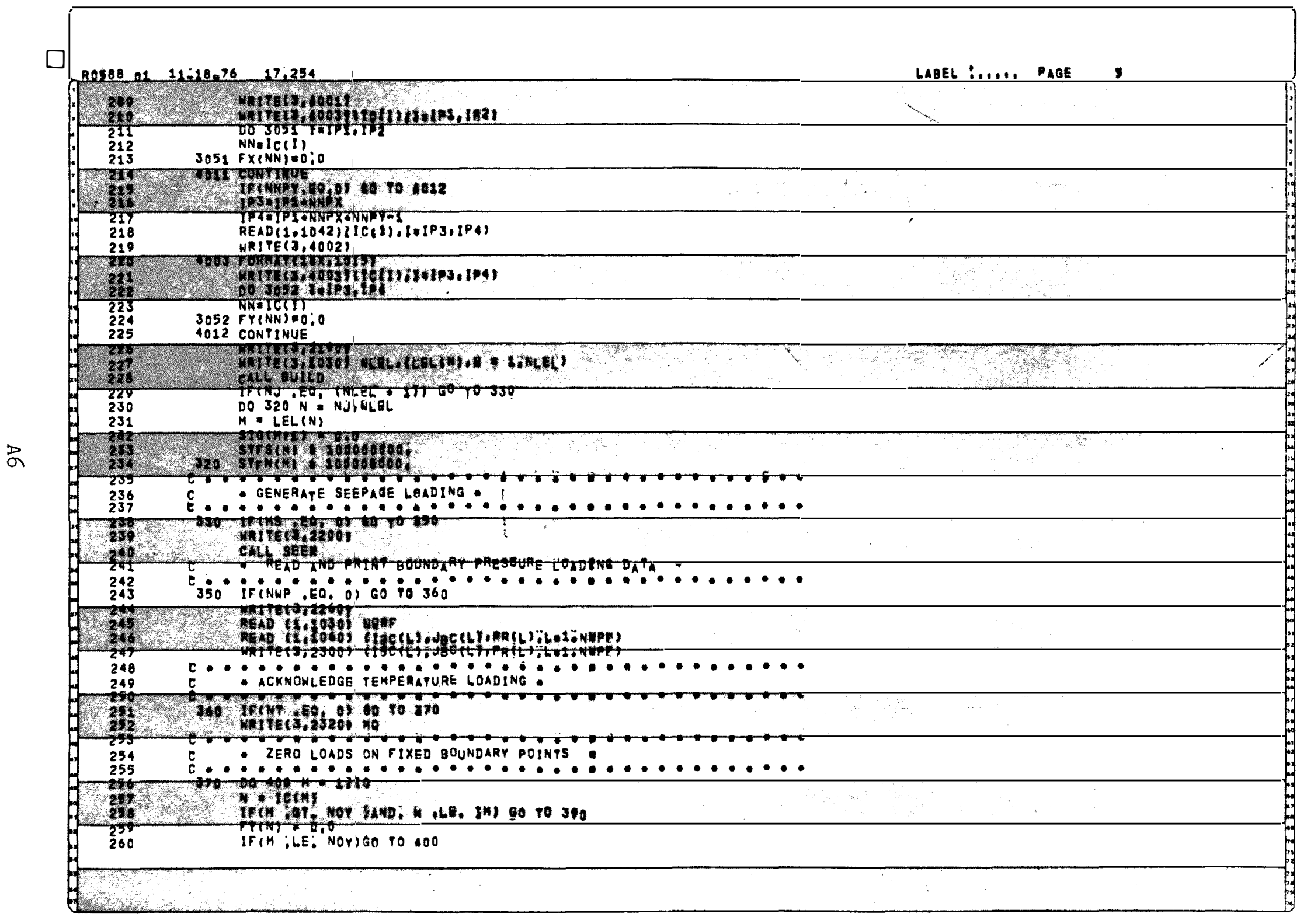




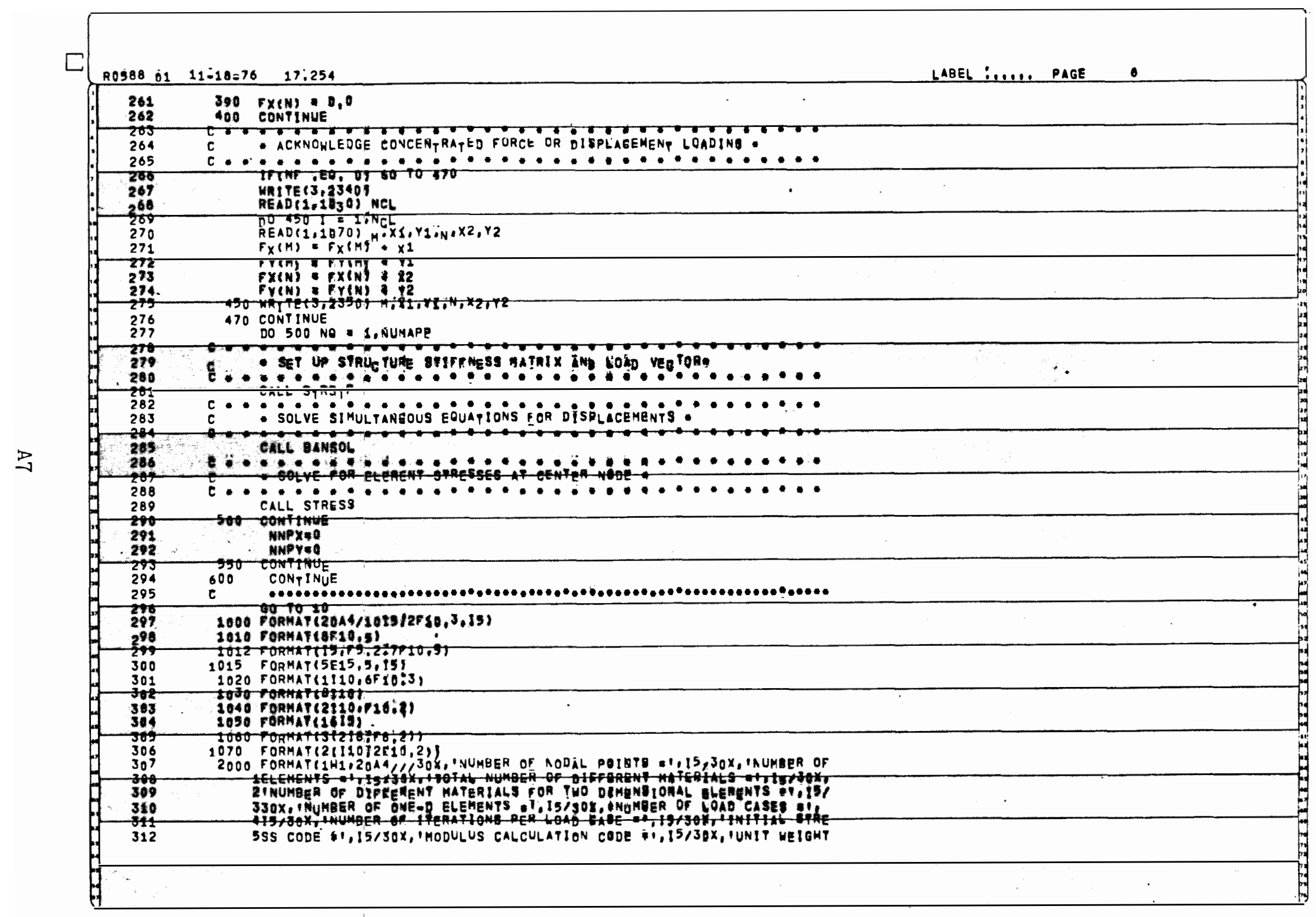




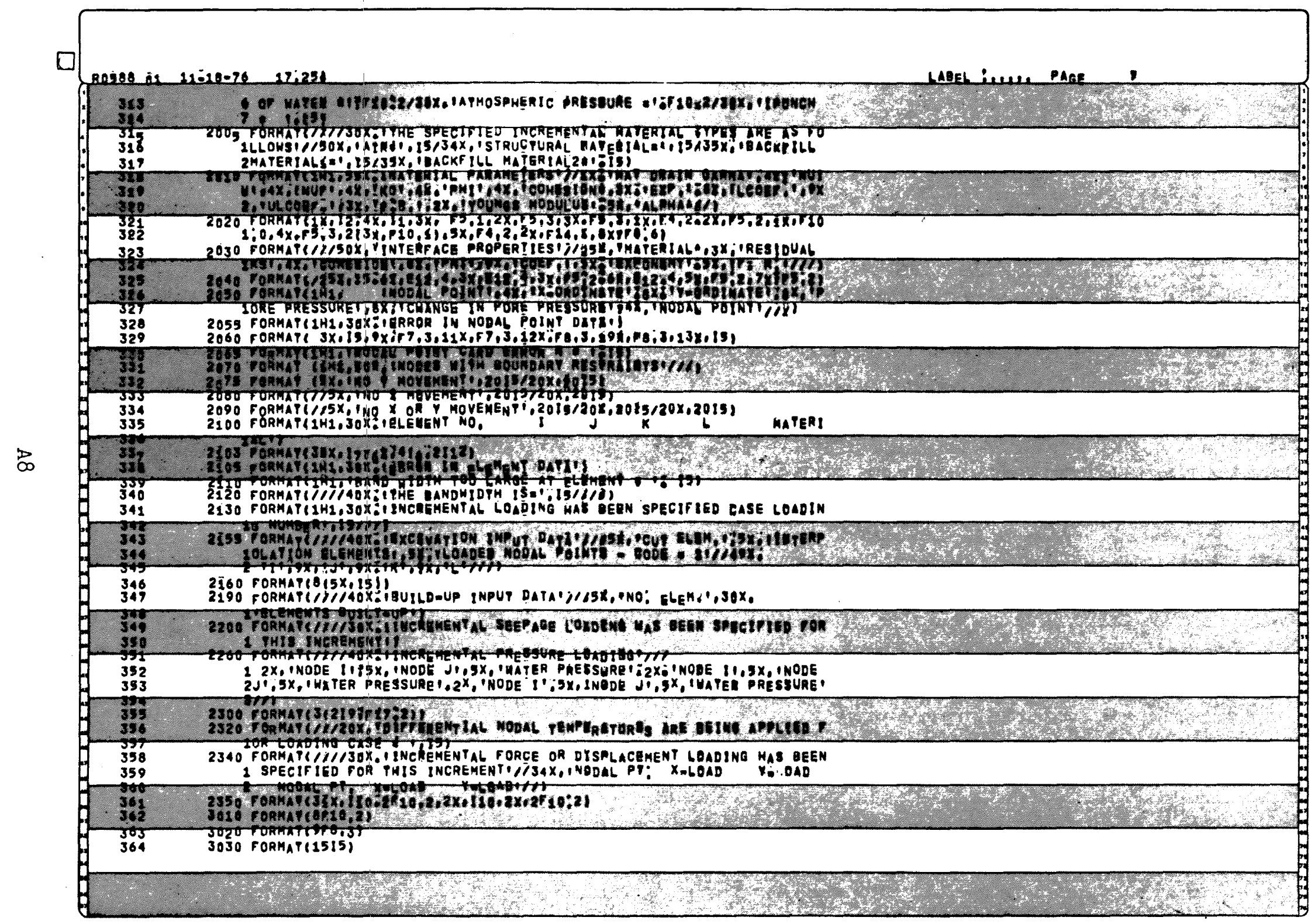




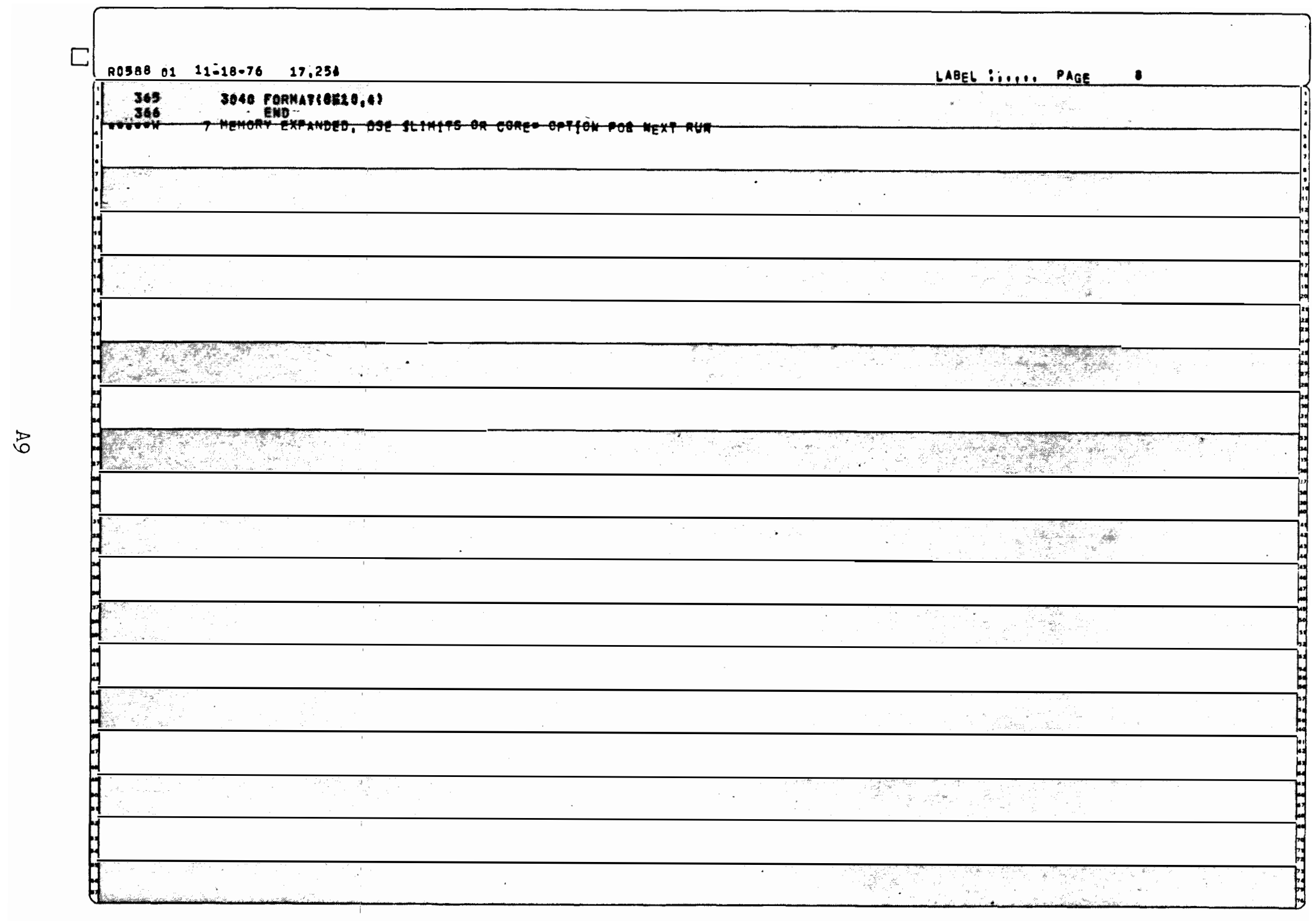




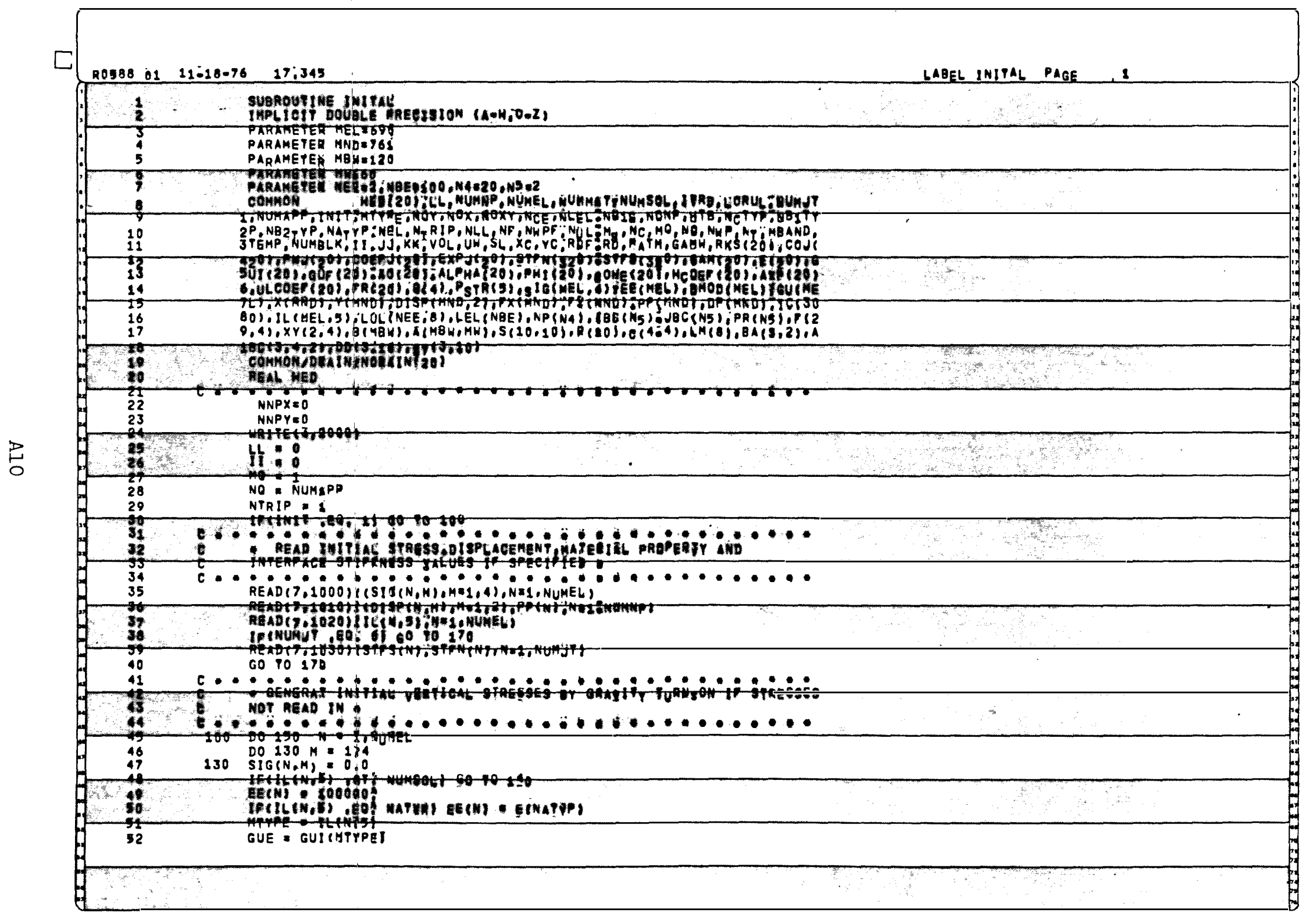




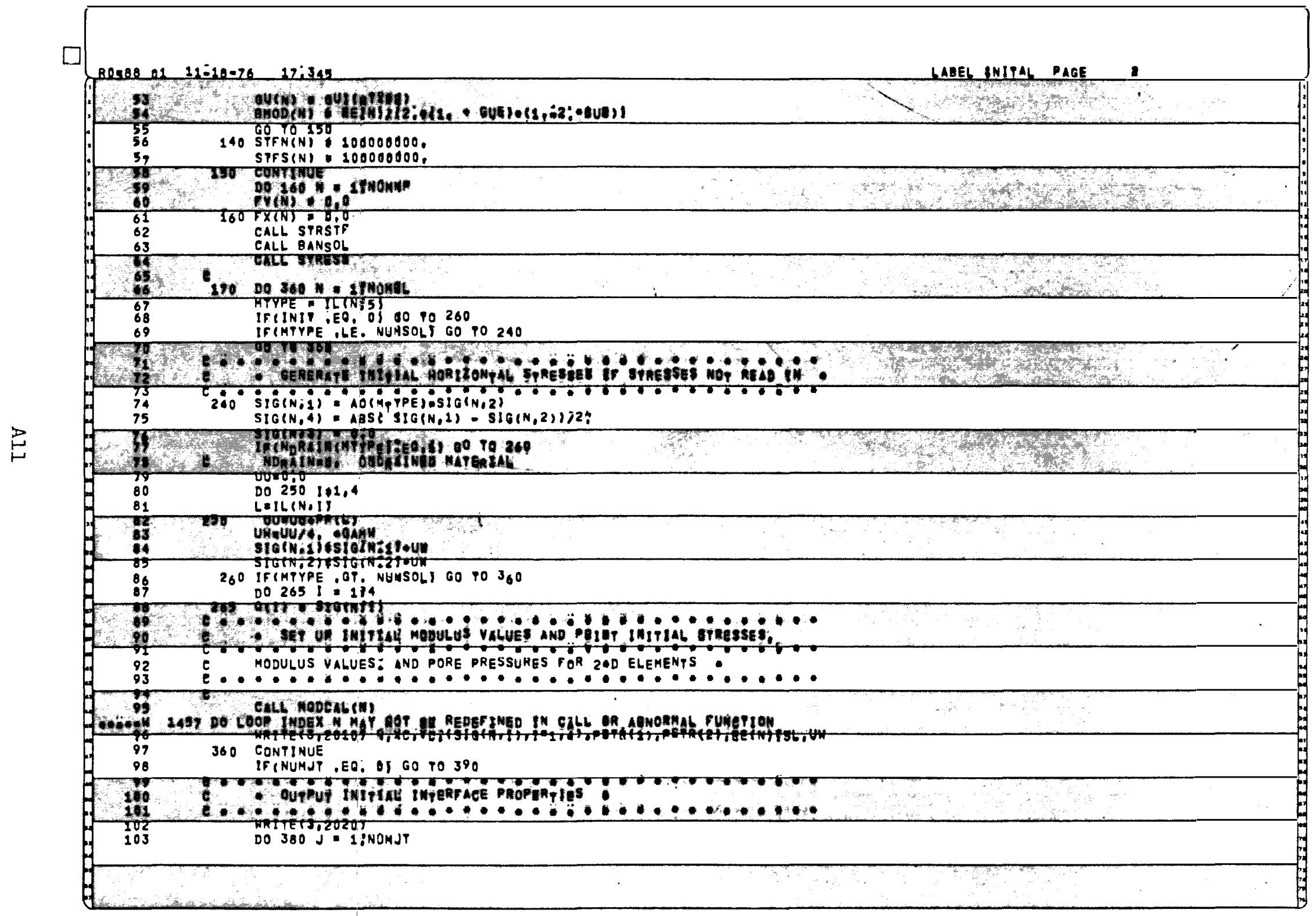




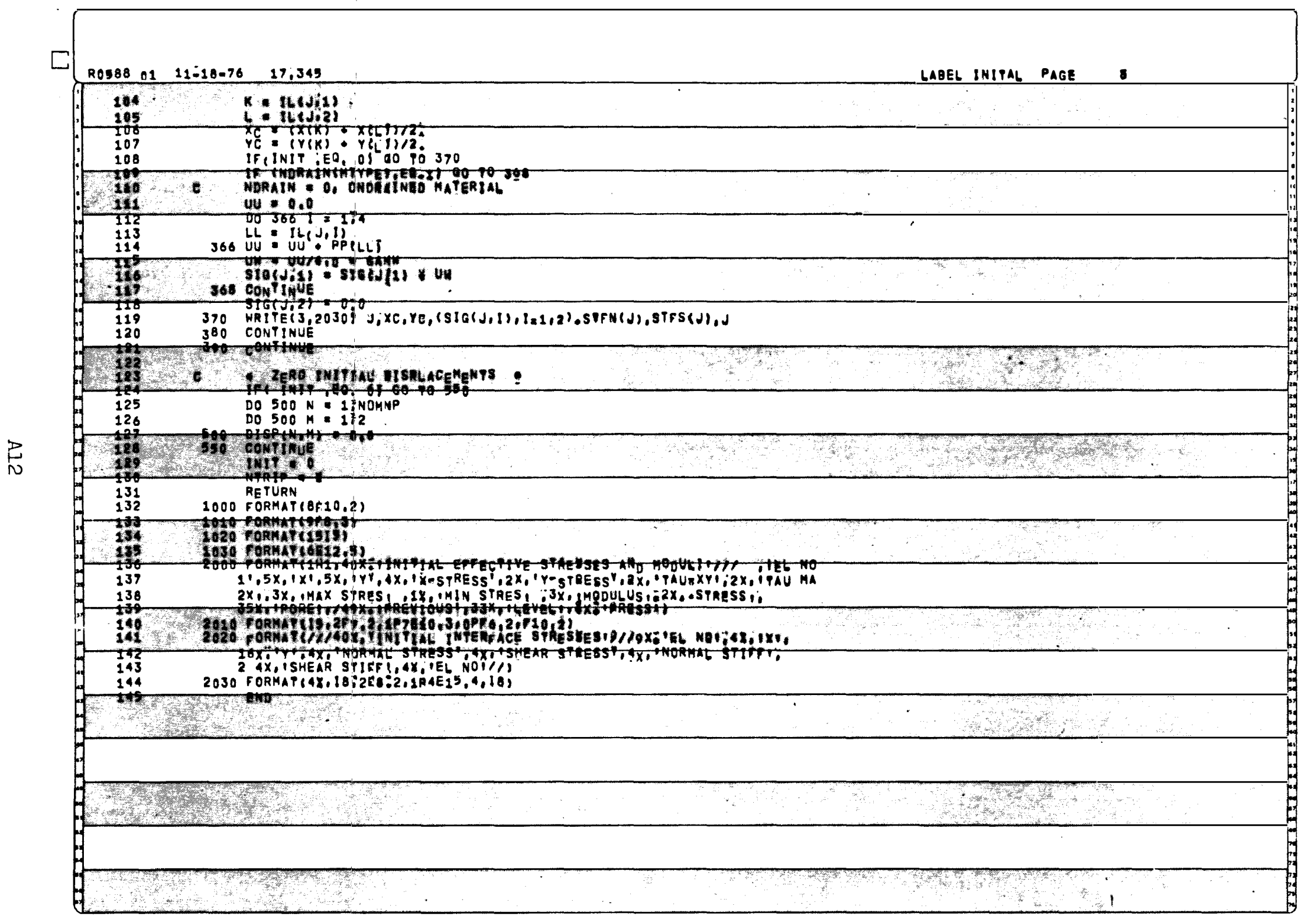




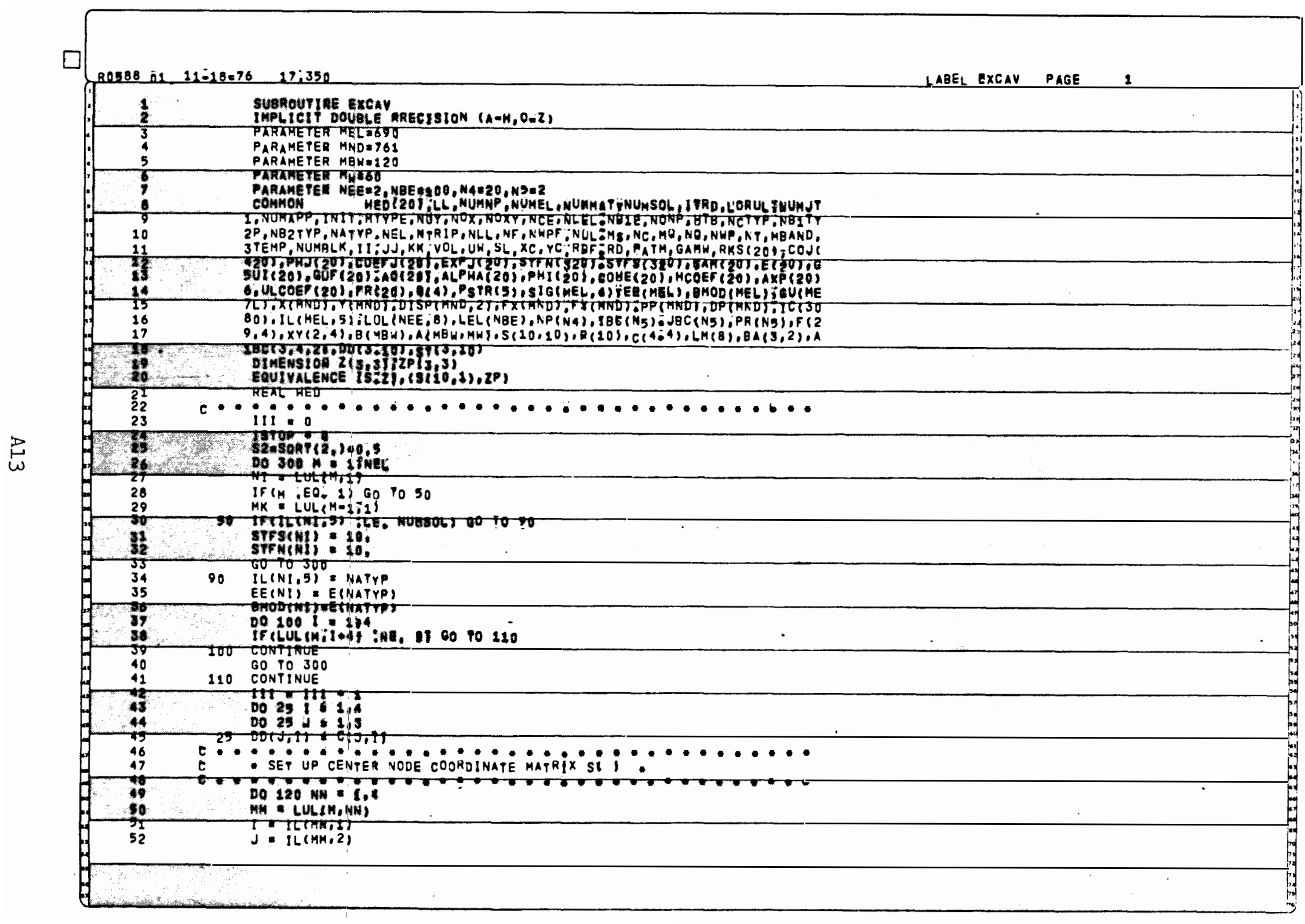




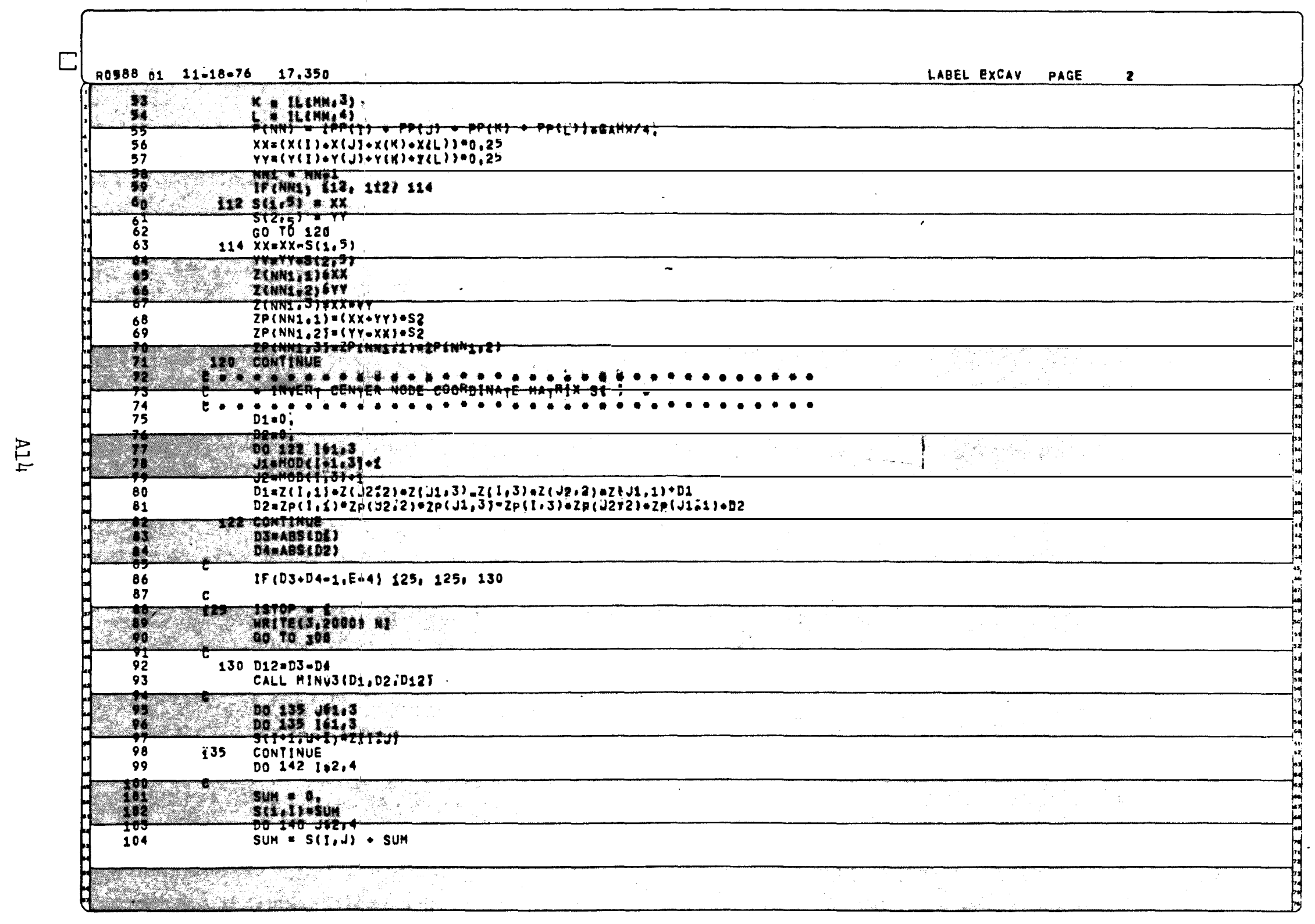




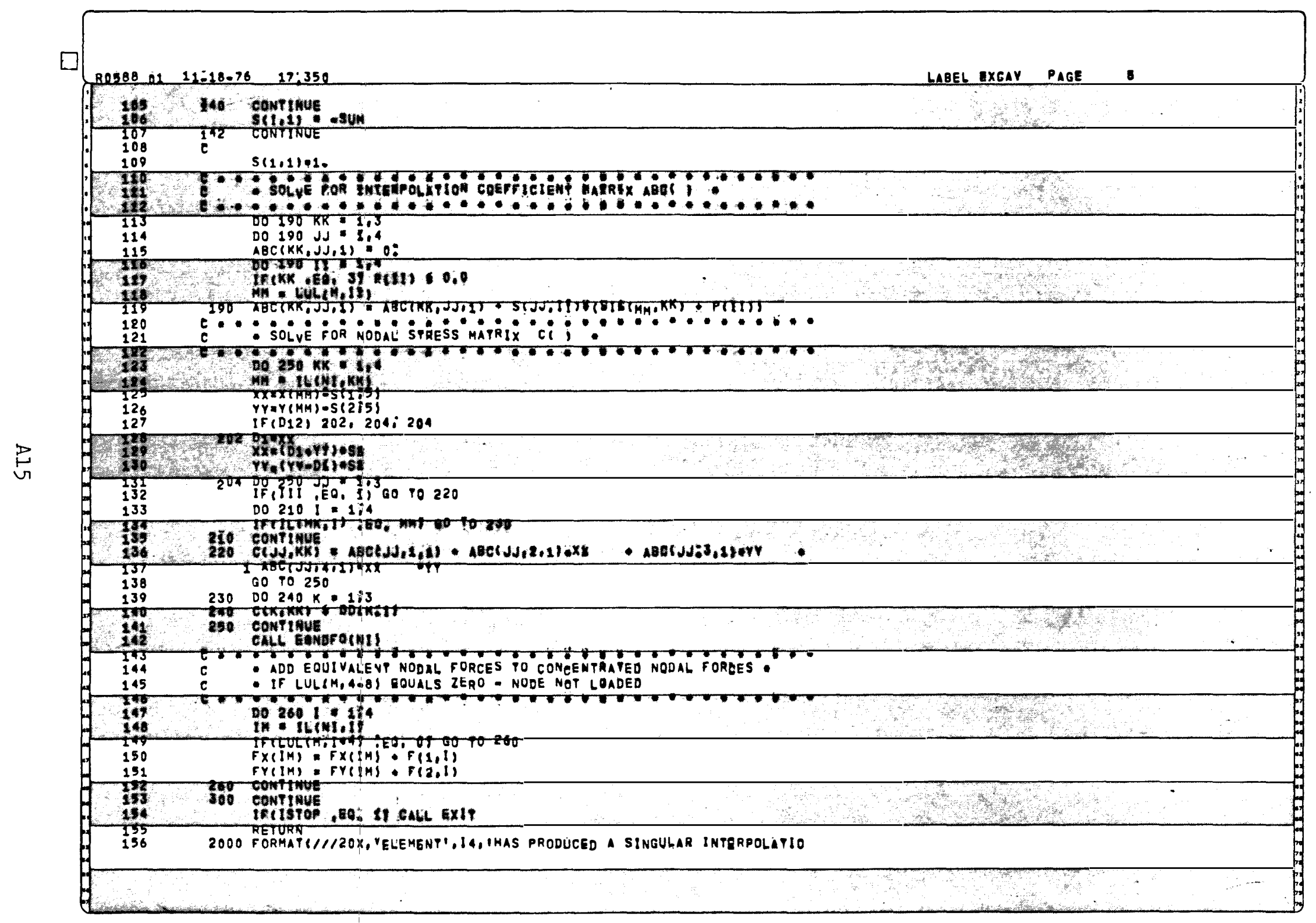




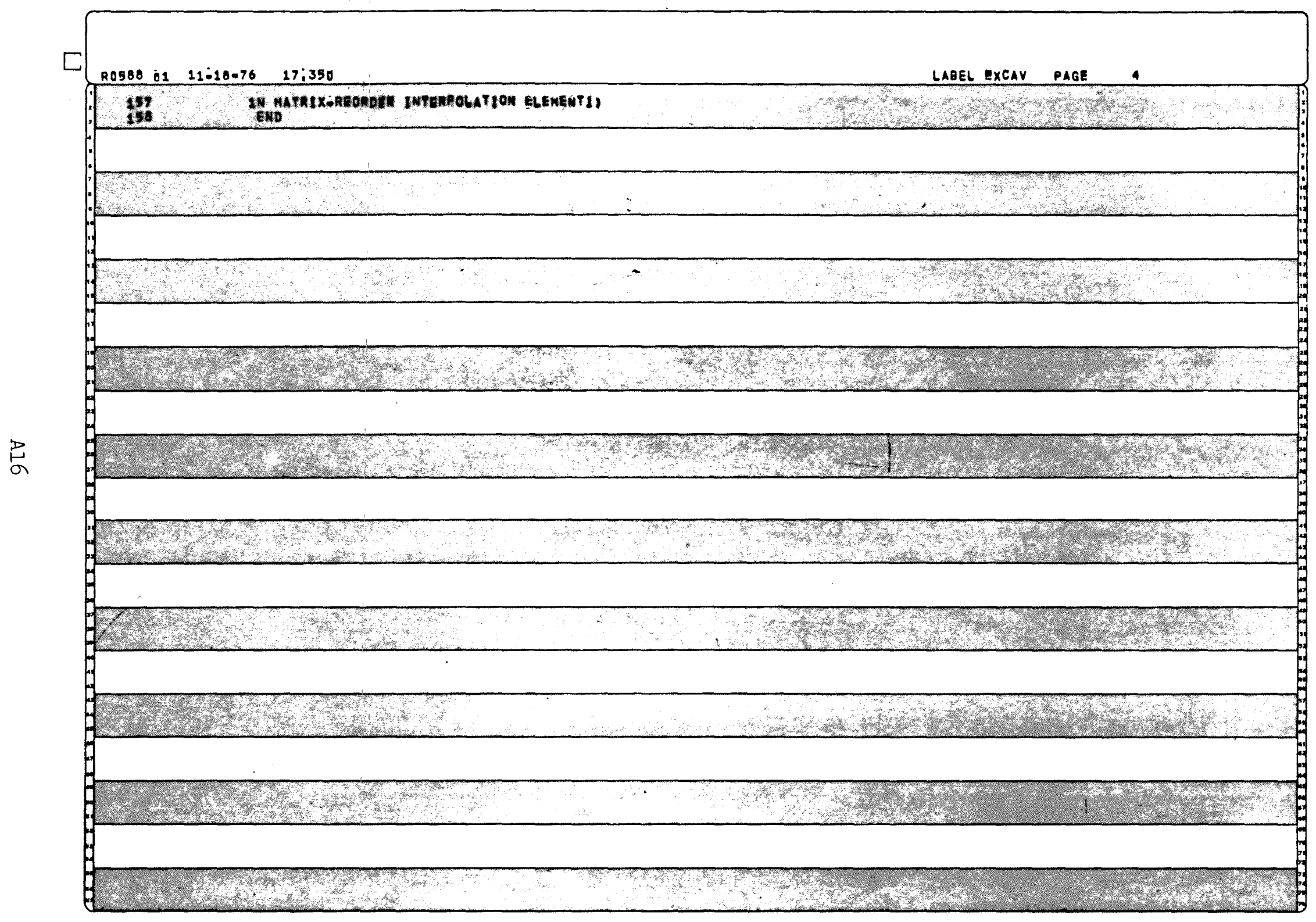




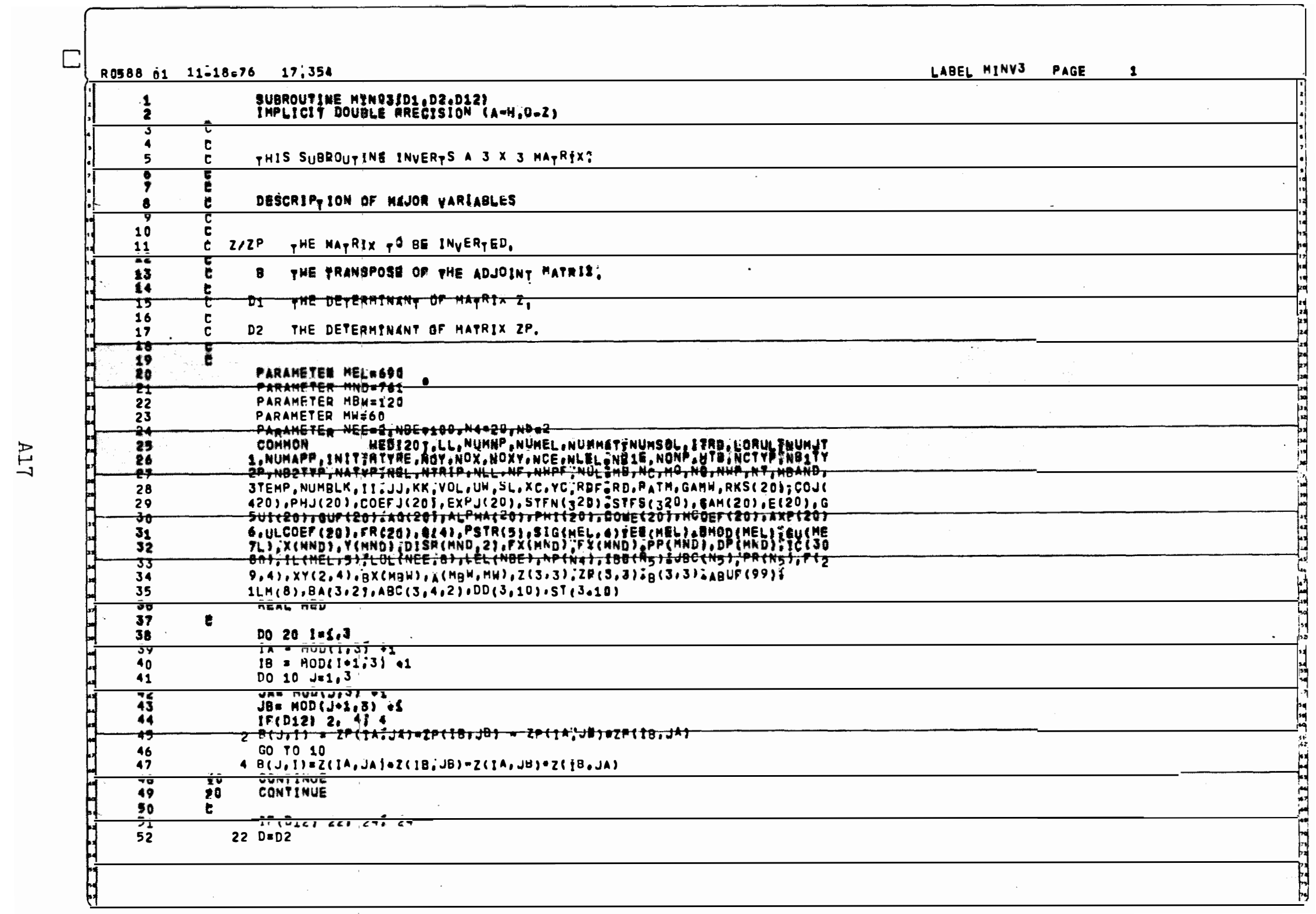




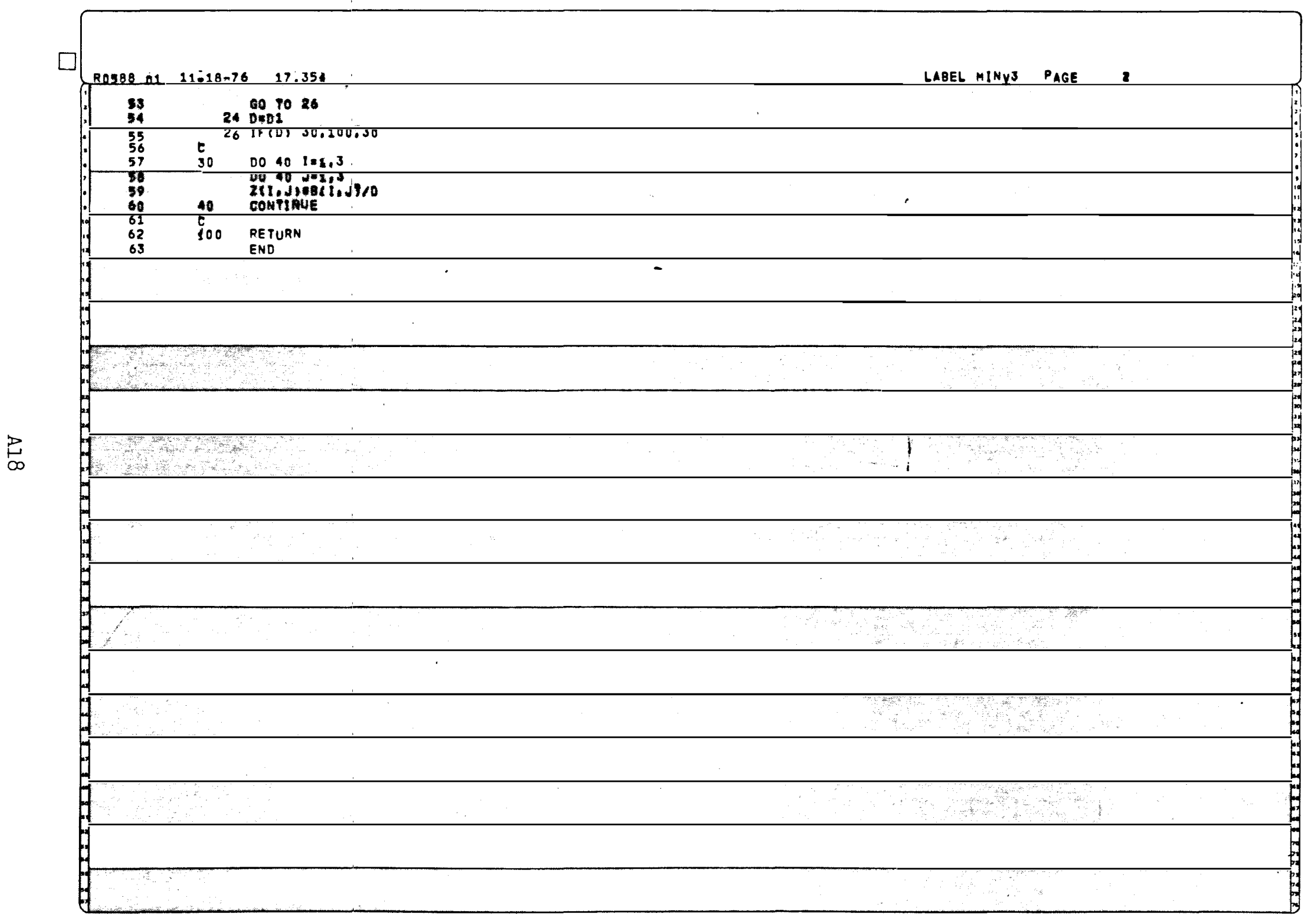




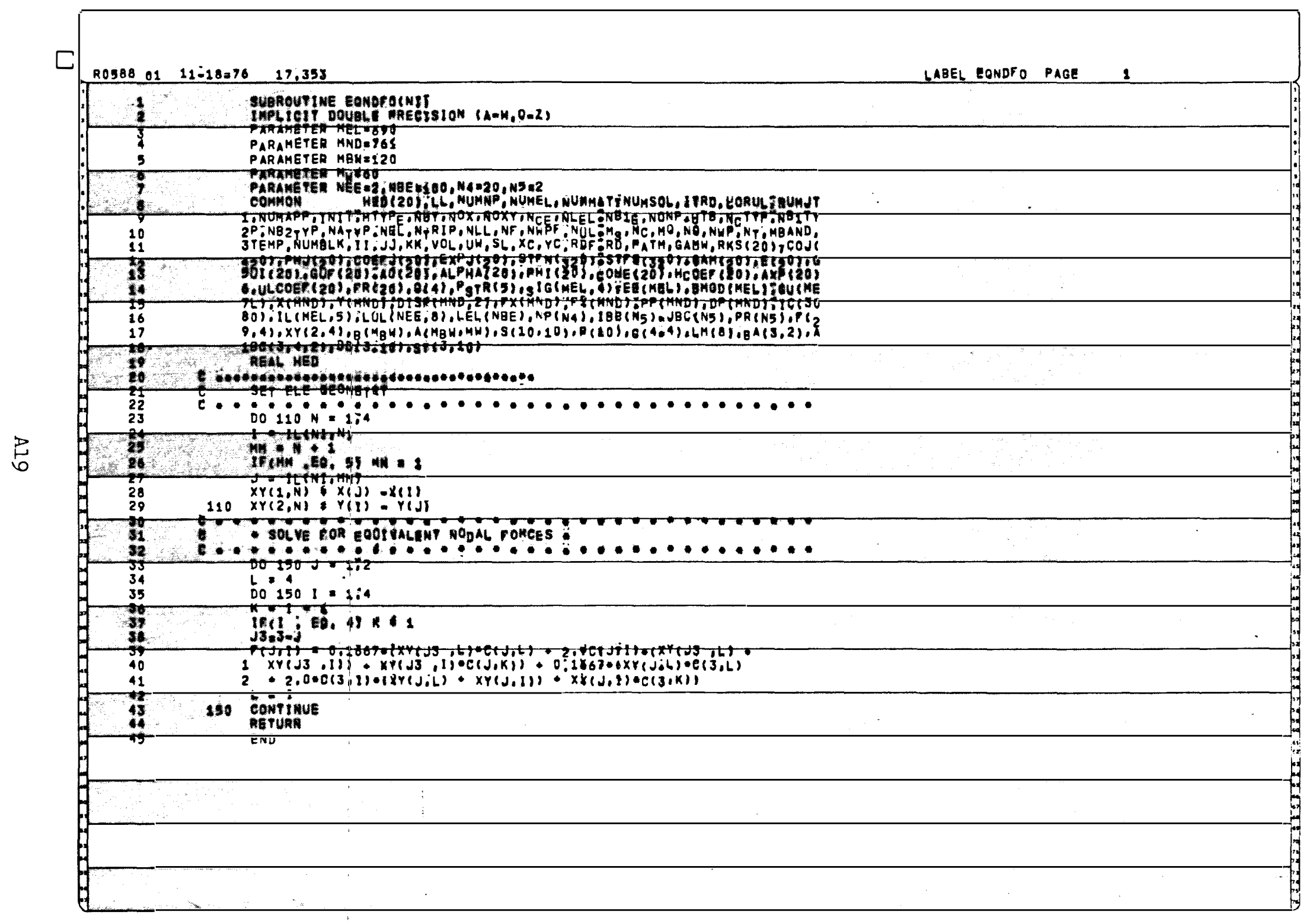




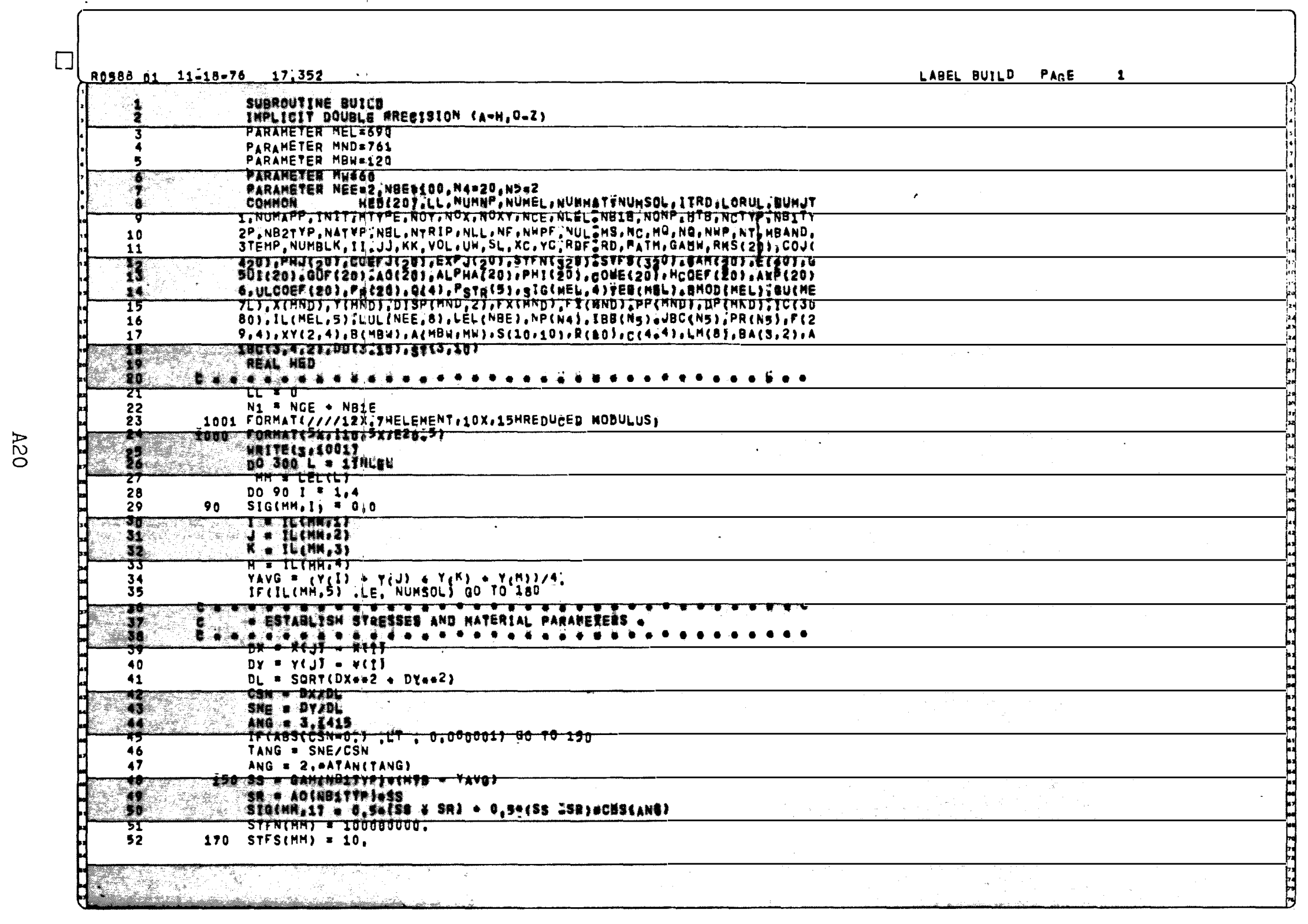


100.9010300

IF(L $69:$ NCET ME

I. (MM,5) $=$ MO

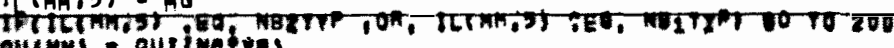

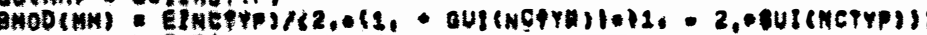
EE(TMT) ETCTYP)

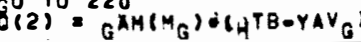

प(3) : $0: 0$

o(4): 0.0

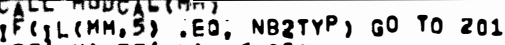

EE (MN) =EE(MM): 0,002

are

siothi:4: 0.0

- enerate cour

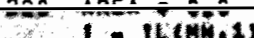

J Itemat

GO 10260

$240 \quad 1=I L(M M, 3)$

T.

ITR: ImK,

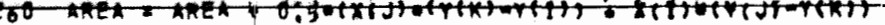

$1 X(k) \cdot(r(1)$ i $r(j)) 1$

I5(1) EO. ILIMA, 1)) 60 10 240

242 iofis

60 TO 266

200 1U1 $=109$

CK M-AREA-GANCMG I/F

cho coosering

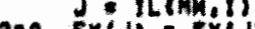

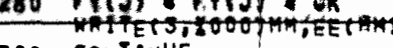

CONTINUE

RETURN 


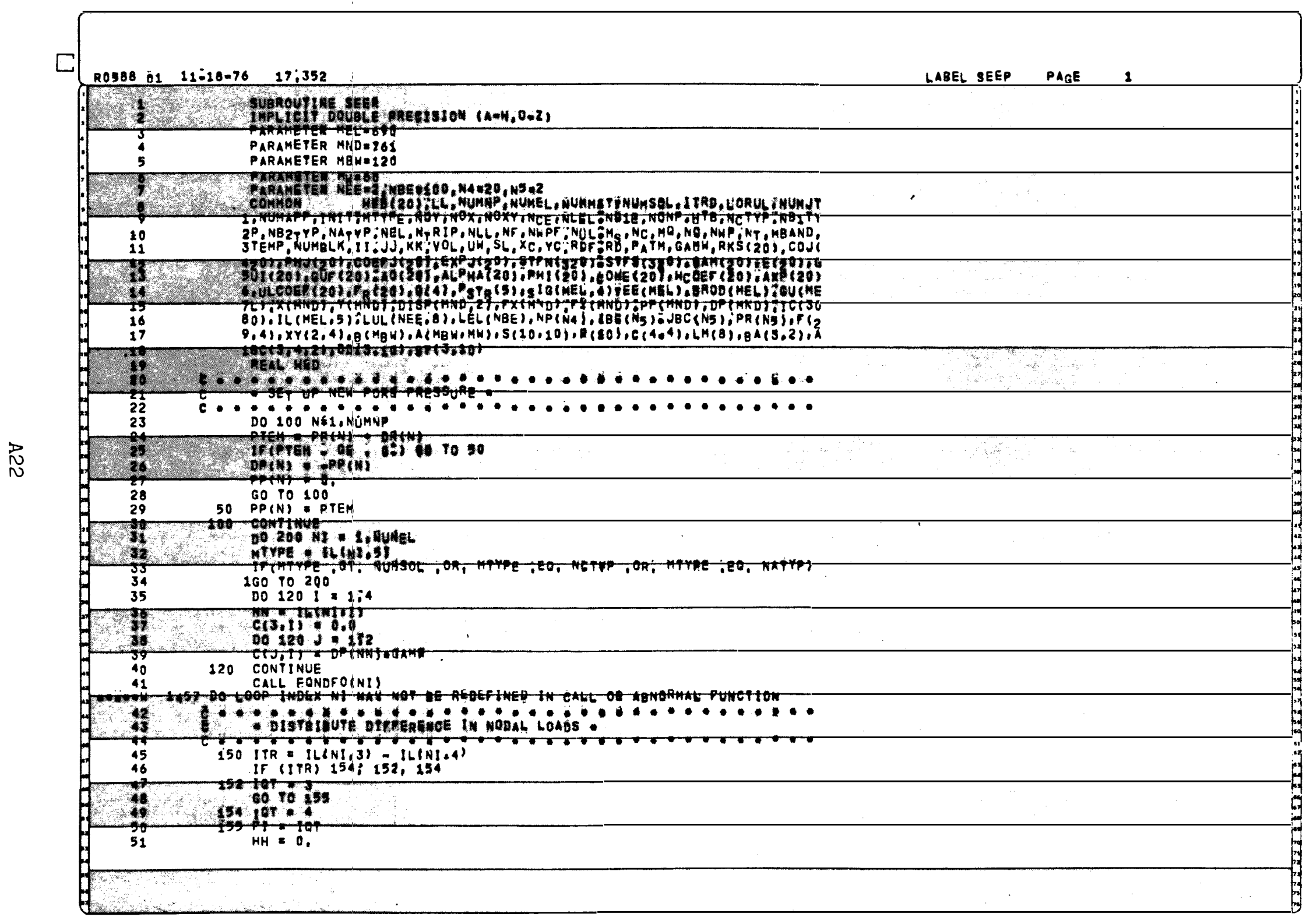




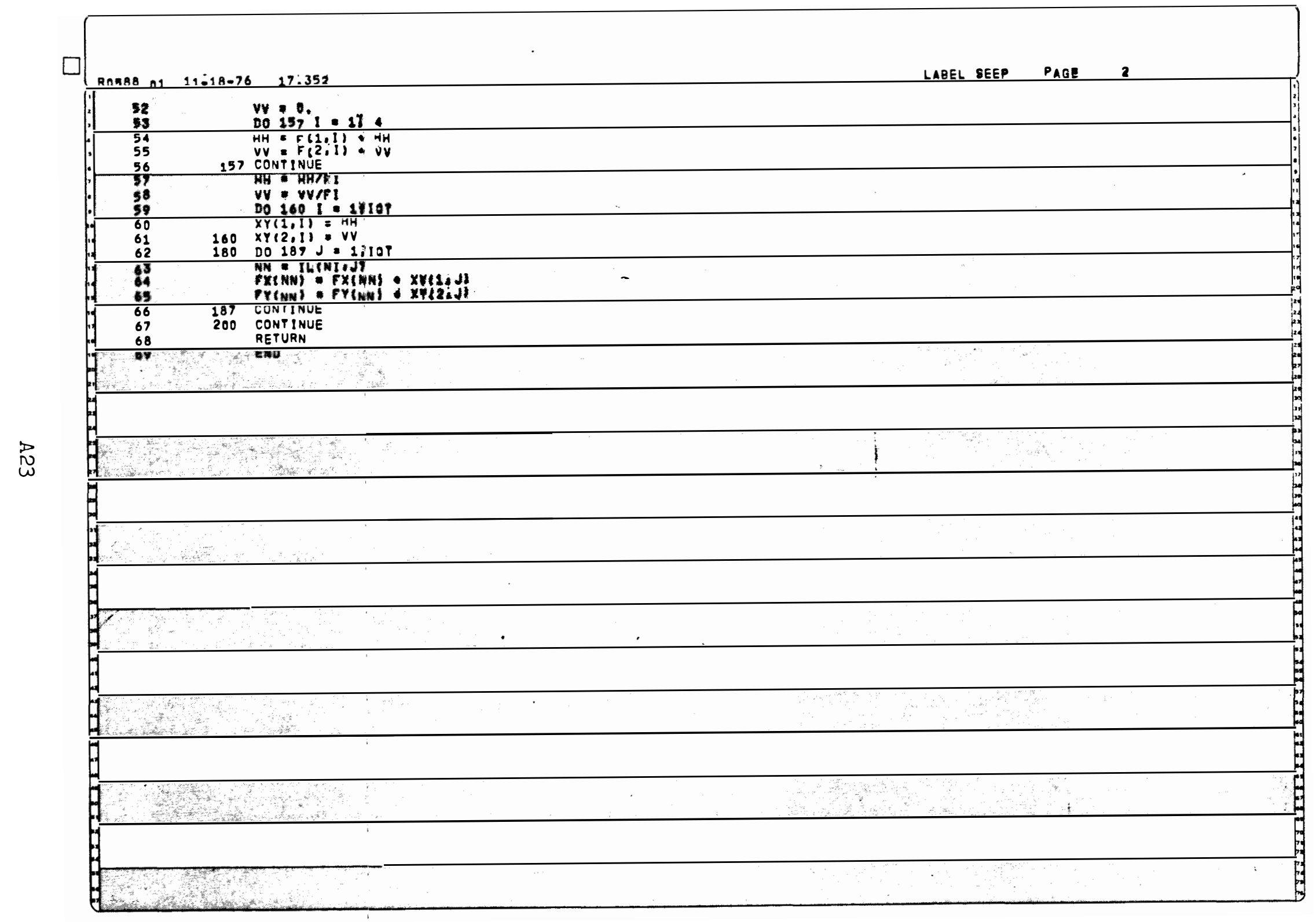




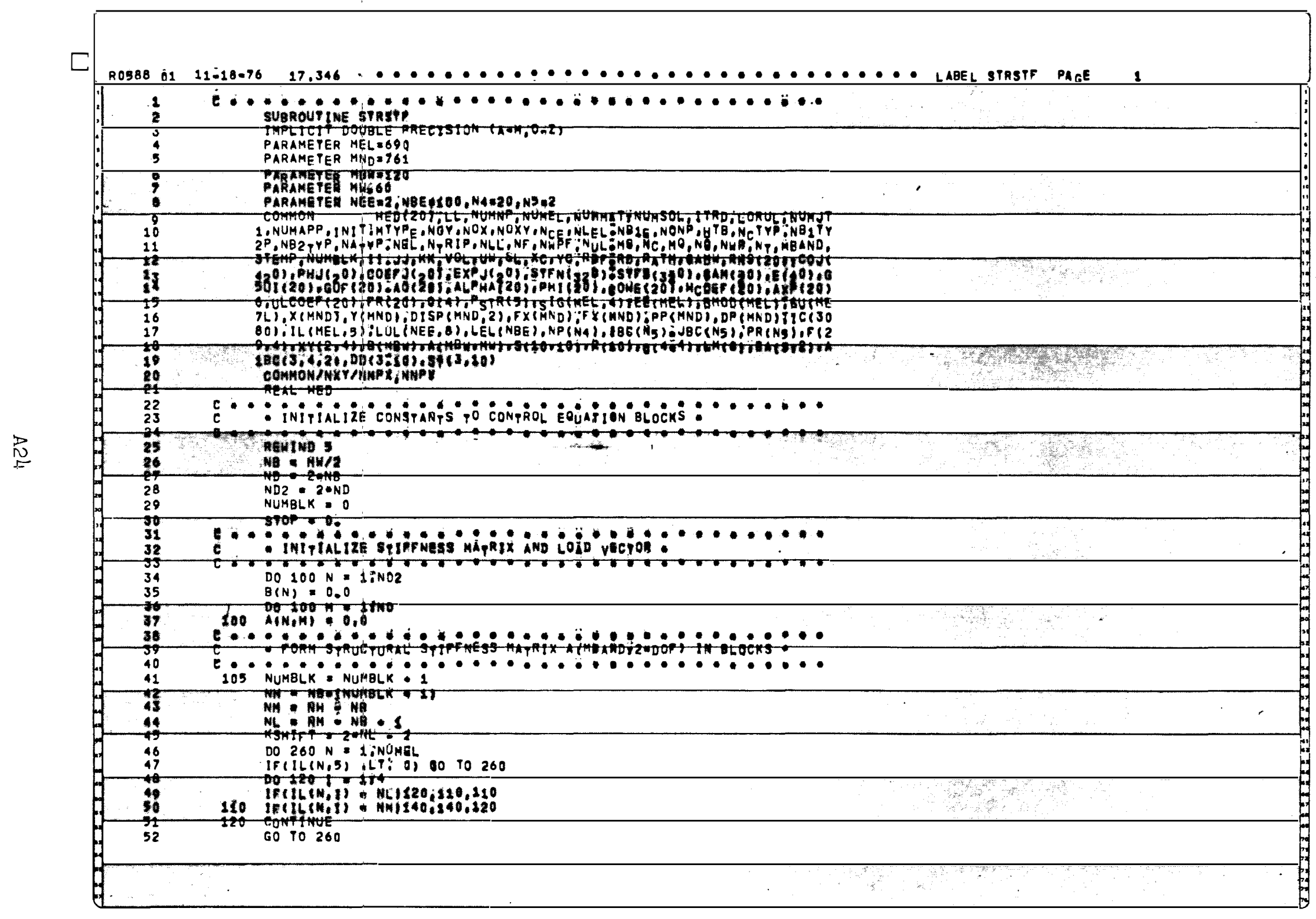




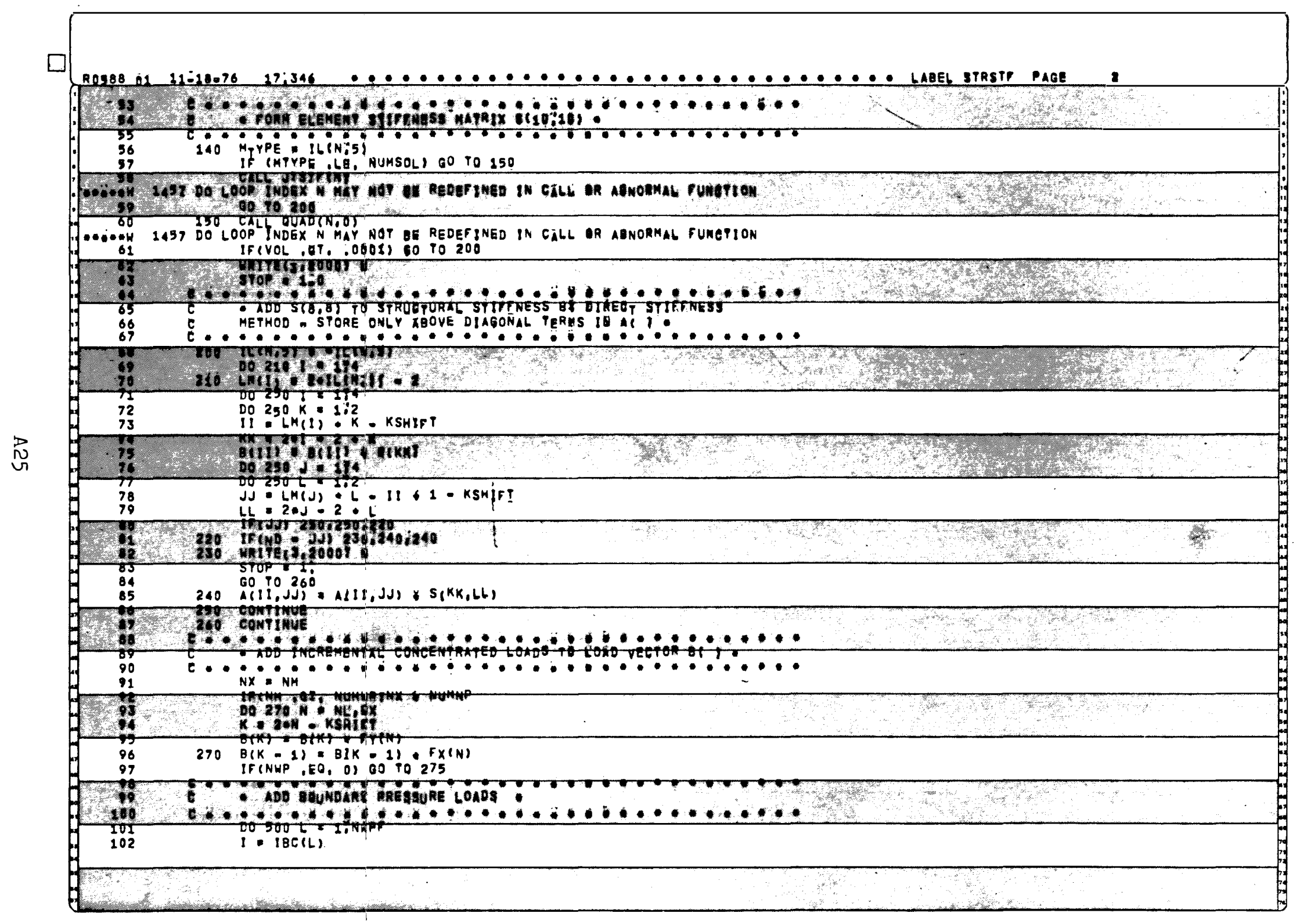




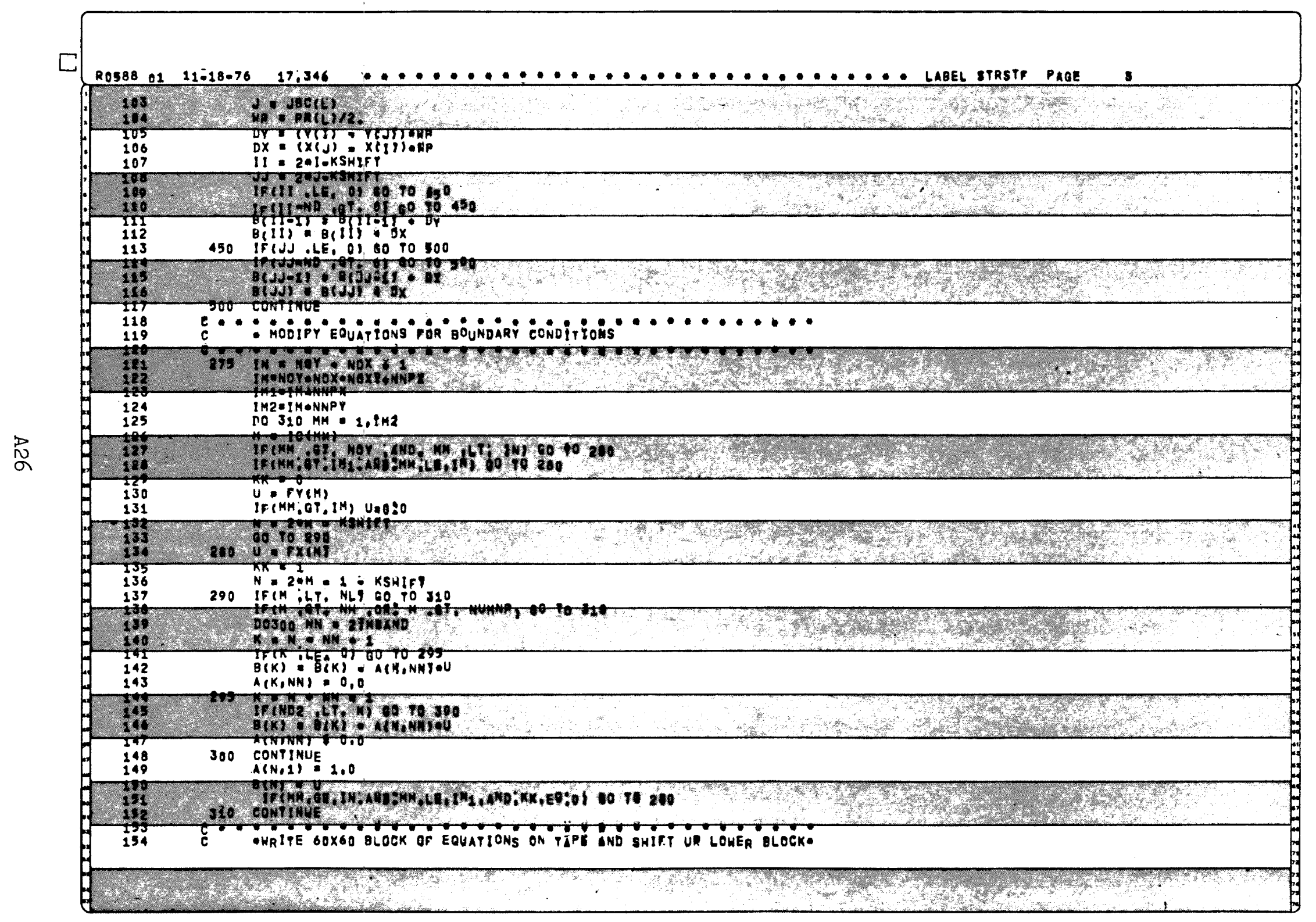




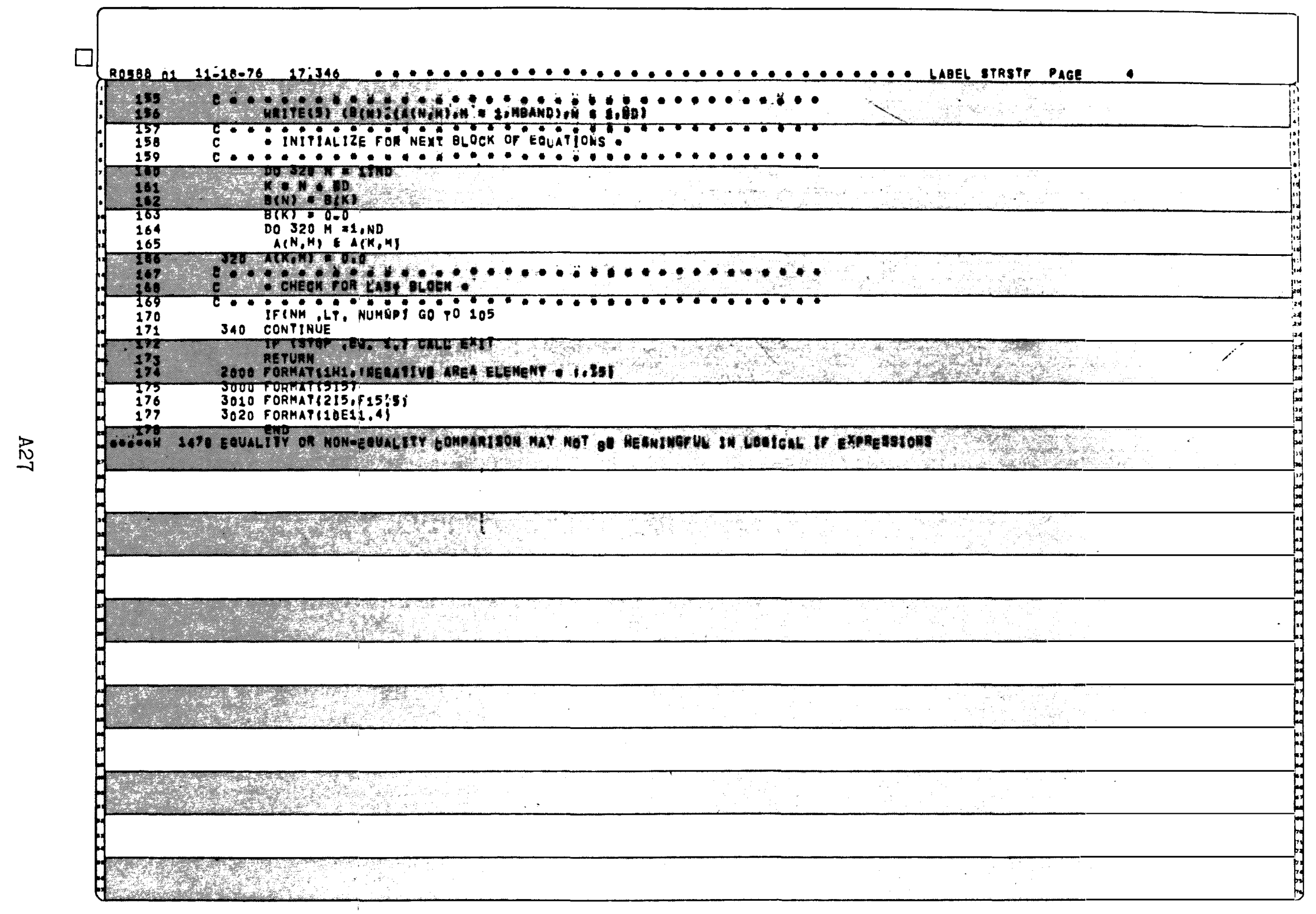




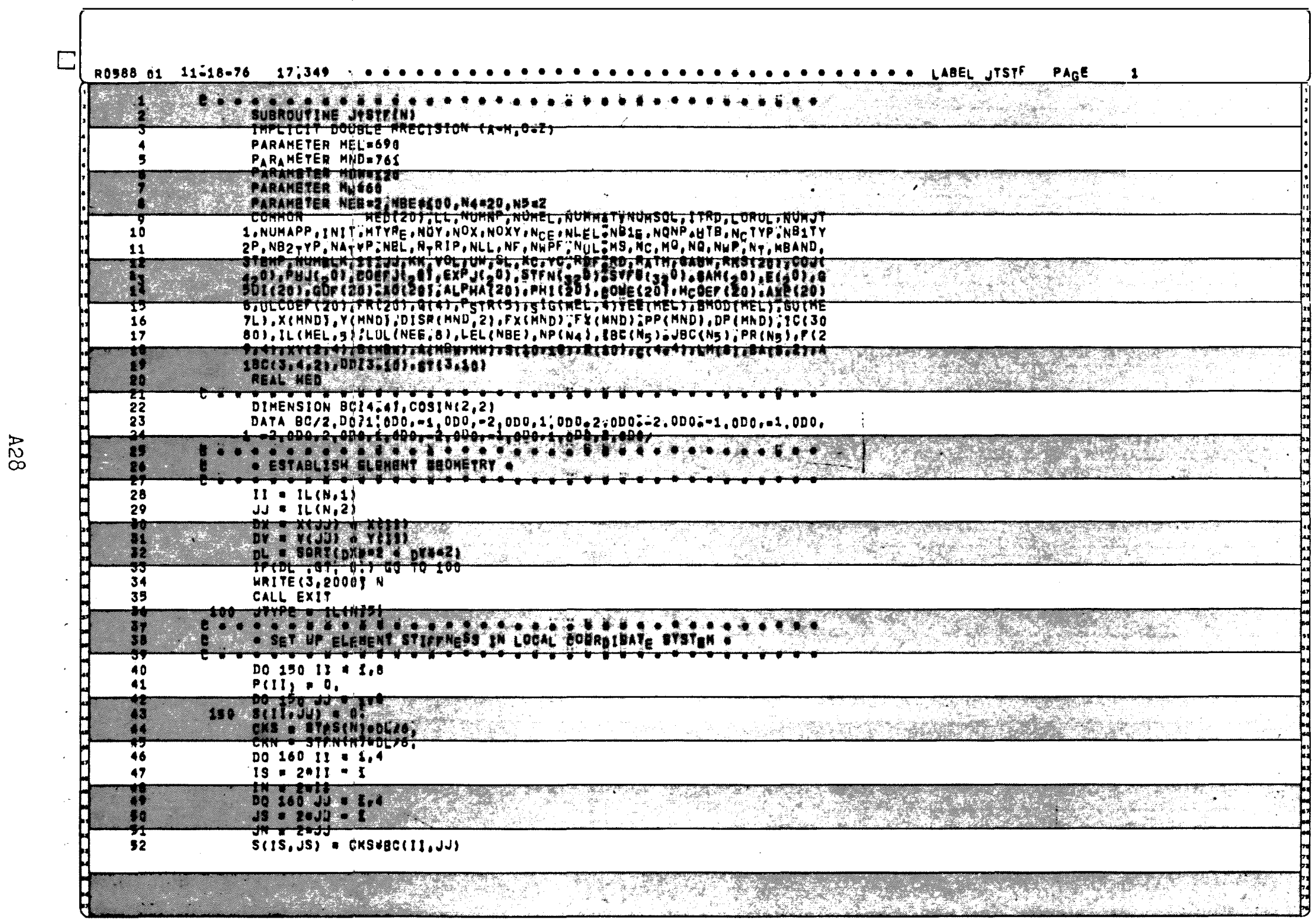




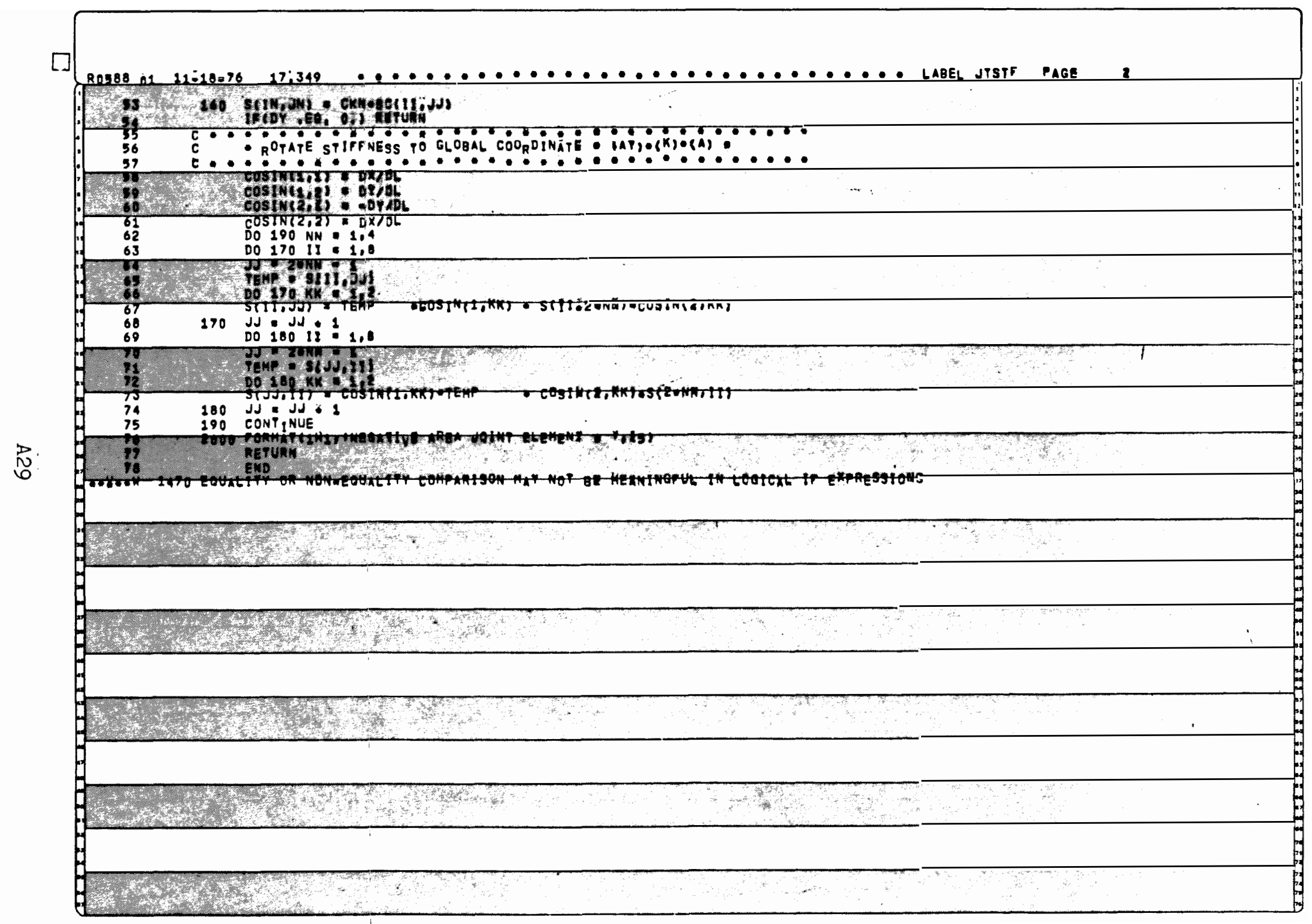




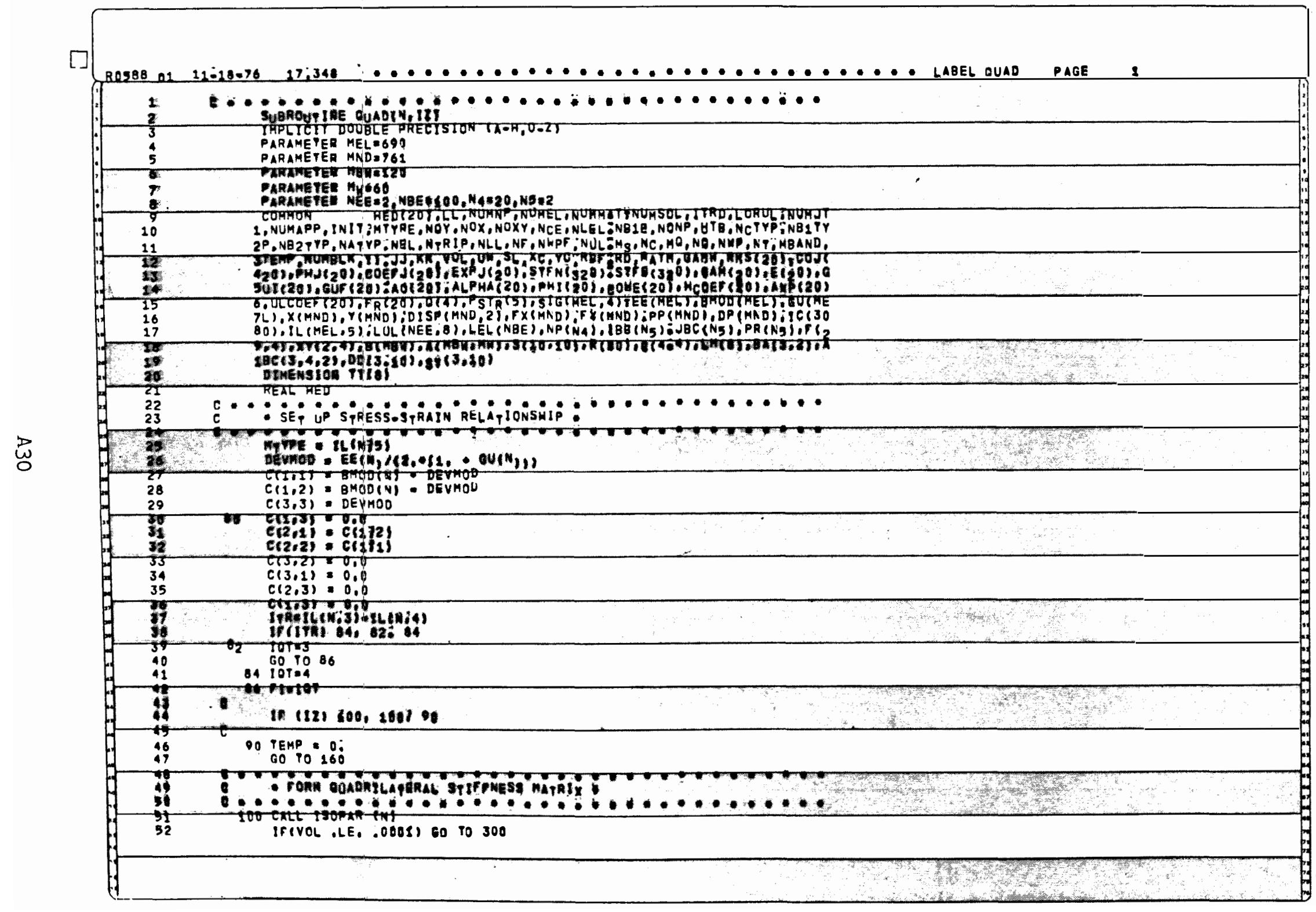




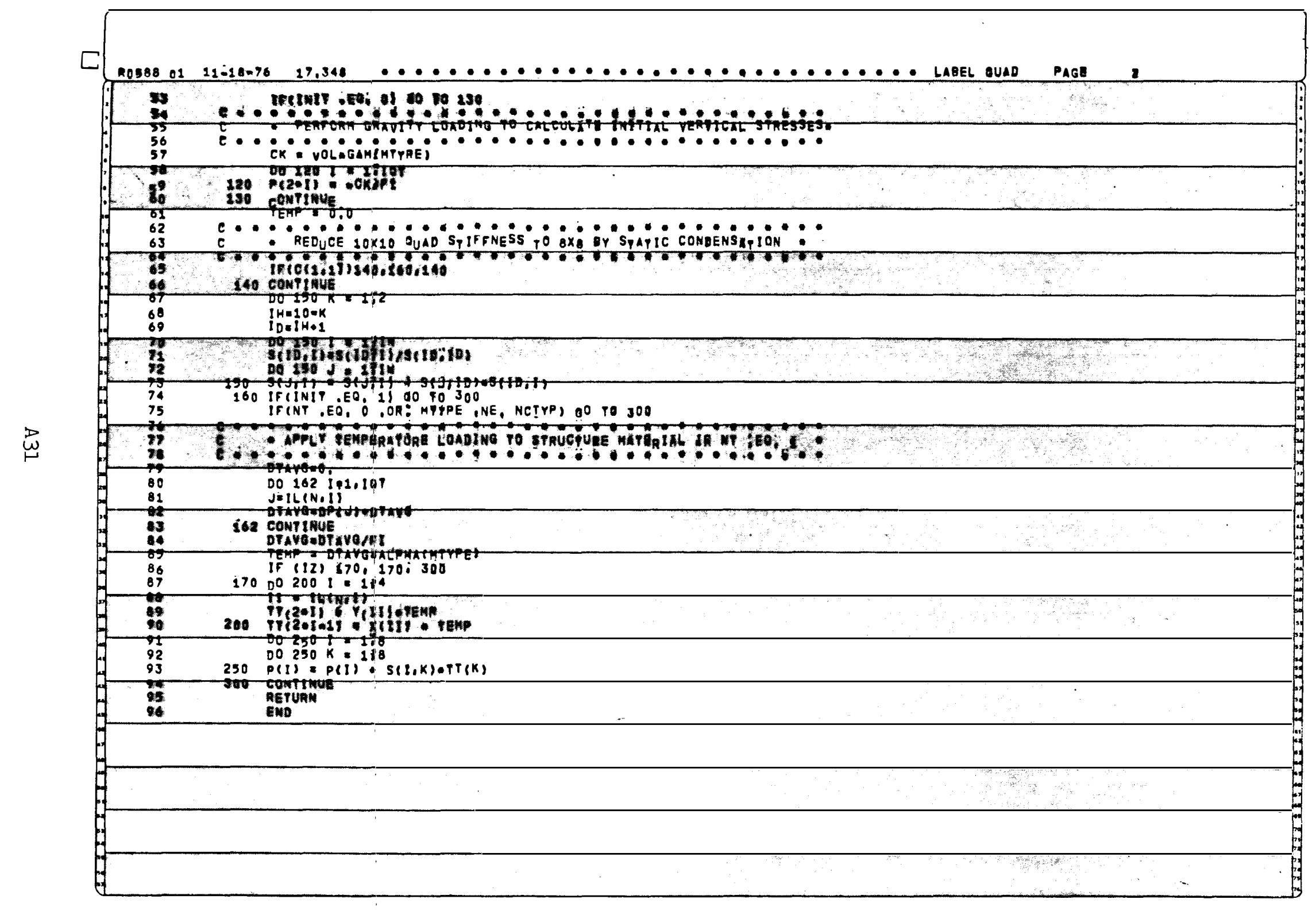




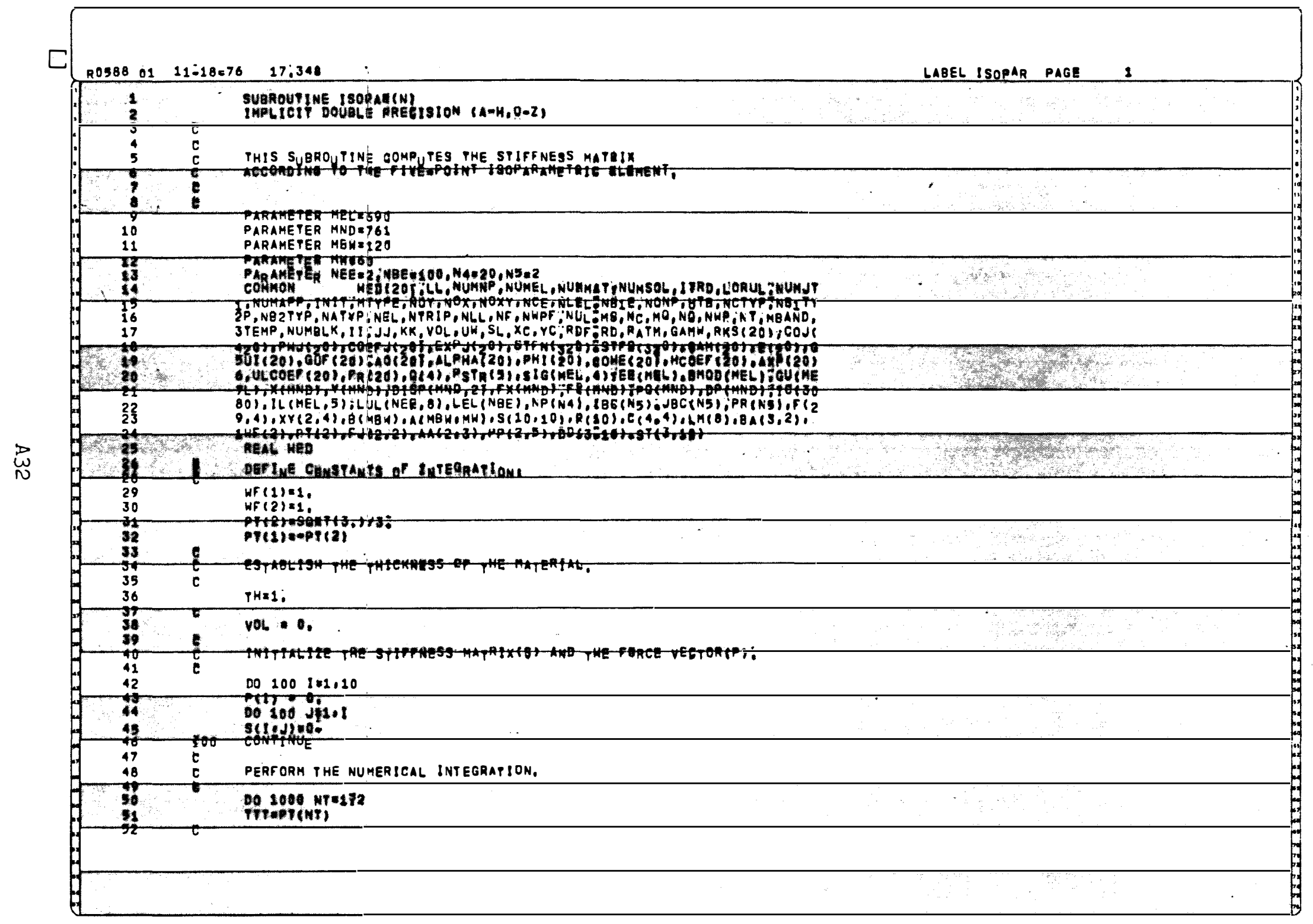




\begin{tabular}{|c|c|c|c|}
\hline Resse a & $6 \quad 17,348$ & LABEL ISOPAR PAGE & 2 \\
\hline $\operatorname{los}_{4}$ & 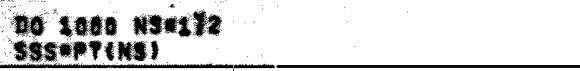 & & \\
\hline \begin{tabular}{|l}
55 \\
56 \\
37
\end{tabular} & COMPUTE THE P PRIME MATRIX, & & \\
\hline 8 & 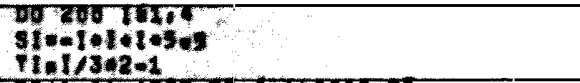 & & \\
\hline $\begin{array}{l}61 \\
62 \\
63 \\
\end{array}$ & 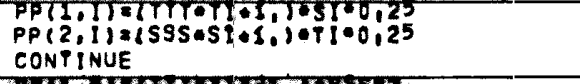 & & \\
\hline 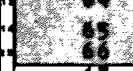 & 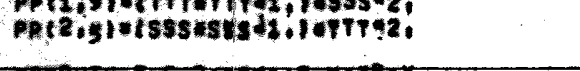 & & \\
\hline $\begin{array}{l}68 \\
69 \\
\end{array}$ & Do 300101,2 & & \\
\hline $\begin{array}{r}74 \\
-\quad 32 \\
\end{array}$ & Coontinge & $\mathrm{C}^{3}+{ }_{2}$ & \\
\hline $\begin{array}{r}74 \\
75 \\
\end{array}$ & 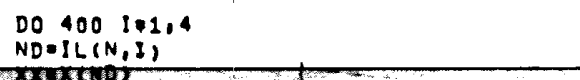 & & \\
\hline 76 & 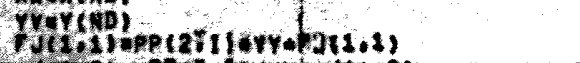 & D. & $=$ \\
\hline $\begin{array}{l}78 \\
81 \\
81\end{array}$ & 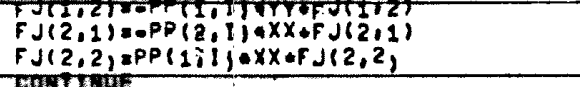 & & \\
\hline$\frac{85}{85}$ & COMPUTA THE VOCUAE OR TME ELERENY. & 3 & \\
\hline $\begin{array}{l}86 \\
87 \\
87\end{array}$ & 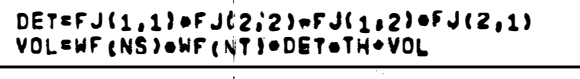 & & \\
\hline$\frac{89}{80}$ & 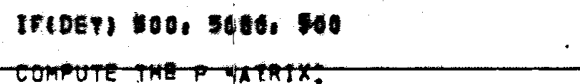 & - & \\
\hline 92 & Do 600 Je 1.5 & & \\
\hline 95 & 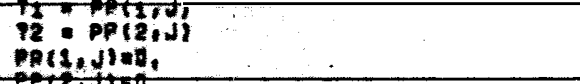 & - & \\
\hline $\begin{array}{r}78 \\
99 \\
99\end{array}$ & 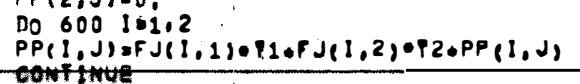 & & \\
\hline $\begin{array}{l}101 \\
102 \\
\end{array}$ & COMPUTE THE STLFRNESS MatrIx, & & \\
\hline $\begin{array}{l}104 \\
104\end{array}$ & T3=WF(NS)•HF (NT)/DEP & & \\
\hline
\end{tabular}




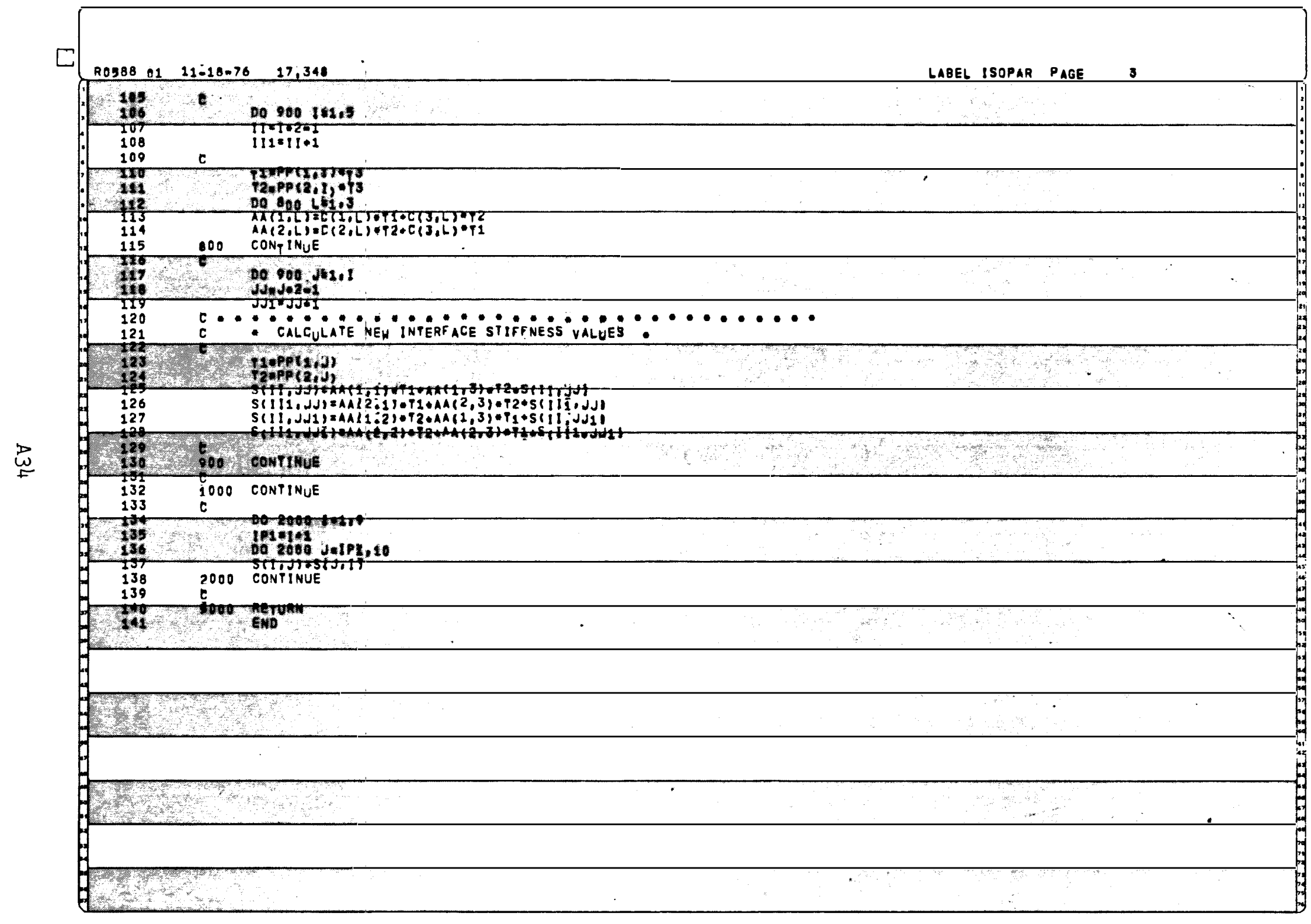




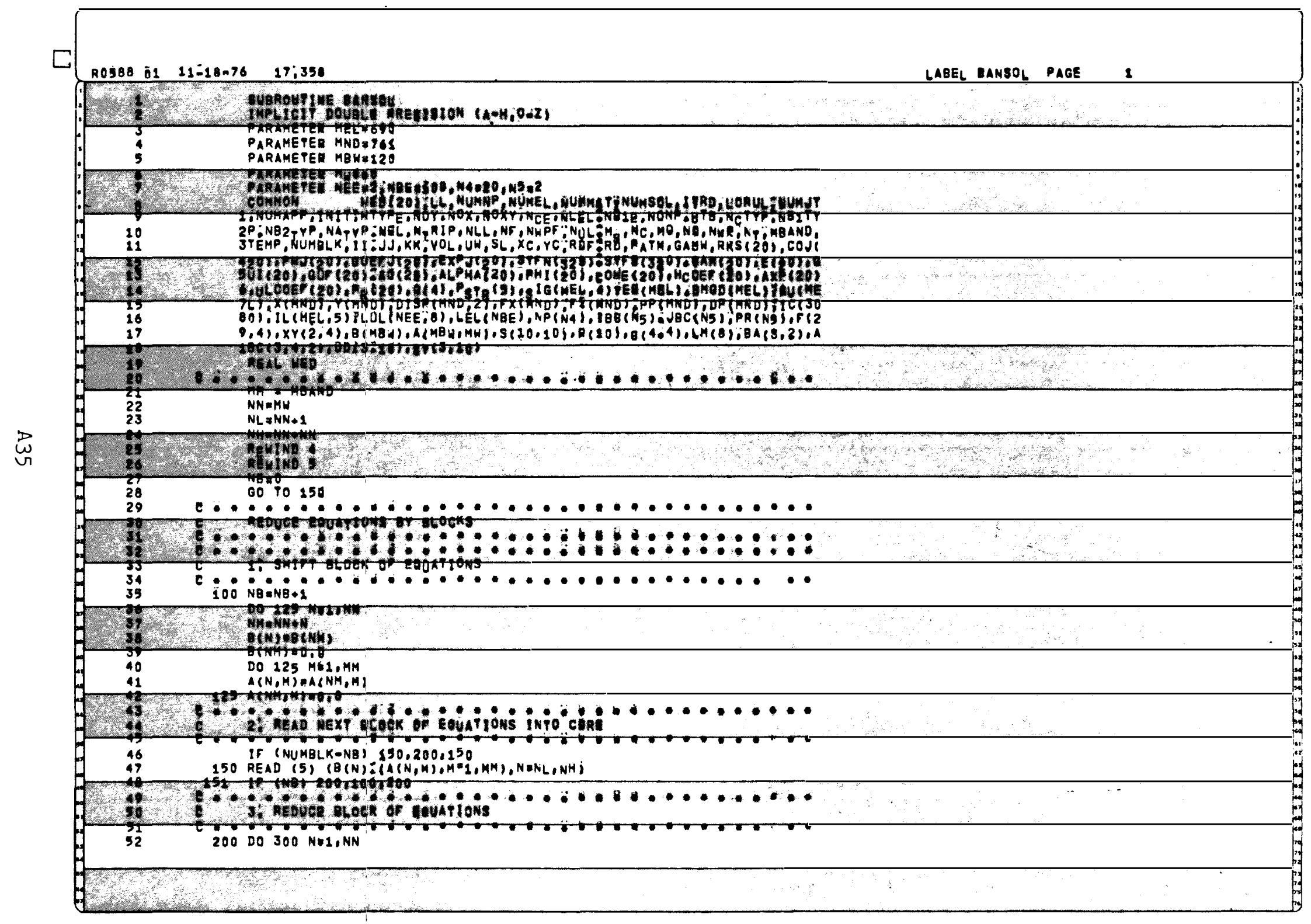




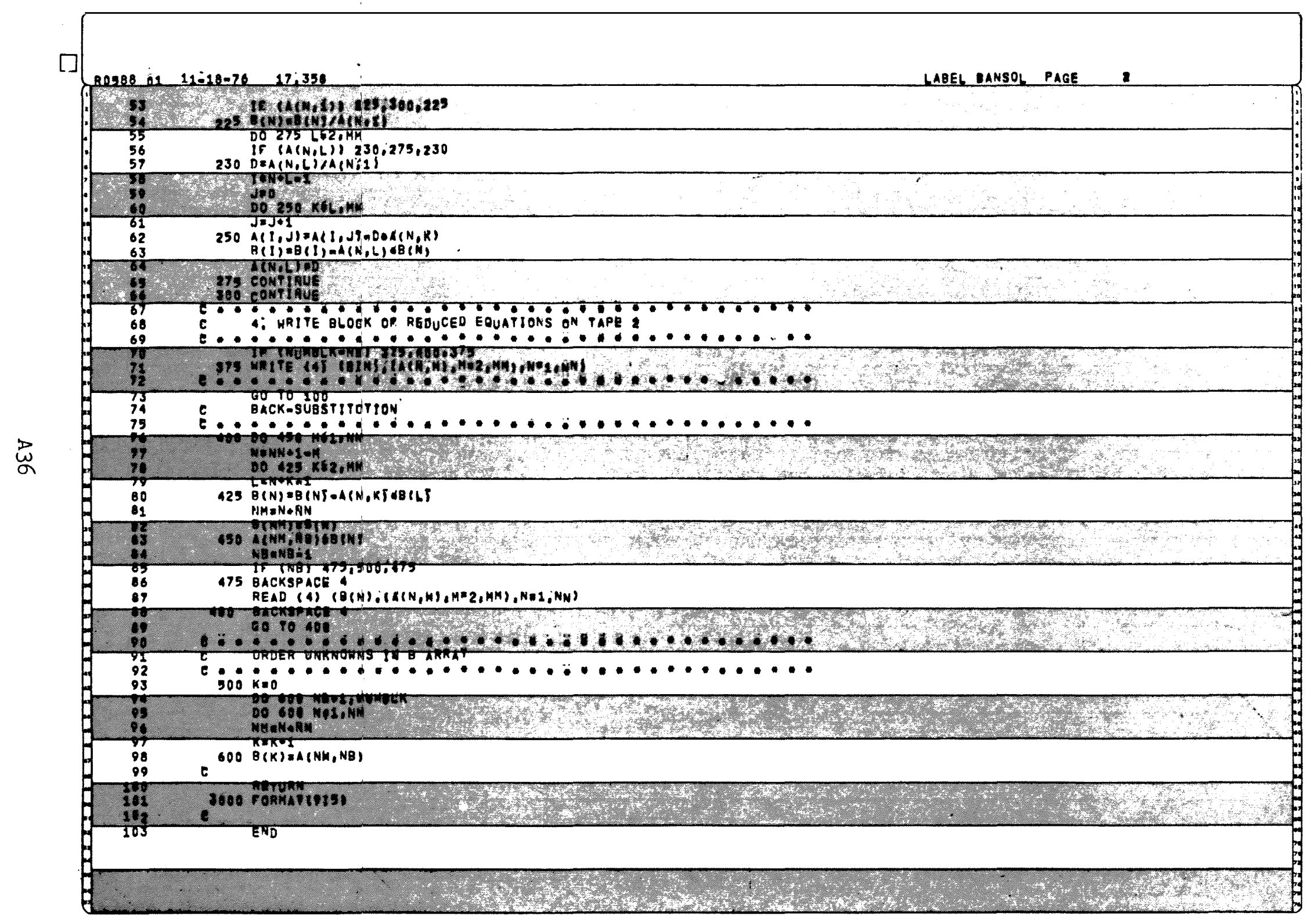




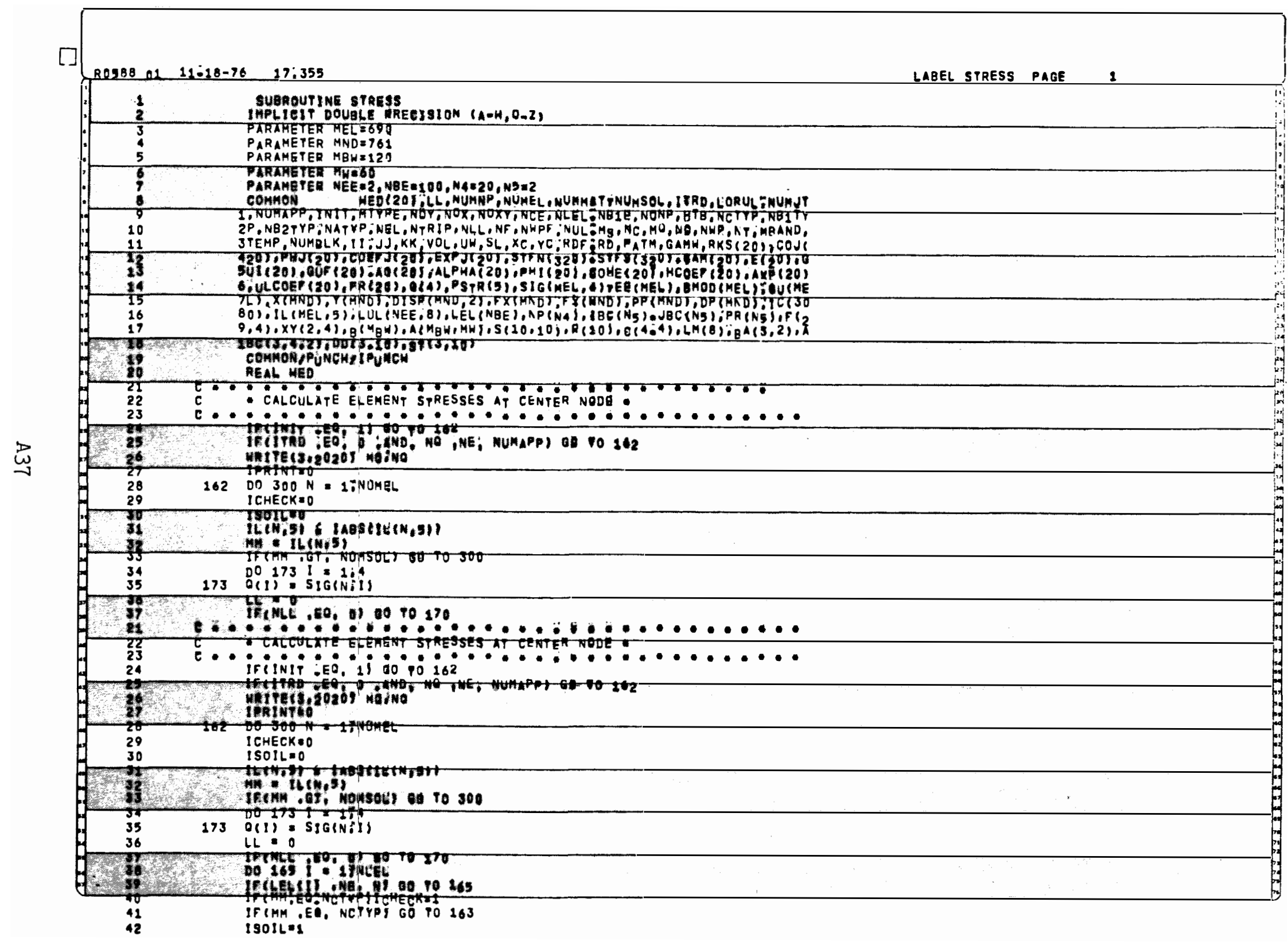




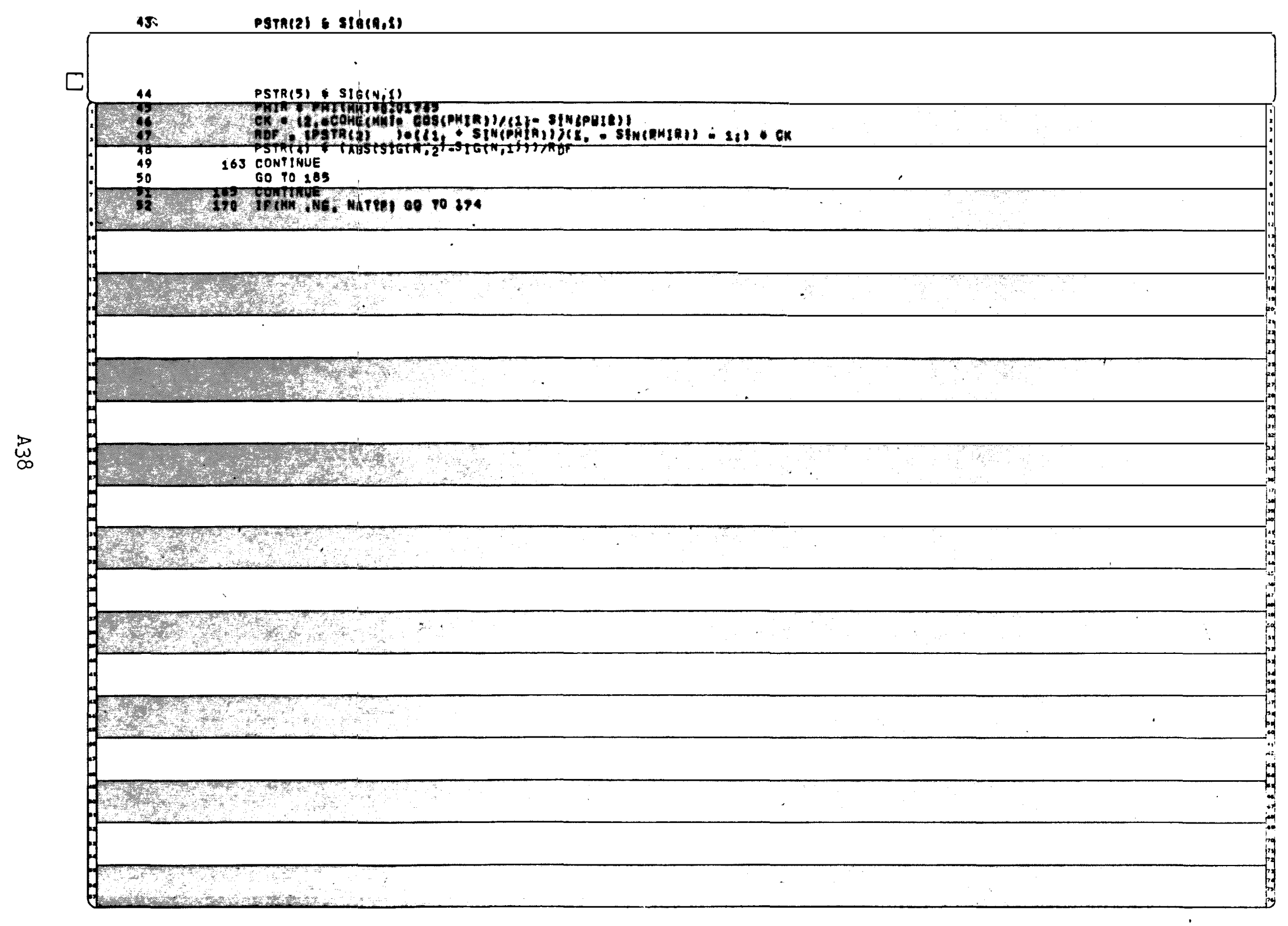




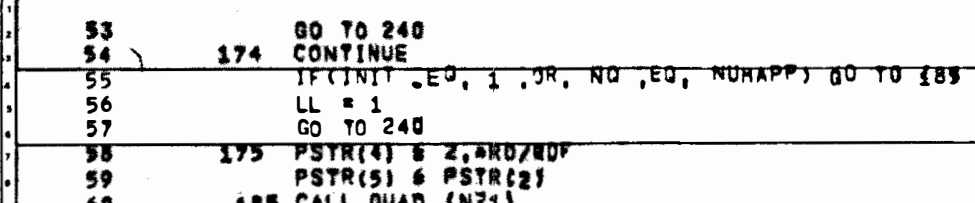

285 och

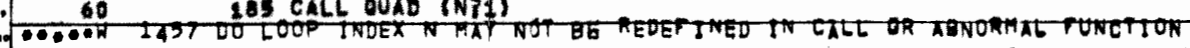

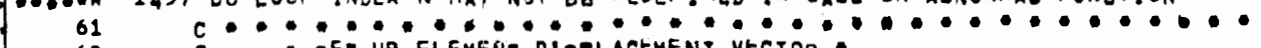

62 C C O SEY UP ELEMEVT DISPLACEMENT VECTOR

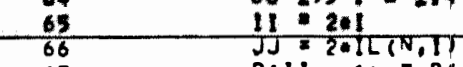

$67 \quad P(1)-1)=8(J)=2 j$

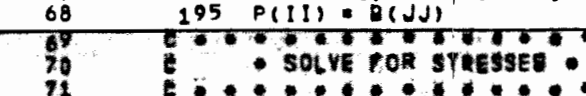

1457 DO LOOP INDEX N MAY NOT BE REUEF INED IN CALL OR ABNORMAL FUNCPION

IF (ICHECK,EO, I) O(1) GUU(N),O(2)/(1, O-GUSNI)

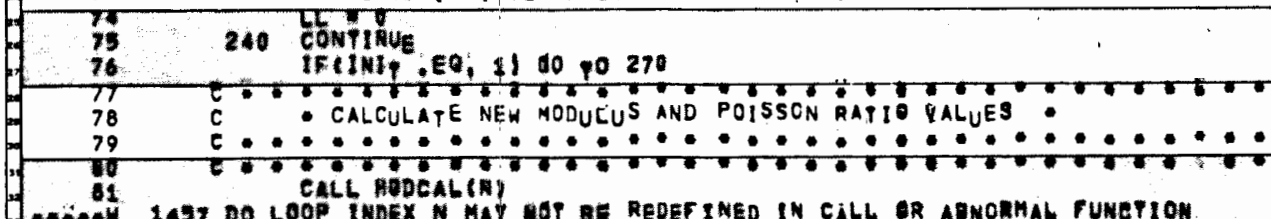

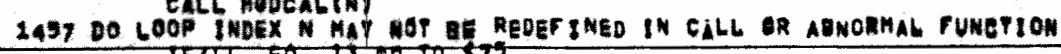

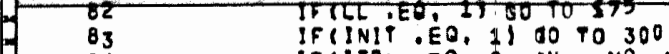

84 IFIITRD .EO: D. AND. NO, NE, NUMAPPI 6080300

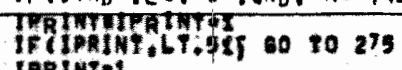

275 CONTINUE

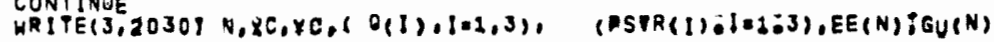

ITRTIT:

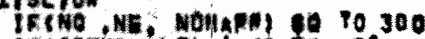

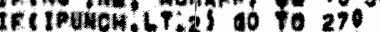

270 DO $2801=110$

280 SIGCN,II: $=1$ i

$280-510$

incuout

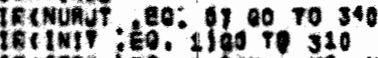

Prtho

101 WRITES3,2040 


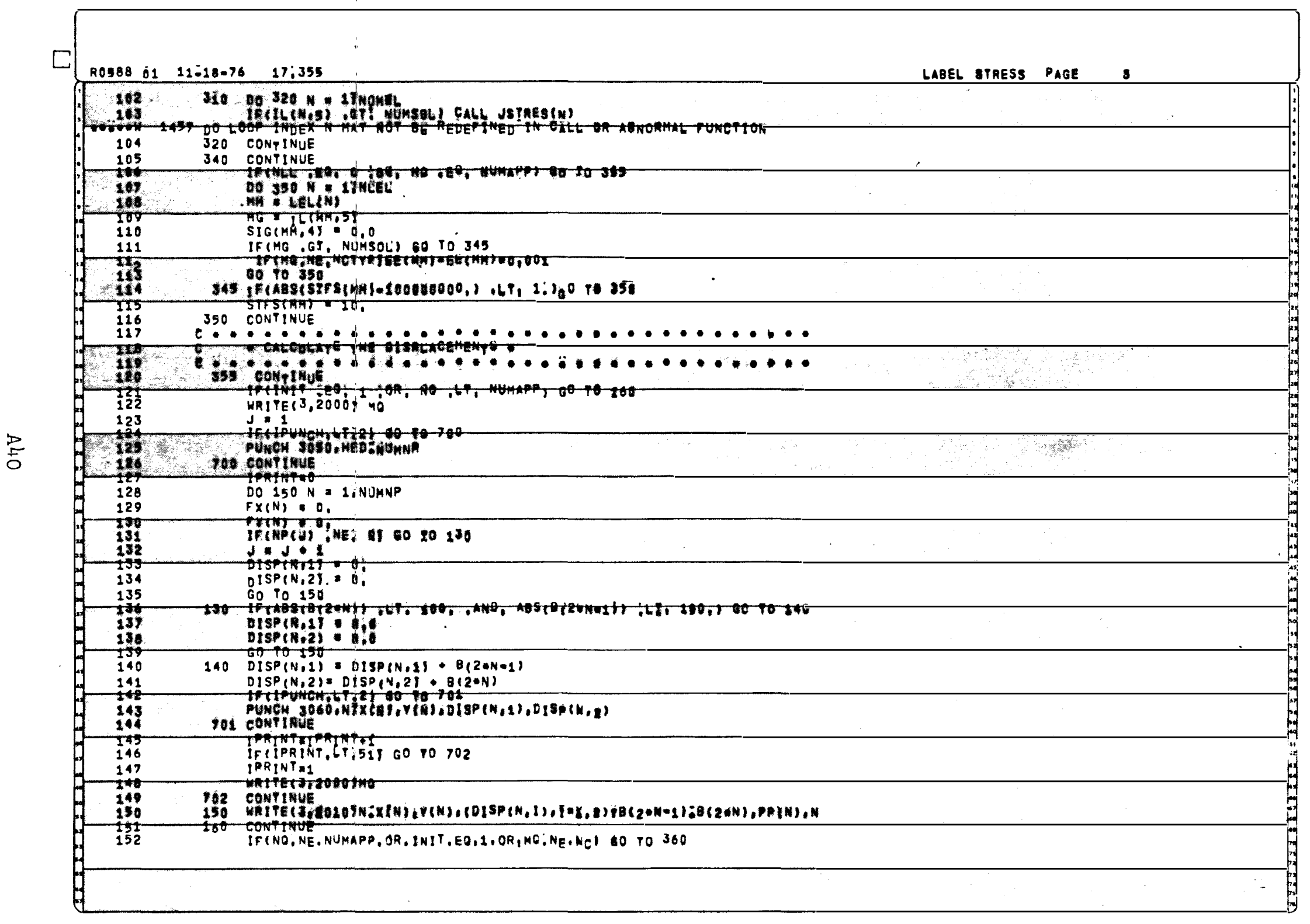




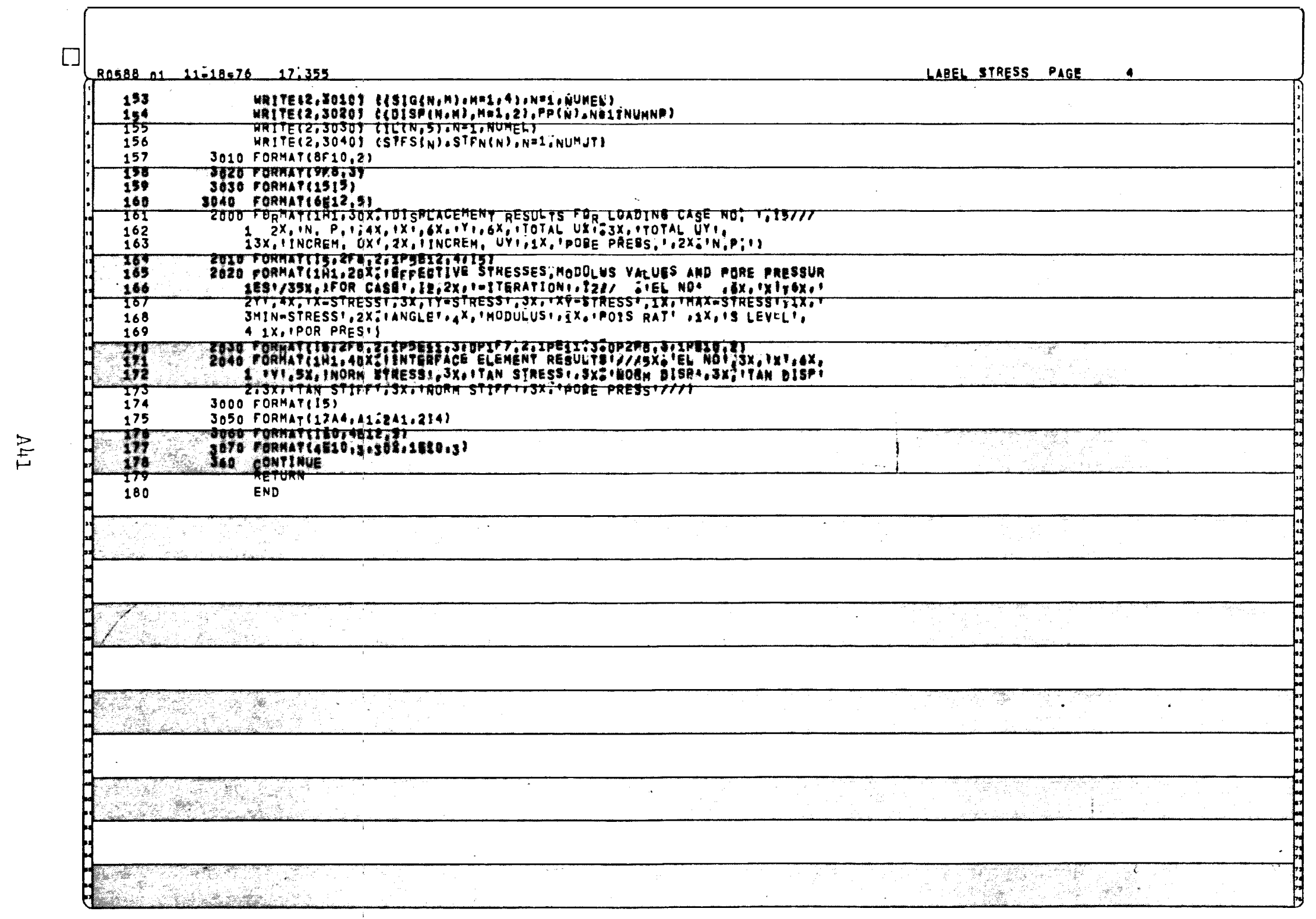




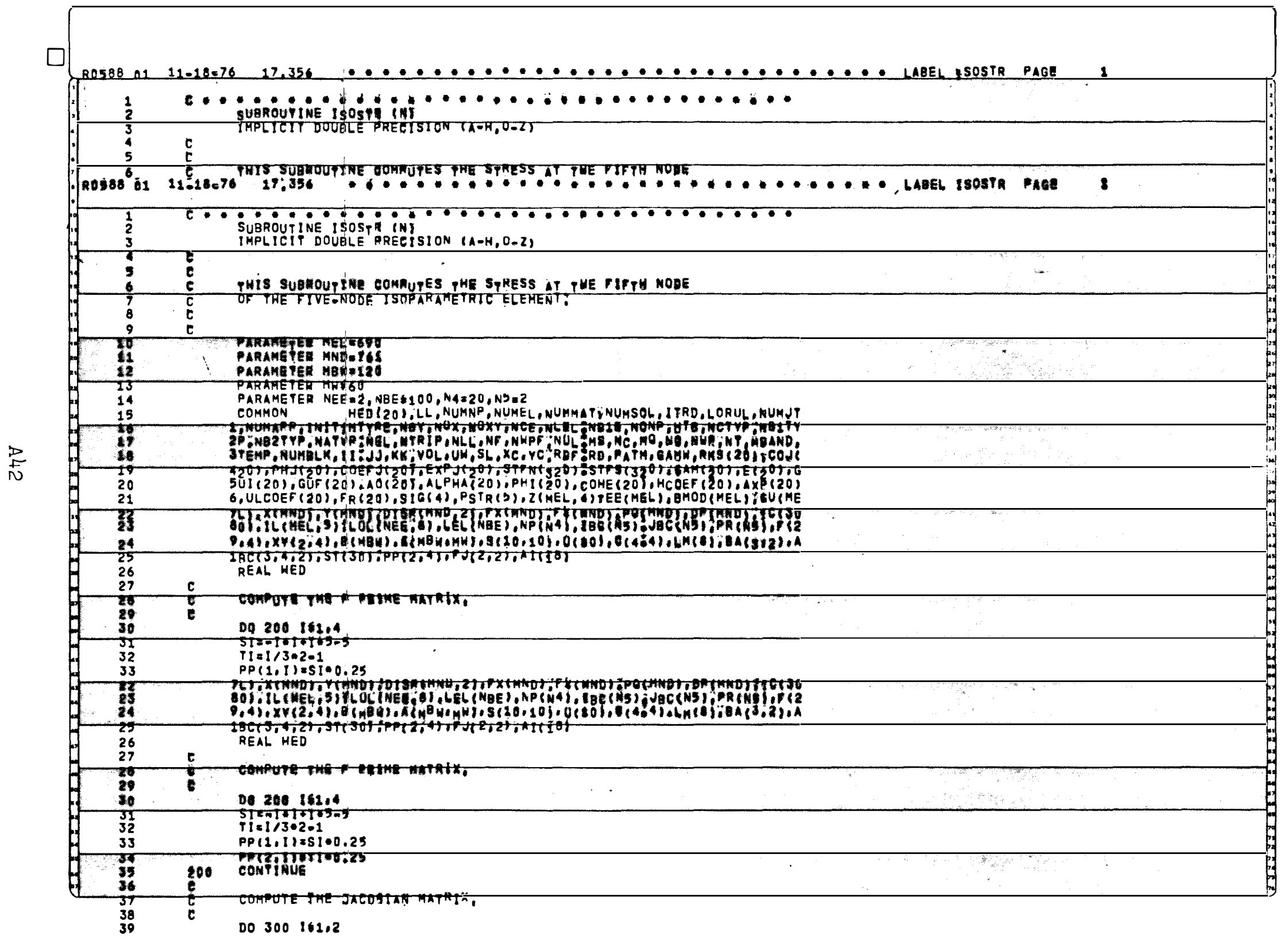




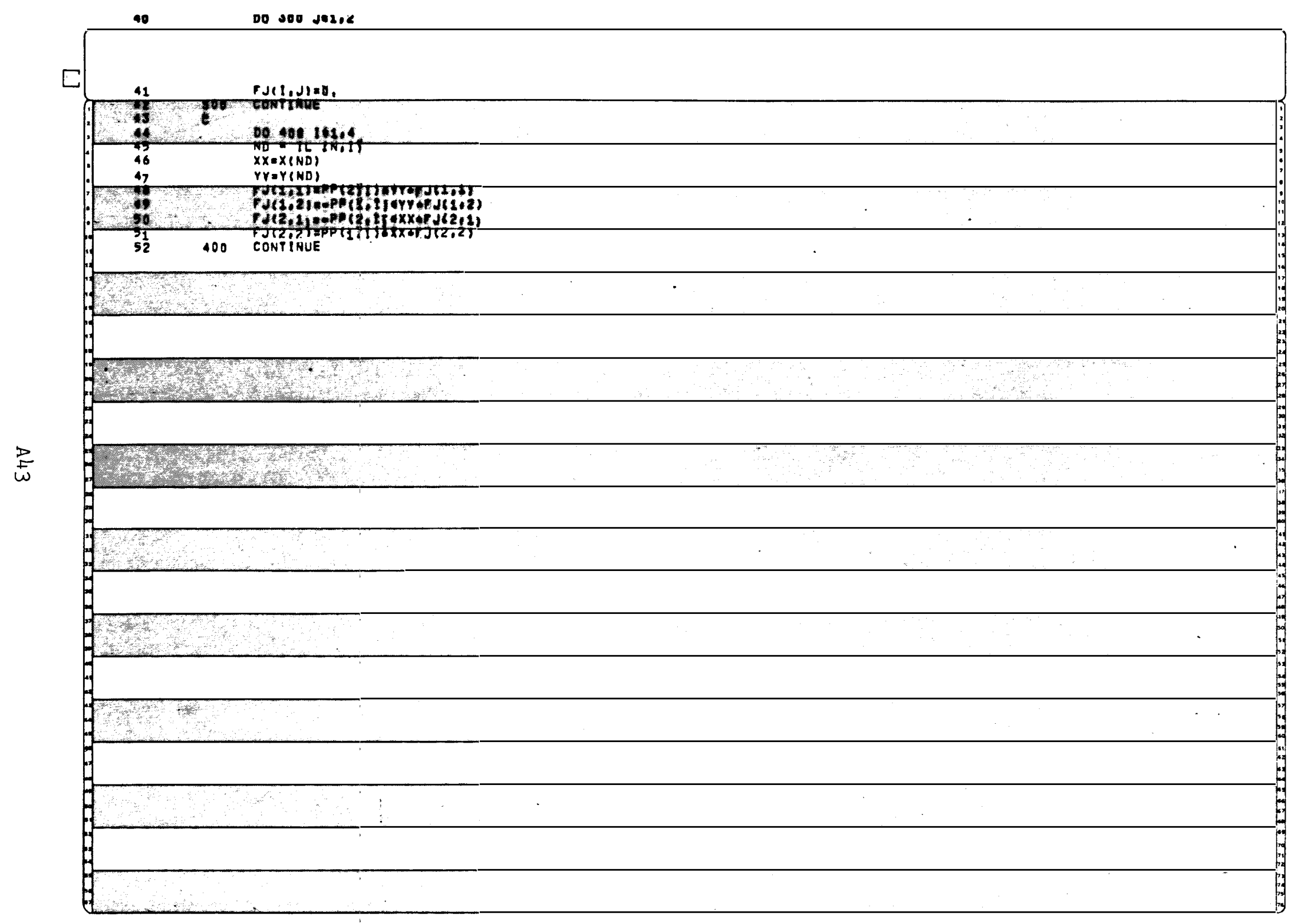




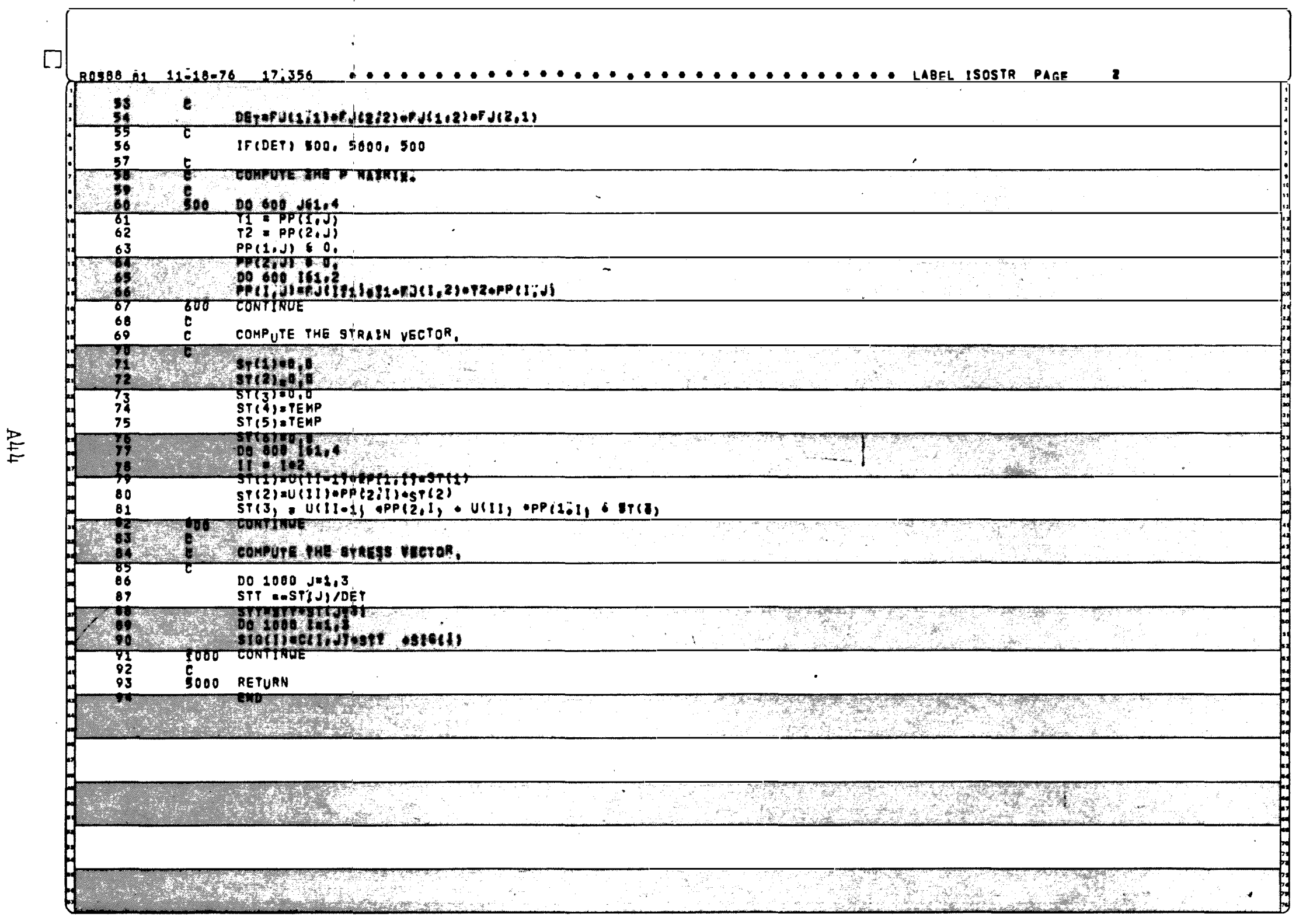




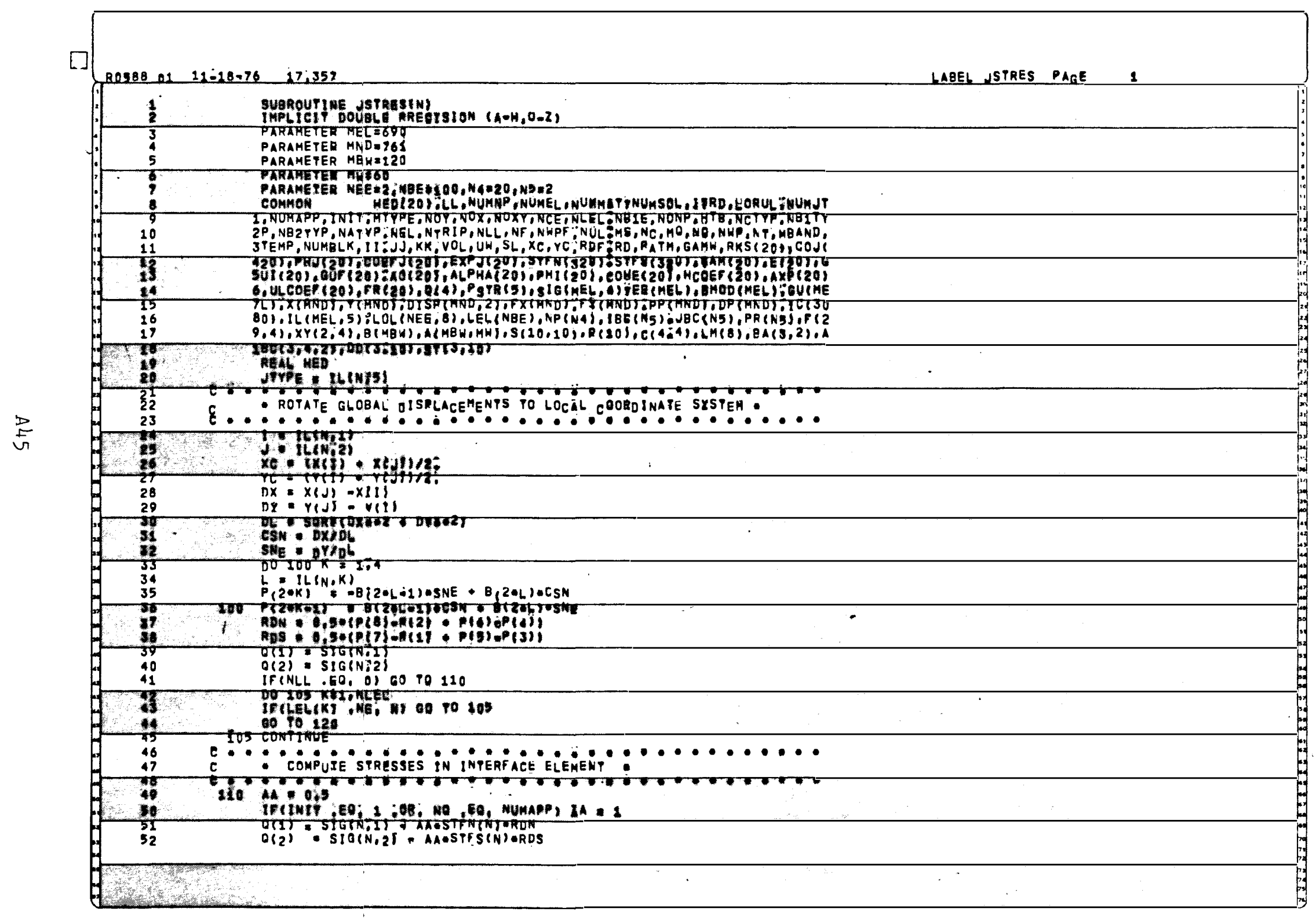




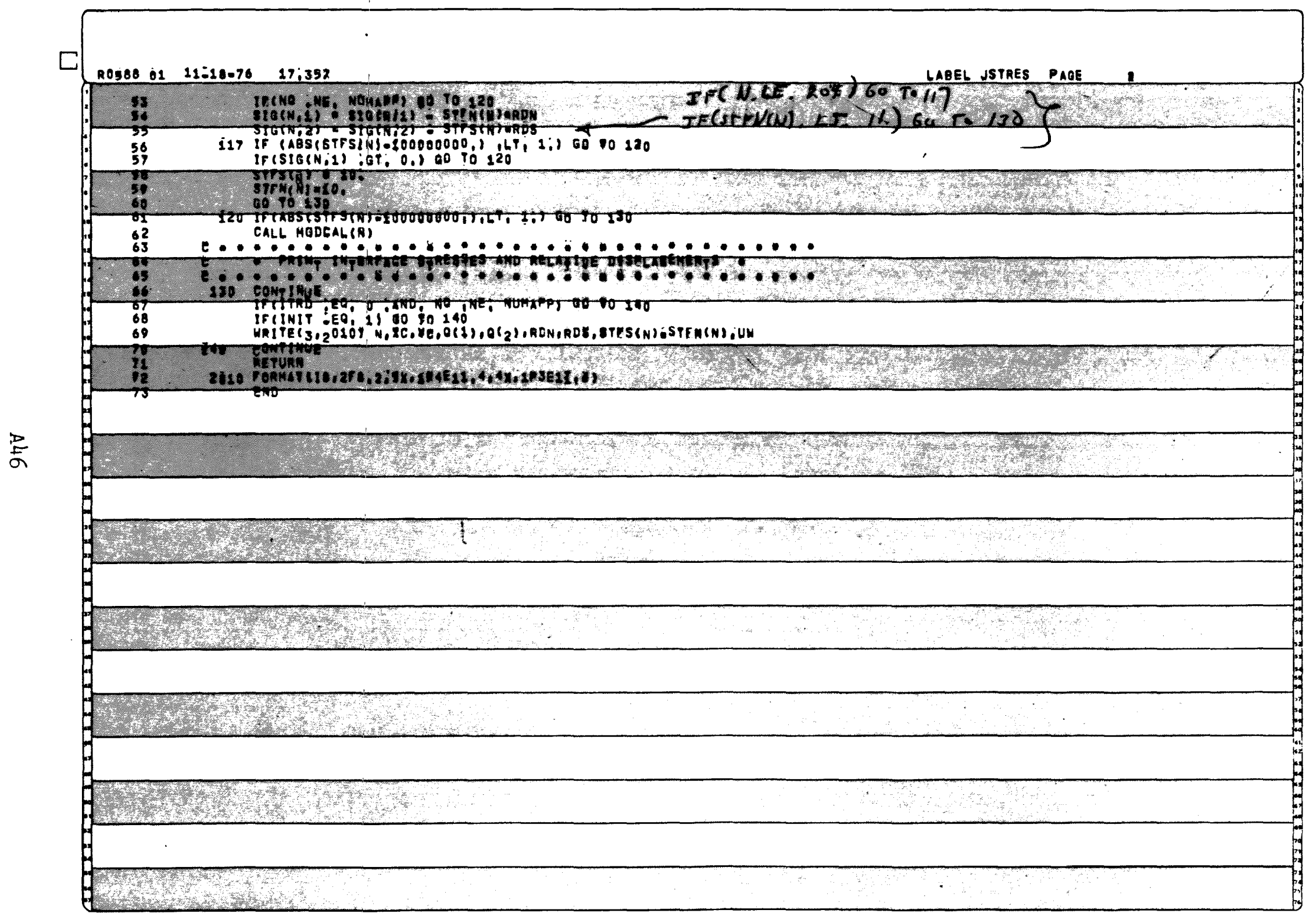




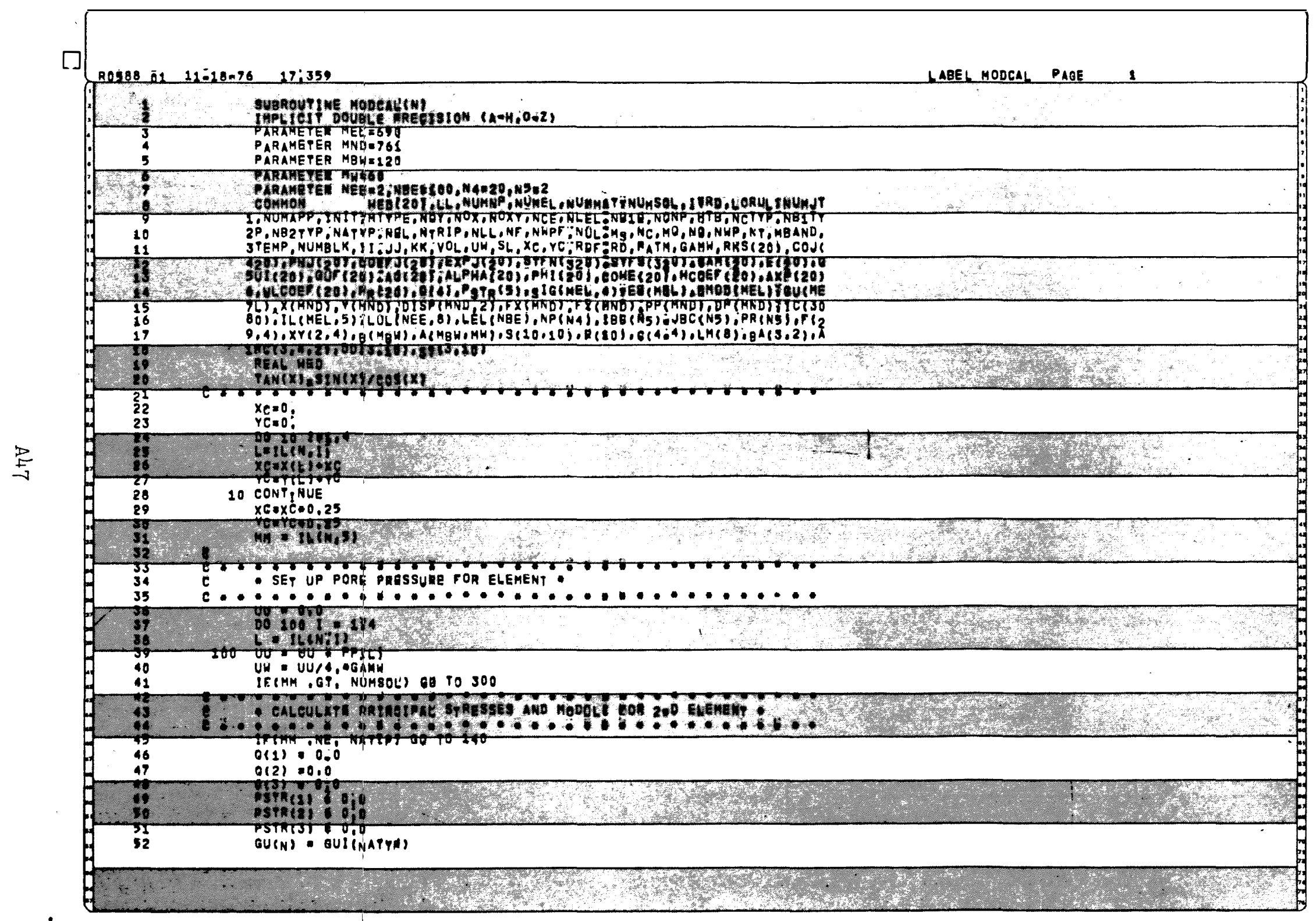




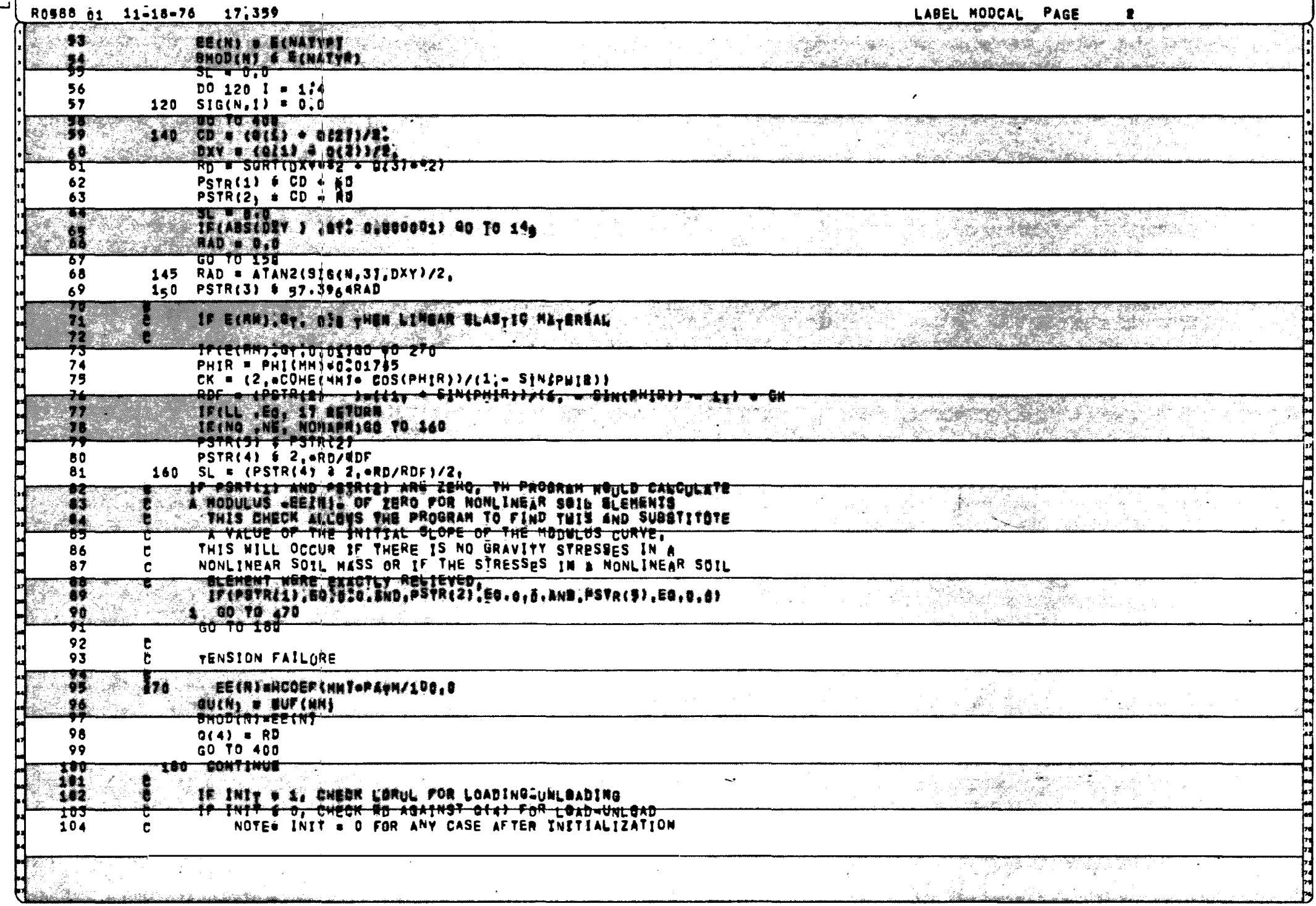




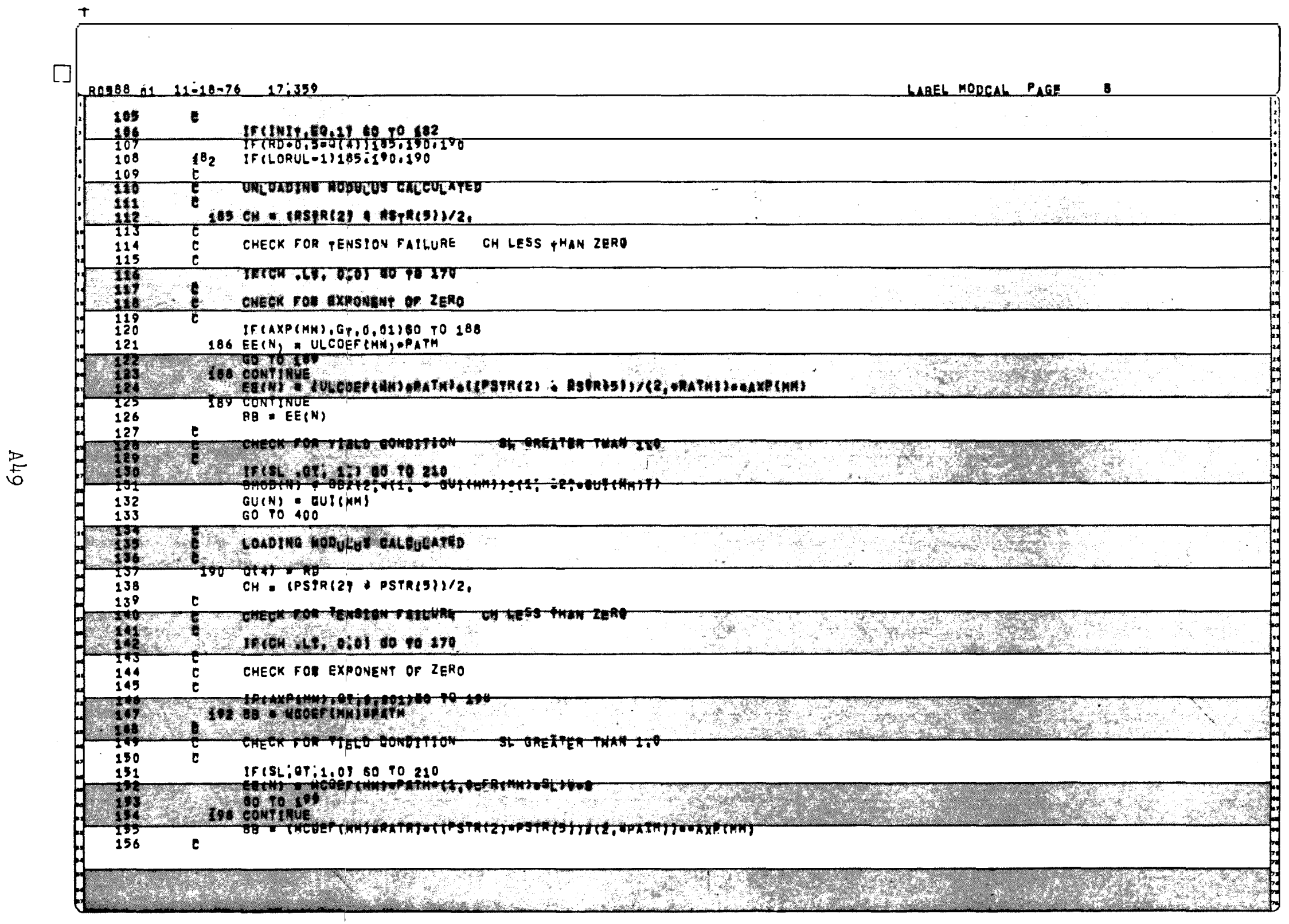




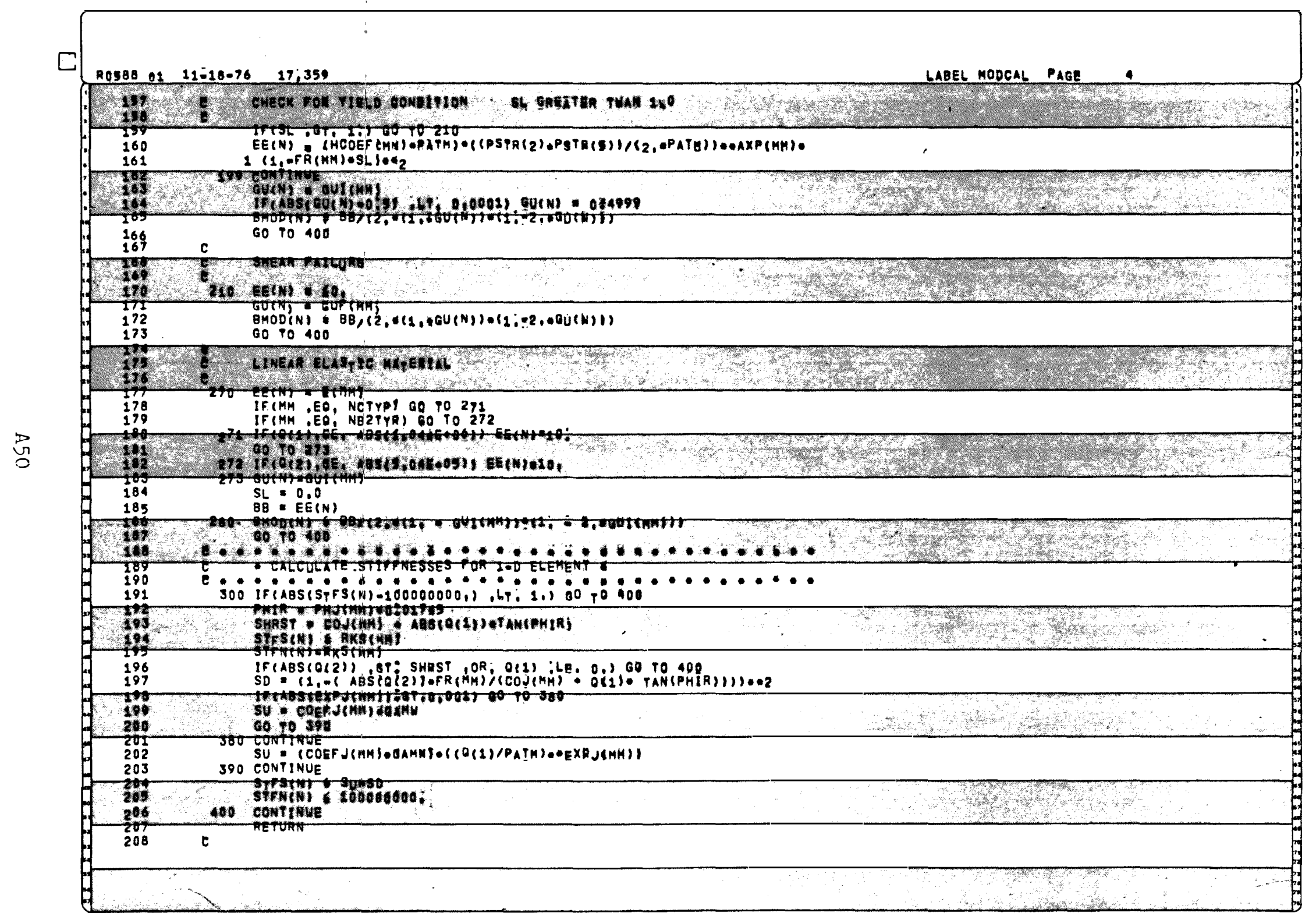




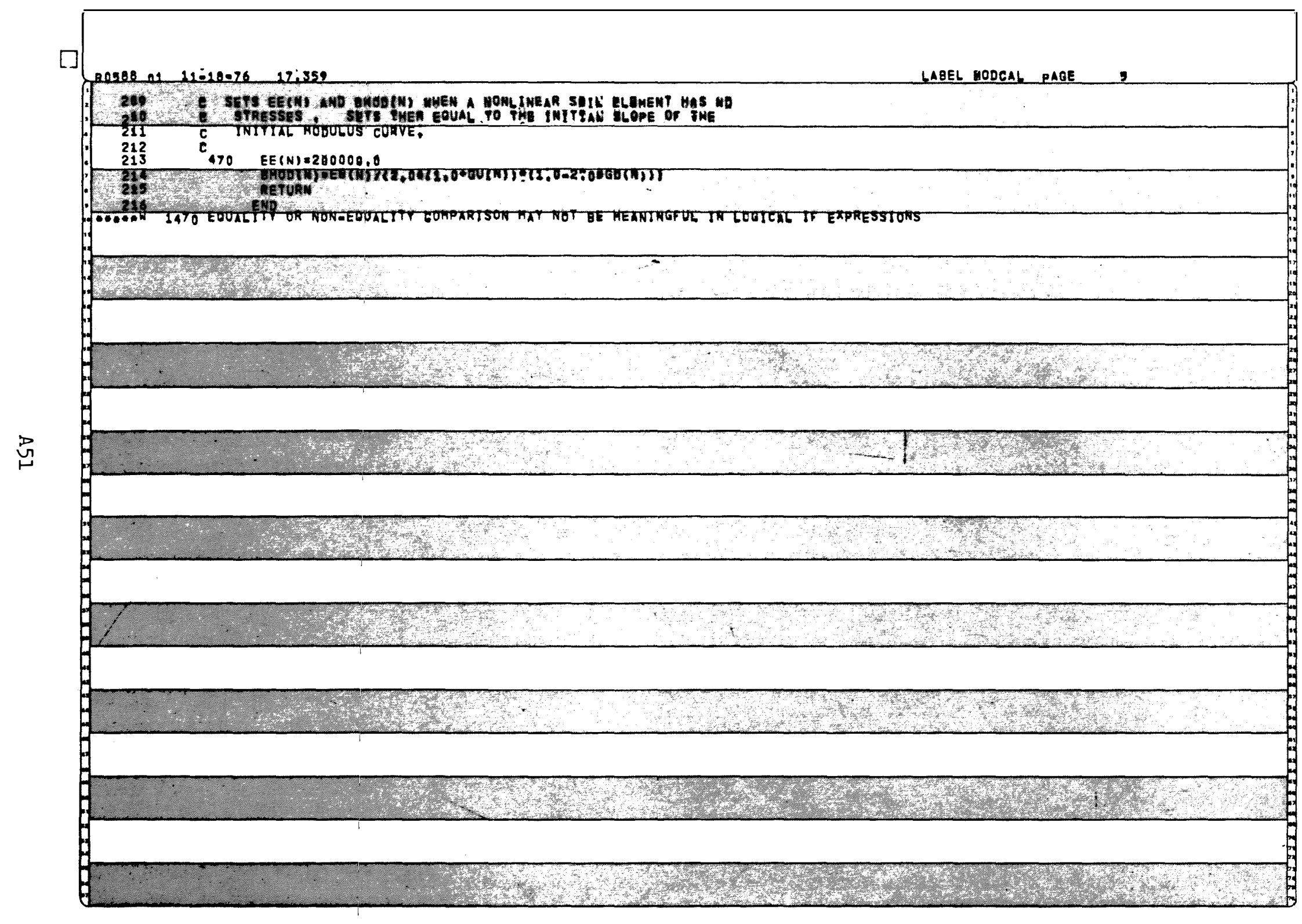


APPENDIX B: NONLINEAR STRESS-STRAIN BEHAVIOR FOR SOIL 
Homogeneous Soil Element

1. A simple and practical expression for describing the nonlinear soil behavior has been suggested by Kondner ${ }^{* *}$ who assumed that the stress-strain curve as obtained from triaxial compression tests is the following hyperbola:

$$
\left(\sigma_{1}-\sigma_{3}\right)=\frac{\varepsilon_{1}}{a+b \varepsilon_{1}}
$$

where $\left(\sigma_{1}-\sigma_{3}\right)$ is the principal stress difference, $\varepsilon_{1}$ is the axial strain, and $a$ and $b$ are parameters that can be determined by experiment.

2. The physical meaning attached to $a$ and $b$ can be seen in Figure $B l$ in which $a$ is equal to the reciprocal of the initial tangent modulus $E_{i}$ and $b$ is equal to the asymptotic value of the stress

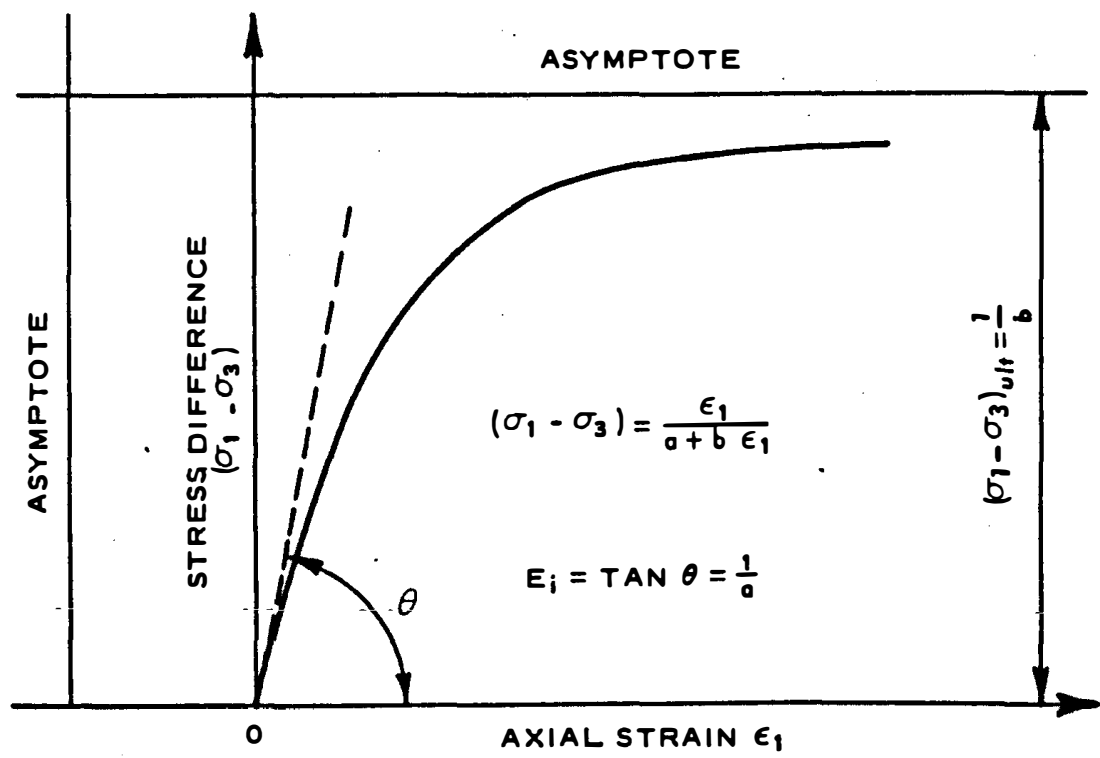

Figure Bl. Kondner hyperbola for representation of stress-strain

* Raised numerals refer to similarly numbered items in the References at the end of the main text. 
difference called the ultimate stress difference $\left(\sigma_{1}-\sigma_{3}\right)$ ult - Equation $B l$ can be simplified by expressing $\varepsilon_{1} /\left(\sigma_{1}-\sigma_{3}\right)$ as a linear function of $\varepsilon_{1}$, which would enable direct evaluation of the parameters a and $\mathrm{b}$ as depicted in Figure B2. The linear form of Equation Bl may be written as:

$$
\frac{\varepsilon_{1}}{\left(\sigma_{1}-\sigma_{3}\right)}=a+b \varepsilon_{1}=\frac{1}{E_{i}}+\frac{\varepsilon_{1}}{\left(\sigma_{1}-\sigma_{3}\right)_{u l t}}
$$

3. Duncan and Chang ${ }^{6}$ expanded Kondner's hyperbolic stress-strain relationship and utilized it for incremental FE analysis by expressing the tangent modulus $E_{t}$ as a function of $\left(\sigma_{1}-\sigma_{3}\right), E_{i}$, and the Mohr-Coulomb strength parameters $c$ and $\phi$ as:

$$
E_{t}=\left[1-\frac{R_{f}(1-\sin \phi)\left(\sigma_{1}-\sigma_{3}\right)}{2 c \cos \phi+2 \sigma_{3} \sin \phi}\right]_{i}^{2} E_{i}
$$

in which $R_{f}$ is the ratio of $\left(\sigma_{1}-\sigma_{3}\right)$ at failure to the asymptotic value of the stress difference $\left(\sigma_{1}-\sigma_{3}\right)$ ult .

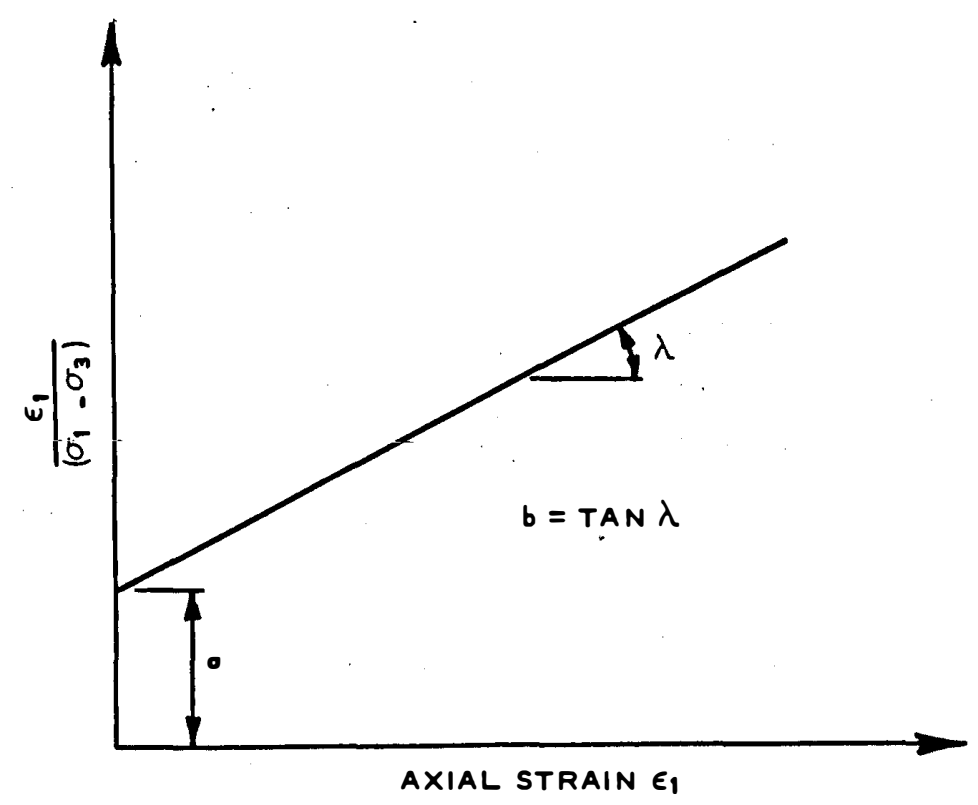

Figure B3. Linear representation of the hyperbolic stress-strain function 
4. Another characteristic of many soils is the dependency of the initial tangent modulus $E_{i}$ upon the confining pressure $\sigma_{3}$. Janbu 9 has suggested and Duncan and Chang ${ }^{6}$ have employed the following exponential relation between the confining pressure $\sigma_{3}$ and $E_{i}$ :

$$
E_{i}=K P_{a}\left(\frac{\sigma_{3}}{P_{a}}\right)^{n}
$$

where $P_{a}$ is the atmospheric pressure expressed in the same units as $\sigma_{3}, K$ is a dimensionless number, and $n$ is a dimensionless exponent. 5. The hyperbolic stress-strain relationship as expressed by Equations $\mathrm{B} 3$ and $\mathrm{B} 4$ is useful and simple. The parameters $\mathrm{K}, \mathrm{n}, \mathrm{c}, \phi$, and $R_{f}$ are all readily determined by conventional triaxial compression tests.

\section{Interface Soil Elements}

6. Although the stress-displacement curve from direct shear tests cannot be used directly for determining the stress-strain relationship for soil, it seems likely that a curve for such a test is indicative of the form of the stress-strain relationship. A comprehensive study by Clough and Duncan ${ }^{4}$ has shown a resemblance of the shear stress relative to the displacement to the hyperbolic form suggested by Kondner, 8 which is appropriate for characterization of the behavior of interface elements.

7. Typical shear stress $\tau$ versus displacement $\Delta_{S}$ for a direct shear test is presented in Figure $B 3 a$, where $K_{i}$ and $K_{\text {st }}$ are the initial and tangent shear stiffnesses, respectively. The hyperbolic form for the shear stress as a function of the relative displacement is:

$$
\tau=\frac{\Delta_{s}}{a+b \Delta_{s}}
$$

where $a$ and $b$ are parameters that can be obtained from laboratory tests. Equation B5 may be transformed to a linear form as shown in Figure B3b: 


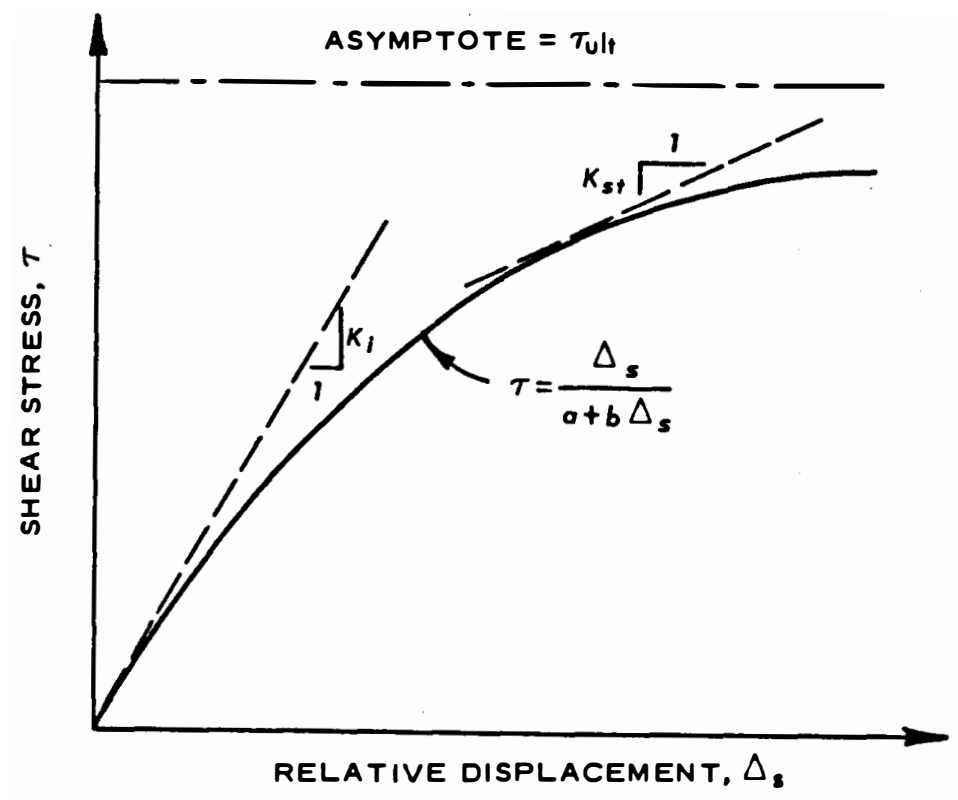

a. CONVENTIONAL SHEAR STRESS - DISPLACEMENT

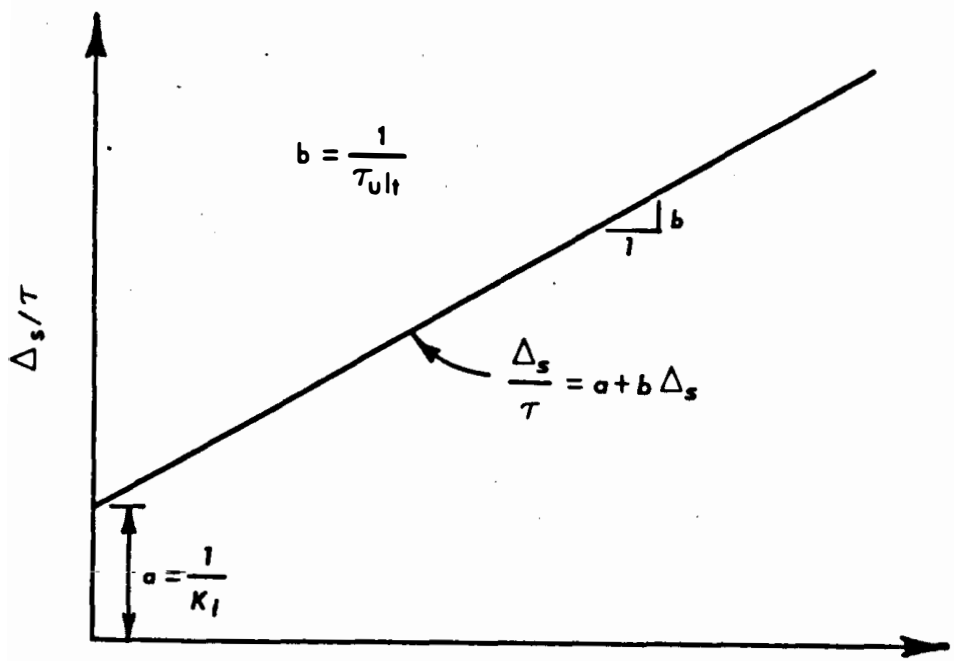

RELATIVE DISPLACEMENT, $\Delta_{S}$

b. TRANSFORMED SHEAR STRESS -DISPLACEMENT

Figure B3. Hyperbolic representation of the variation of shear stress with relative displacement 


$$
\frac{\Delta_{s}}{\tau}=a+b \Delta_{s}
$$

8. It has also been suggested by Clough and Duncan ${ }^{4}$ that it is desirable to determine the straight line for the test data by connecting points on the curve corresponding to 70 and 95 percent of the shear resistance mobilized. The constants $\mathrm{a}$ and $\mathrm{b}$ are related to the initial shear stiffness $K_{i}$ and the ultimate shear resistance $\tau_{u l t}$ as:

$$
\begin{aligned}
& a=\frac{1}{K_{i}} \\
& b=\frac{1}{\tau_{u l t}}
\end{aligned}
$$

The relationships expressed by Equations $B 7$ and $B 8$ can be used to determine $K_{i}$ and $\tau_{\text {ult }}$ from the transformed linear hyperbolic plot shown in Figure B3b by simply evaluating $a$ and $b$.

9. The tangent shear stiffness $K_{s t}$ at any point on the hyperbolic curve may be obtained by differentiating Equation B5 as:

$$
\mathrm{K}_{\mathrm{st}}=\frac{\mathrm{d} \tau}{\mathrm{d} \Delta_{\mathrm{s}}}=\frac{\mathrm{a}}{\left(\mathrm{a}+\mathrm{b} \Delta_{\mathrm{s}}\right)^{2}}
$$

From Equation B5 it is possible to obtain an expression for $\Delta_{s}$ by rearranging terms to read:

$$
\Delta_{s}=\frac{a \tau}{1-b \tau}
$$

By substituting $\mathrm{a}, \mathrm{b}$, and $\Delta_{\mathrm{s}}$ as expressed in Equations B7, B8, and B10, respectively, in Equation B9, an expression for $K_{s t}$ can be obtained:

$$
K_{s t}=K_{i}\left(1-\frac{\tau}{\tau_{u l t}}\right)^{2}
$$

Experiments have shown that $\tau_{\text {ult }}$ overestimates the actual value of the shear stress at failure $\tau_{f}$, and the ratio between two shear stresses 
$R_{f}$ does not vary significantly for a given soil. By introducing the failure ratio $R_{f}$ into Equation BIl, the following may be obtained:

$$
K_{s t}=K_{i}\left(1-\frac{R_{f} \tau}{\tau_{f}}\right)^{2}
$$

10. From Mohr-Coulomb failure criteria, presented in Figure B4,

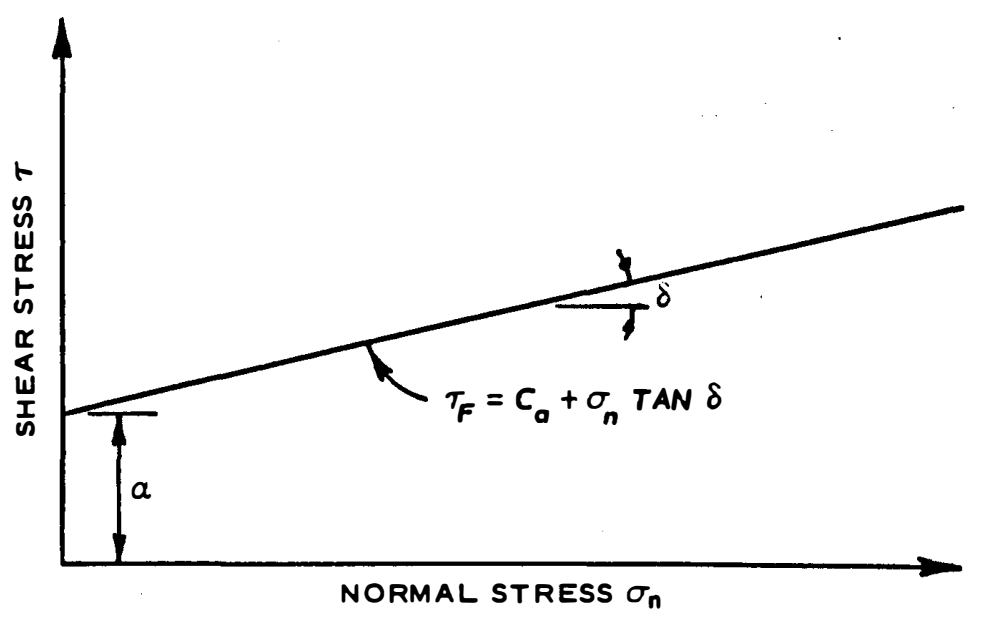

Figure B4. Variation of friction resistance with normal stress

the shear stress at failure may be related to the normal stress $\sigma_{n}$ by the following expression:

$$
\tau_{f}=C_{a}+\sigma_{n} \tan \delta
$$

where $C_{a}$ is the adhesion and $\delta$ is the angle of skin friction. Therefore, by substituting Equation B13 in Equation B12, the following is obtained:

$$
K_{s t}=K_{i}\left(I-\frac{R_{f^{\tau}}}{c_{a}+\sigma_{n} \tan \delta}\right)^{2}
$$

11. Laboratory studies by Clough and Duncan ${ }^{4}$ have shown that the initial shear stiffness $K_{i}$ may be related to the normal stress $\sigma_{n}$ 
by the following exponential relationship:

$$
K_{i}=K_{j} \gamma_{w}\left(\frac{\sigma_{n}}{P_{a}}\right)^{m}
$$

where $\gamma_{w}$ is the unit weight of water, $P_{a}$ is the atmospheric pressure, and $K_{j}$ and $m$ are parameters that can be determined from laboratory tests. Equations $\mathrm{Bl} 4$ and $\mathrm{Bl} 5$ define a simplified and practical relationship which describes the nonlinear shear stress-displacement relationship for the interface elements. 
APPENDIX C: NOTATION 
$\mathrm{a}, \mathrm{b}$ Experimental parameters

$A_{e}$ Equivalent cross-sectional area of reinforcing strips

A Cross-sectional area of reinforcing strip

c Cohesion

C Adhesion

$\mathrm{E}_{\mathrm{a}}$ Modulus of elasticity of aluminum panel

$\mathrm{E}_{\mathrm{e}} \quad$ Equivalent modulus of elasticity

$\mathrm{E}_{i} \quad$ Initial modulus

$\mathrm{E}_{\mathrm{s}} \quad$ Modulus of elasticity of galvanized steel reinforcing strips

$E_{t}$ Tangent modulus

$I_{a}$ Moment of inertia of aluminum panel per unit width

$I_{e} \quad$ Equivalent moment of inertia per unit width

$I_{x}$ Moment of inertia of metal sheet at back of aluminum panel per unit width

$\mathrm{K} \quad$ Hyperbolic loading parameter

$\mathrm{K}_{\mathrm{i}} \quad$ Initial shear stiffness

$\mathrm{K}$ Dimensionless number

$\mathrm{K}_{\mathrm{r}} \quad$ Residual shear stiffness

$K_{\text {st }}$ Tangent shear stiffness

$\mathrm{I}_{a}$ Length of beam $\left(\mathrm{S}_{z}\right)$ between any two rows of reinforcing strips

$\mathrm{L}_{\mathrm{e}} \quad$ Equivalent length

$L_{s} \quad$ Length of reinforcing strip

$m_{f}$ Magnification factor

$\mathrm{n}$. Pure number; also total number of strips in each row

$\mathrm{N}$ Number of reinforcing ties in each reinforced elevation

$P_{\text {a }}$ Atmospheric pressure

$R_{f} \quad$ Failure ratio

S Total axial stiffness of reinforcing strip

$\mathrm{S}$ Equivalent stiffness of plate substituting for reinforcing strips

$t$ Actual thickness of reinforcing tie

$t_{e} \quad$ Equivalent thickness of reinforcing tie in $\mathrm{FE}$ mesh

$\mathrm{w}$ Water content of soil 


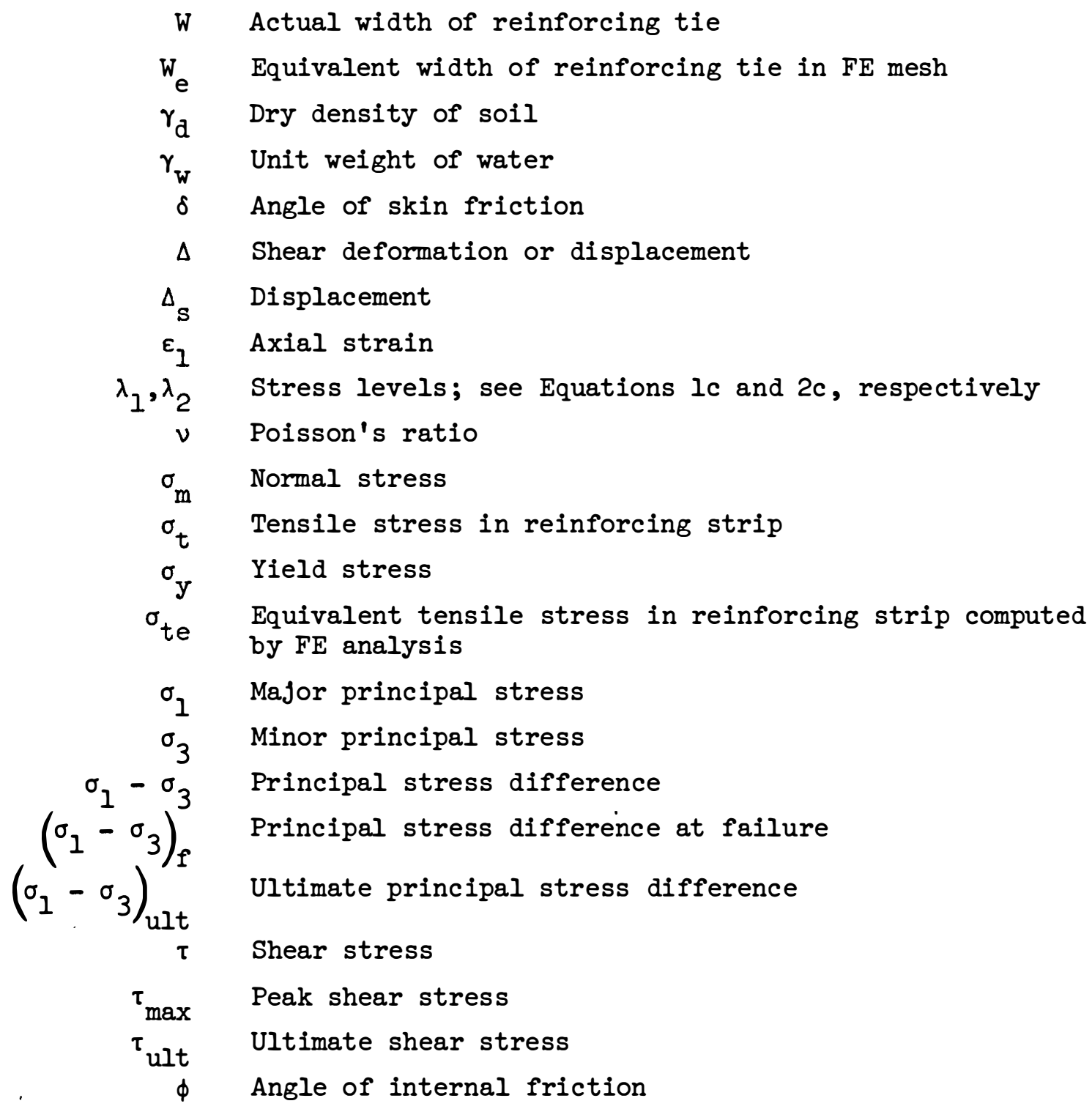

